Cochrane Database of Systematic Reviews

\title{
Interventions for improving sit-to-stand ability following stroke
} (Review)

Pollock A, Gray C, Culham E, Durward BR, Langhorne P

Pollock A, Gray C, Culham E, Durward BR, Langhorne P.

Interventions for improving sit-to-stand ability following stroke.

Cochrane Database of Systematic Reviews 2014, Issue 5. Art. No.: CD007232.

DOI: 10.1002/14651858.CD007232.pub4.

www.cochranelibrary.com 
TABLE OF CONTENTS

HEADER 1

ABSTRACT

PLAIN LANGUAGE SUMMARY

SUMMARY OF FINDINGS

BACKGROUND

OBJECTIVES

METHODS

RESULTS

Figure 1.

Figure 2.

DISCUSSION

AUTHORS' CONCLUSIONS

ACKNOWLEDGEMENTS

REFERENCES

CHARACTERISTICS OF STUDIES

DATA AND ANALYSES

Analysis 1.1. Comparison 1 Any intervention versus control (immediate outcomes), Outcome 1 Ability to sit-to-stand independently.

Analysis 1.2. Comparison 1 Any intervention versus control (immediate outcomes), Outcome 2 Time.

Analysis 1.3. Comparison 1 Any intervention versus control (immediate outcomes), Outcome 3 Lateral symmetry.

Analysis 1.4. Comparison 1 Any intervention versus control (immediate outcomes), Outcome 4 Peak vertical ground reaction force.

Analysis 1.5. Comparison 1 Any intervention versus control (immediate outcomes), Outcome 5 Falls (number of participants falling).

Analysis 1.6. Comparison 1 Any intervention versus control (immediate outcomes), Outcome 6 Functional ability. ................

Analysis 2.1. Comparison 2 Any intervention versus control (follow-up outcomes), Outcome 1 Time.

Analysis 2.2. Comparison 2 Any intervention versus control (follow-up outcomes), Outcome 2 Lateral symmetry.

Analysis 3.1. Comparison 3 Subgroup analysis: type of intervention, Outcome 1 Time.

Analysis 3.2. Comparison 3 Subgroup analysis: type of intervention, Outcome 2 Lateral symmetry.

Analysis 4.1. Comparison 4 Subgroup analysis: duration and intensity of intervention, Outcome 1 Weeks of intervention: Time.

Analysis 4.2. Comparison 4 Subgroup analysis: duration and intensity of intervention, Outcome 2 Sessions per week: Time. ....

Analysis 4.3. Comparison 4 Subgroup analysis: duration and intensity of intervention, Outcome 3 Weeks of intervention: Lateral symmetry.

Analysis 4.4. Comparison 4 Subgroup analysis: duration and intensity of intervention, Outcome 4 Sessions per week: Lateral symmetry.

Analysis 5.1. Comparison 5 Subgroup analysis: time post-stroke, Outcome 1 Time.

Analysis 5.2. Comparison 5 Subgroup analysis: time post-stroke, Outcome 2 Lateral symmetry.

Analysis 6.1. Comparison 6 Feedback versus no feedback, Outcome 1 Time.

Analysis 6.2. Comparison 6 Feedback versus no feedback, Outcome 2 Lateral symmetry.

APPENDICES

HISTORY

CONTRIBUTIONS OF AUTHORS

DECLARATIONS OF INTEREST

SOURCES OF SUPPORT

DIFFERENCES BETWEEN PROTOCOL AND REVIEW

INDEX TERMS 
[Intervention Review]

\title{
Interventions for improving sit-to-stand ability following stroke
}

\author{
Alex Pollock ${ }^{1}$, Charla Gray², Elsie Culham², Brian R Durward ${ }^{3}$, Peter Langhorne 4
}

${ }^{1}$ Nursing, Midwifery and Allied Health Professions Research Unit, Glasgow Caledonian University, Glasgow, UK. ${ }^{2}$ School of Rehabilitation Therapy, Queen's University, Kingston, Ontario, Canada. ${ }^{3} \mathrm{NHS}$ Education for Scotland, Edinburgh, UK. ${ }^{4}$ Academic Section of Geriatric Medicine, University of Glasgow, Glasgow, UK

Contact address: Alex Pollock, Nursing, Midwifery and Allied Health Professions Research Unit, Glasgow Caledonian University, Buchanan House, Cowcaddens Road, Glasgow, G4 0BA, UK. alex.pollock@gcu.ac.uk.

Editorial group: Cochrane Stroke Group

Publication status and date: New, published in Issue 5, 2014.

Citation: Pollock A, Gray C, Culham E, Durward BR, Langhorne P. Interventions for improving sit-to-stand ability following stroke. Cochrane Database of Systematic Reviews 2014, Issue 5. Art. No.: CD007232. DOI: 10.1002/14651858.CD007232.pub4.

Copyright @ 2014 The Cochrane Collaboration. Published by John Wiley \& Sons, Ltd.

\section{A B S T R A C T}

\section{Background}

Standing up from a seated position is one of the most frequently performed functional tasks, is an essential pre-requisite to walking and is important for independent living and preventing falls. Following stroke, patients can experience a number of problems relating to the ability to sit-to-stand independently.

\section{Objectives}

To review the evidence of effectiveness of interventions aimed at improving sit-to-stand ability after stroke. The primary objectives were to determine (1) the effect of interventions that alter the starting posture (including chair height, foot position, hand rests) on ability to sitto-stand independently; and (2) the effect of rehabilitation interventions (such as repetitive practice and exercise programmes) on ability to sit-to-stand independently. The secondary objectives were to determine the effects of interventions aimed at improving ability to sitto-stand on: (1) time taken to sit-to-stand; (2) symmetry of weight distribution during sit-to-stand; (3) peak vertical ground reaction forces during sit-to-stand; (4) lateral movement of centre of pressure during sit-to-stand; and (5) incidence of falls.

\section{Search methods}

We searched the Cochrane Stroke Group Trials Register (June 2013), CENTRAL (2013, Issue 5), MEDLINE (1950 to June 2013), EMBASE (1980 to June 2013), CINAHL (1982 to June 2013), AMED (1985 to June 2013) and six additional databases. We also searched reference lists and trials registers and contacted experts.

\section{Selection criteria}

Randomised trials in adults after stroke where: the intervention aimed to affect the ability to sit-to-stand by altering the posture of the patient, or the design of the chair; stated that the aim of the intervention was to improve the ability to sit-to-stand; or the intervention involved exercises that included repeated practice of the movement of sit-to-stand (task-specific practice of rising to stand).

The primary outcome of interest was the ability to sit-to-stand independently. Secondary outcomes included time taken to sit-to-stand, measures of lateral symmetry during sit-to-stand, incidence of falls and general functional ability scores.

\section{Data collection and analysis}

Two review authors independently screened abstracts, extracted data and appraised trials. We undertook an assessment of methodological quality for random sequence generation, allocation concealment, blinding of outcome assessors and method of dealing with missing data. 


\section{Main results}

Thirteen studies (603 participants) met the inclusion criteria for this review, and data from 11 of these studies were included within metaanalyses. Twelve of the 13 included studies investigated rehabilitation interventions; one (nine participants) investigated the effect of altered starting posture for sit-to-stand. We judged only four studies to be at low risk of bias for all methodological parameters assessed. The majority of randomised controlled trials included participants who were already able to sit-to-stand or walk independently.

Only one study (48 participants), which we judged to be at high risk of bias, reported our primary outcome of interest, ability to sit-to-stand independently, and found that training increased the odds of achieving independent sit-to-stand compared with control (odds ratio (OR) $4.86,95 \%$ confidence interval $(\mathrm{Cl}) 1.43$ to 16.50 , very low quality evidence).

Interventions or training for sit-to-stand improved the time taken to sit-to-stand and the lateral symmetry (weight distribution between the legs) during sit-to-stand (standardised mean difference (SMD) $-0.34 ; 95 \% \mathrm{Cl}-0.62$ to -0.06 , seven studies, 335 participants; and SMD $0.85 ; 95 \% \mathrm{Cl} 0.38$ to 1.33 , five studies, 105 participants respectively, both moderate quality evidence). These improvements are maintained at long-term follow-up.

Few trials assessing the effect of sit-to-stand training on peak vertical ground reaction force (one study, 54 participants) and functional ability (two studies, 196 participants) were identified, providing very low and low quality evidence respectively.

The effect of sit-to-stand training on number of falls was imprecise, demonstrating no benefit or harm $(\mathrm{OR} 0.75,95 \% \mathrm{Cl} 0.46$ to 1.22 , five studies, 319 participants, low quality evidence). We judged the majority of studies that assessed falls to be at high risk of bias.

\section{Authors' conclusions}

This review has found insufficient evidence relating to our primary outcome of ability to sit-to-stand independently to reach any generalisable conclusions. This review has found moderate quality evidence that interventions to improve sit-to-stand may have a beneficial effect on time taken to sit-to-stand and lateral symmetry during sit-to-stand, in the population of people with stroke who were already able to sit-to-stand independently. There was insufficient evidence to reach conclusions relating to the effect of interventions to improve sit-tostand on peak vertical ground reaction force, functional ability and falls. This review adds to a growing body of evidence that repetitive task-specific training is beneficial for outcomes in people receiving rehabilitation following stroke.

\section{PLAIN LANGUAGE SUMMARY}

\section{Interventions for improving the ability to rise to stand from sitting following stroke}

\section{Question}

We wanted to assess the effectiveness of training, exercises or other interventions aimed at helping people who have had a stroke stand up independently from a sitting position, compared with usual care or no intervention.

\section{Background}

Rising to stand from sitting is one of the most frequently performed tasks of daily living and is something people need to be able to do to start walking. After a stroke, people may have difficulty rising to stand from sitting. This review looked at the effect of training or exercises on ability to rise to stand, and also aimed to look at the effect of different chair positions that might help people rise to stand.

\section{Study characteristics}

We identified 13 studies up to June 2013. These studies included 603 participants who had had a stroke. Twelve of the studies investigated the effect of different types of training or exercise: six studies (276 participants) investigated repetitive sit-to-stand training, four studies (264 participants) investigated an exercise training programme that included sit-to-stand training, one study (12 participants) included a training programme (sitting training) aiming to improve sit-to-stand, and one study (42 participants) investigated feedback (information about the symmetry of weight taken through the feet) during sit-to-stand. One of the studies investigated the effect of starting posture for sit-to-stand: this study (nine participants) compared sit-to-stand with a cane and without a cane. This study measured people during three tests of rising to stand with a cane, and three tests of rising to stand without a cane; there was no training period.

\section{Key results}

Combining the results of these studies provides us with evidence that training or exercises aiming to improve sit-to-stand performance have beneficial effects compared with usual care, no treatment or an alternative intervention: people who participated in training or exercises got faster at rising to stand and increased the amount of weight that they took through the leg affected by the stroke. There was also some evidence that these beneficial effects were still present several months after the end of training. Sit-to-stand training did not seem to affect the number of falls that people had, although the evidence was of poor quality. There was not enough evidence to say what the ideal amount of training or exercise was, but the results do suggest that training three times a week for two to three weeks may be enough to have a beneficial effect. We did not find any evidence of effects on outcomes other than time to sit-to-stand or the weight through the affected leg, or any evidence that the length of the training programme or the time since the participants had their stroke made 
any difference to outcomes. The studies that we found mainly included people who were able to walk and sit-to-stand independently at the start of the study, so these results are only relevant to this group of people. In other words, these results are not relevant to people who are unable to sit-to-stand independently and further research is needed to investigate the effect of sit-to-stand training for these people. The available studies suggest that effective interventions can either be specific repetitive training of sit-to-stand or exercise programmes that include repetitive sit-to-stand. The evidence is insufficient to reach conclusions relating to the duration or intensity of training.

\section{Quality of the evidence}

We found insufficient evidence relating to our primary outcome of ability to sit-to-stand independently to reach any generalisable conclusions. However, we found moderate quality evidence, from a relatively low number of small studies, that interventions to improve sit-tostand may have a beneficial effect on the speed of rising to stand and the weight taken through the affected leg. We found insufficient evidence to reach any conclusions about the effect of sit-to-stand training on other outcomes. We recommend large clinical trials to confirm the results of this review, and to investigate the effects of different numbers of repetitions and durations of therapy. Future studies should include a measure of functional ability, and should measure long-term outcomes as well as outcomes straight after therapy. 


\section{SUMMARY OF FINDINGS}

\section{Summary of findings for the main comparison.}

\section{Any intervention compared with control for improving sit-to-stand ability following stroke}

Patient or population: people with stroke

Intervention: any therapy intervention or training for sit-to-stand

Comparison: control intervention, usual care or no treatment

\begin{tabular}{|c|c|c|c|c|}
\hline Outcomes & $\begin{array}{l}\text { Treatment effect } \\
(95 \% \mathrm{CI})\end{array}$ & $\begin{array}{l}\text { No of partici- } \\
\text { pants } \\
\text { (studies) }\end{array}$ & $\begin{array}{l}\text { Quality of } \\
\text { the evi- } \\
\text { dence } \\
\text { (GRADE) }\end{array}$ & Comments \\
\hline $\begin{array}{l}\text { Ability to sit- } \\
\text { to-stand in- } \\
\text { dependently }\end{array}$ & $\begin{array}{l}\text { OR } 4.86(95 \% \mathrm{Cl} 1.43 \text { to } \\
16.50)\end{array}$ & $\begin{array}{l}48 \text { participants } \\
\text { (1 study) }\end{array}$ & $\begin{array}{l}\oplus \ominus \ominus \ominus \\
\text { very low }\end{array}$ & 1 small study, judged to be at high risk of bias \\
\hline $\begin{array}{l}\text { Time } \\
\text { (to sit-to- } \\
\text { stand) }\end{array}$ & $\begin{array}{l}\text { SMD }-0.34(95 \% \mathrm{Cl}-0.62 \\
\text { to }-0.06) \\
\text { (favours intervention) }\end{array}$ & $\begin{array}{l}346 \text { partici- } \\
\text { pants } \\
\text { (7 studies) }\end{array}$ & $\begin{array}{l}\oplus \oplus \oplus \ominus \\
\text { moderate }\end{array}$ & $\begin{array}{l}\text { Sensitivity analyses found no difference in direction of } \\
\text { effect } \\
\text { Significant result maintained at follow-up ( } 149 \text { partici- } \\
\text { pants; } 4 \text { studies; SMD }-0.45(95 \% \mathrm{Cl}-0.78 \text { to }-0.12))\end{array}$ \\
\hline $\begin{array}{l}\text { Lateral sym- } \\
\text { metry }\end{array}$ & $\begin{array}{l}\text { SMD } 0.85 \text { ( } 95 \% \mathrm{Cl} 0.38 \\
\text { to } 1.33 \text { ) } \\
\text { (favours intervention) }\end{array}$ & $\begin{array}{l}105 \text { partici- } \\
\text { pants } \\
\text { (5 studies) }\end{array}$ & $\begin{array}{l}\oplus \oplus \oplus \ominus \\
\text { moderate }\end{array}$ & $\begin{array}{l}\text { Sensitivity analyses found no difference in direction of } \\
\text { effect } \\
\text { Significant result maintained at follow-up ( } 75 \text { partici- } \\
\text { pants; } 3 \text { studies; SMD } 0.59 \text { ( } 95 \% \mathrm{Cl} 0.11 \text { to } 1.07) \text { ) }\end{array}$ \\
\hline $\begin{array}{l}\text { Peak vertical } \\
\text { ground reac- } \\
\text { tion force }\end{array}$ & $\begin{array}{l}\text { SMD }-0.02(95 \% \mathrm{Cl}-0.55 \\
\text { to } 0.52)\end{array}$ & $\begin{array}{l}54 \text { participants } \\
\text { (1 study) }\end{array}$ & $\begin{array}{l}\oplus \ominus \ominus \ominus \\
\text { very low }\end{array}$ & $\begin{array}{l}1 \text { small study, with poor reporting of methodological } \\
\text { criteria }\end{array}$ \\
\hline $\begin{array}{l}\text { Falls (num- } \\
\text { ber of partici- } \\
\text { pants falling) }\end{array}$ & $\begin{array}{l}\text { OR } 0.75(95 \% \mathrm{Cl} 0.46 \text { to } \\
1.22)\end{array}$ & $\begin{array}{l}319 \text { partici- } \\
\text { pants } \\
\text { (5 studies) }\end{array}$ & $\begin{array}{l}\oplus \oplus \odot \odot \\
\text { low }\end{array}$ & Methodological limitations with 3 of the 5 studies \\
\hline $\begin{array}{l}\text { Functional } \\
\text { ability }\end{array}$ & $\begin{array}{l}\text { SMD }-0.24(95 \% \mathrm{Cl}-0.52 \\
\text { to } 0.04)\end{array}$ & $\begin{array}{l}196 \text { partici- } \\
\text { pants } \\
\text { ( } 2 \text { studies) }\end{array}$ & $\begin{array}{l}\oplus \oplus \odot \ominus \\
\text { low }\end{array}$ & $\begin{array}{l}2 \text { studies, judged to be at low risk of bias, demonstrat- } \\
\text { ing consistent results }\end{array}$ \\
\hline
\end{tabular}

GRADE Working Group grades of evidence

High quality: Further research is very unlikely to change our confidence in the estimate of effect

Moderate quality: Further research is likely to have an important impact on our confidence in the estimate of effect and may change the estimate

Low quality: Further research is very likely to have an important impact on our confidence in the estimate of effect and is likely to change the estimate

Very low quality: We are very uncertain about the estimate

\section{$\mathrm{Cl}$ : confidence interval}

OR: odds ratio

SMD: standardised mean difference 


\section{B A C K G R O U N D}

Standing up from a seated position is one of the most frequently performed functional tasks, and it is an essential pre-requisite to walking (Alexander 2000). The ability to stand up without assistance is important for independent living (Alexander 2000), and preventing falls (Cheng 2001).

After a stroke, individuals can experience a number of problems relating to the ability to sit-to-stand independently. Rehabilitation of the sit-to-stand movement is therefore an important goal after stroke. To facilitate and promote evidence-based practice it is necessary to know the evidence of effectiveness of interventions aimed at improving the ability to sit-to-stand after stroke.

\section{Description of the condition}

The inability to sit-to-stand independently can prevent independent function during activities of daily living. It is common for people with hemiplegia to demonstrate considerable asymmetry of weight distribution during rising to stand, with significantly increased weight-bearing on the unaffected side (Cheng 1998; Durward 1994; Engardt 1992). People who have had a stroke also commonly exhibit a reduced peak vertical reaction force, an increased time to complete the movement of rising to stand and a larger medio-lateral centre of pressure displacement compared with healthy adults (Cheng 1998).

\section{Description of the intervention}

Interventions aimed specifically at improving ability to sit-to-stand independently include:

1. a range of rehabilitation interventions, such as repetitive practice of sit-to-stand, and of the components required for movement from sitting to standing: muscle strength training and provision of feedback;

2. a range of interventions that alter the movement of rising to stand, such as changing the chair height, chair design or starting posture of the movement.

\section{How the intervention might work}

These interventions may work by restoration of impairments (e.g. improved muscle strength, motor learning), compensation for impairments (e.g. increased chair height) or substitution for impairments (e.g. provision of arm rests to aid sit-to-stand using arms).

\section{Why it is important to do this review}

A recent Cochrane review of repetitive task training after stroke investigated the effect of repetitive task training on measures of sitto-stand; seven trials were included and a significant effect of repetitive task training was found (standardised effect $0.39,95 \%$ confidence intervals (CI) 0.18 to 0.61 ) (French 2007). This review provides convincing evidence that repetitive practice may be beneficial for sit-to-stand. Our review differs substantially from the repetitive task training review, which focuses on a specific treatment (repetitive training). Our proposed review focuses on a specific outcome (sit-to-stand ability) and will include any treatments providing that improving ability to sit-to-stand was a goal of the treatment. This potentially includes a wide range of different treatments such as altering chair height or design; changing the starting posture for the movement; muscle strengthening; or providing feed- back during training. As stated previously, sit-to-stand is essential for function, and important for walking and safe independent living; synthesis of the evidence relating to interventions to improve sit-to-stand ability is therefore important. We are unaware of any previous systematic reviews focusing specifically on this topic.

\section{O B JECTIVES}

To review the evidence of effectiveness of interventions aimed at improving sit-to-stand ability after stroke. The primary objectives were to determine (1) the effect of interventions that alter the starting posture (including chair height, foot position, hand rests) on ability to sit-to-stand independently; and (2) the effect of rehabilitation interventions (such as repetitive practice and exercise programmes) on ability to sit-to-stand independently. The secondary objectives were to determine the effects of interventions aimed at improving ability to sit-to-stand on: (1) time taken to sit-to-stand; (2) symmetry of weight distribution during sit-to-stand; (3) peak vertical ground reaction forces during sit-to-stand; (4) lateral movement of centre of pressure during sit-to-stand; and (5) incidence of falls.

\section{METHODS}

\section{Criteria for considering studies for this review}

\section{Types of studies}

We included controlled trials where participants were randomly assigned. We planned to include the first phase of cross-over studies where the order of assignment was determined randomly. We included trials with or without blinding of participants, treating therapist(s) and assessor(s). We documented and explored these parameters within the review.

\section{Types of participants}

We included trials enrolling adult participants (aged over 18 years) with a clinical diagnosis of stroke (World Health Organization definition, Hatano 1976), which could be either ischaemic or haemorrhagic in origin (with confirmation of the clinical diagnosis using imaging not compulsory).

\section{Types of interventions}

We included any interventions that:

1. aimed to affect the ability to sit-to-stand by altering the posture of the patient, or the design of the chair; or

2. stated that the aim of the intervention was to improve the ability to sit-to-stand; or

3. involved an exercise intervention that included repeated practice of the movement of sit-to-stand (task-specific practice of rising to stand).

\section{Types of outcome measures}

\section{Primary outcomes}

The primary outcome was defined as the ability to sit-to-stand independently.

\section{Secondary outcomes}

The secondary outcomes were outcomes relating to sit-to-stand movement: 
- time taken to sit-to-stand (or sit-to-walk);

- measures of lateral symmetry during sit-to-stand; including weight distribution, lateral movement of centre of pressure during sit-to-stand;

- peak vertical ground reaction forces during sit-to-stand;

- joint kinematics; including range of movement at the hip, knee or ankle.

Additional outcomes:

- incidence of falls;

- general functional ability scores (e.g. Barthel Index).

We documented when outcomes were recorded in relation to the end of the intervention period.

\section{Search methods for identification of studies}

See the 'Specialized register' section in the Cochrane Stroke Group module. We searched for relevant trials in all languages and planned to arrange translation of trial reports published in languages other than English.

\section{Electronic searches}

We searched the Cochrane Stroke Group Trials Register (June 2013), the Cochrane Central Register of Controlled Trials (CENTRAL) (2013, Issue 5) (Appendix 1), MEDLINE (Ovid) (1950 to June 2013) (Appendix 2), EMBASE (Ovid) (1980 to June 2013) (Appendix 3), ClNAHL (EBSCO) (1982 to June 2013) (Appendix 4) and AMED (Ovid) (1985 to June 2013) (Appendix 5).

We also searched the following databases and trials registries (June 2013):

- British Nursing Index (Ovid) (from 1993) (Appendix 6);

- REHABDATA (http://www.naric.com/?q=en/REHABDATA)(Appendix 7);

- OTseeker (http://www.otseeker.com/) (Appendix 8);

- Physiotherapy Evidence database (PEDro, http://www.pedro.fhs.usyd.edu.au/index.html), Chartered Society of Physiotherapy Research Database (Appendix 9);

- OT Search (http://www1.aota.org/otsearch/index.asp);

- Dissertation abstracts (http://wwwlib.umi.com/dissertations/search);

- ClinicalTrials.gov (http://www.clinicaltrials.gov/);

- National Research Register (https://portal.nihr.ac.uk/Pages/NRRArchiveSearch.aspx);

- UK Clinical Research Network Portfolio Database (http://public.ukcrn.org.uk/search/);

- Current Controlled Trials (http://www.controlled-trials.com/) (which also includes the UK Clinical Trials Gateway);

- EU Clinical Trials Register (https://www.clinicaltrialsregister.eu);

- Stroke Trials Registry (www.strokecenter.org/trials/);

- WHO International Clinical Trials Registry Platform (http://apps.who.int/trialsearch/).

We developed search strategies in consultation with the Cochrane Stroke Group Trials Search Co-ordinator to avoid duplication of effort.

\section{Searching other resources}

In an effort to identify further published, unpublished and ongoing trials, we:

- checked reference lists of all relevant articles;

- contacted investigators known to be involved in research in this area;

- used Science Citation Index cited reference search for forward tracking of important papers.

\section{Data collection and analysis}

\section{Selection of studies}

One review author (AP or $\mathrm{CG}$ ) read the titles and abstracts of the identified references and eliminated any obviously irrelevant studies. We obtained the full text of the remaining studies and then, based on the inclusion criteria (types of studies, types of participants, aims of interventions, outcome measures), two review authors (AP, CG or BD) independently ranked these as 'include' or 'exclude'. We included studies classified as 'include' by both review authors at this stage and excluded trials classified as 'exclude' by both review authors. If there was disagreement between review authors, or a decision could not be reached, we reached consensus through discussion, including a third review author where necessary.

\section{Data extraction and management}

Two review authors (AP, CG or BD) independently extracted data from the studies using a standard data extraction form. We attempted to obtain any missing data by contacting trial authors. Where possible we documented:

1. participant details (including age, gender, place of residence, type of stroke, time since stroke, initial functional ability, comorbid conditions, pre-morbid disability);

2. the inclusion and exclusion criteria;

3. a brief description of the intervention (we classified the intervention using the three groups defined in Types of interventions and documented details including, where relevant, the nature of the intervention, duration/intensity/frequency of the intervention, details of the chair, involvement of treating therapist and qualifications and experience of treating therapist(s));

4. the comparison intervention;

5. the outcomes.

\section{Assessment of risk of bias in included studies}

Two review authors (AP, CG or BD) independently assessed the risk of bias by answering the following questions for each included study, and documenting this information using the Cochrane 'Risk of bias' tool (Higgins 2011).

\section{Was random sequence generation adequate?}

We considered studies to have low risk of bias in relation to random sequence generation if the study described an adequate random component in the sequence generation process. Adequate methods for random sequence generation included random number tables, computer random number generators, coin tossing, shuffling cards or envelopes, throwing dice, drawing lots and randomised minimisation. Studies judged to be at high risk of bias included those where a non-random component was described in the se- 
quence generation process. Inadequate methods of random sequence generation included methods that were systematic such as dates or hospital/clinic numbers and methods that involved judgement or non-random categorisation, such as preference of patient or availability of the intervention. If there was insufficient information about the sequence generation process to permit judgement of 'low risk' or 'high risk' we documented this as unclear.

\section{Was allocation adequately concealed?}

Studies with adequate concealment include those that have used central randomisation at a site remote from the study; computerised allocation, in which records are in a locked readable file that can be accessed only after entering patient details; and the drawing of opaque envelopes. Studies with inadequate concealment include those using an open list or table of random numbers, open computer systems or drawing of non-opaque envelopes. Studies with unclear concealment will include those with no or inadequate information in the report.

\section{Was knowledge of the allocated intervention adequately concealed from the outcome assessor?}

We considered studies adequately concealed if the outcome assessor was masked and the report did not identify any unmasking. We considered studies inadequately concealed if the outcome assessor was not masked or where the report clearly identified that unmasking occurred during the study. We documented concealment as unclear if a study did not state whether or not an outcome assessor was masked or there was insufficient information to judge.

\section{Were incomplete outcome data adequately addressed?}

Studies adequately addressing incomplete outcome data have no missing outcome data, missing outcome data that were unlikely to be related to true outcome, missing outcome data that were balanced in numbers across intervention groups with similar reasons for missing data across groups, a reported effect size (difference in means or standardised difference in means) among missing outcomes that was insufficient to have clinical relevance to observed effect size, or missing data that had been imputed using appropriate methods. Studies inadequately addressing incomplete outcome data either have missing outcome data that were likely to be related to true outcome with either imbalance in numbers or reasons for missing data across intervention groups, a reported effect size (difference in means or standardised difference in means) among missing outcomes enough to induce clinically relevant bias in observed effect size, or as-treated analysis done with substantial departure of the intervention received from that assigned at randomisation. We documented the addressing of incomplete outcome data as unclear if there was insufficient reporting to allow assessment, or if this was not addressed in the report.

\section{Was the study apparently free of other problems that could put it at a high risk of bias?}

We assessed whether studies had any other important risk of bias such as a potential source of bias related to the specific study design used, an extreme baseline imbalance, a claim to have been fraudulent or some other problem. As we found it difficult to ever be certain, due to potential poor reporting, whether a study was free of any other problems that put it at a high risk of bias, we decided that it was unhelpful to class studies as 'low risk' of bias due to other factors (as this would more likely be as a consequence of poor reporting than of genuine confidence that the study was at low risk of bias). Therefore, we did not include the assessment of whether studies were free of other problems in the 'Risk of bias' tables or summary figures, but we documented relevant information in the notes section for each study.

We produced a 'Risk of bias' summary figure to illustrate the potential biases within each of the included studies.

We resolved any disagreements through discussion, including a third review author if necessary. We attempted to contact study authors for clarification and to obtain missing data when required.

\section{Measures of treatment effect}

For each comparison, we used the study results for ability to sit-tostand independently, measures of sit-to-stand ability, incidence of falls and general functional ability, if documented. We used RevMan 5.2 for all analyses (RevMan 2012).

\section{Unit of analysis issues}

We analysed outcomes providing dichotomous data using the odds ratio $(\mathrm{OR})$ and $95 \%$ confidence interval $(\mathrm{Cl})$ employing a random-effects model with exploration of sources of heterogeneity. We analysed continuous outcomes as mean differences (MD) where the same scales were used, and standardised mean differences (SMD) where different studies reported different scales, with 95\% $\mathrm{Cl}$. We treated activities of daily living data, such as the Barthel Index, as continuous outcomes and recorded mean and standard deviation data.

\section{Dealing with missing data}

If an included study did not report a particular outcome, we planned not to include that study in the analysis of that outcome. If an included study had missing data (e.g. reported means but not standard deviations for the follow-up data) we contacted the study authors requesting the required data. If the data were unavailable, we planned to take logical steps to enter an assumed value. Such steps may have included estimating a standard deviation based on a reported standard error, or estimating a follow-up standard deviation based on a baseline value. We planned to perform sensitivity analyses to investigate the effect of entering assumed values.

\section{Assessment of heterogeneity}

We subjected all results to a random-effects meta-analysis to take account of statistical heterogeneity. We determined heterogeneity using the 12 statistic ( 12 greater than $50 \%$ was considered substantial heterogeneity). If heterogeneity was found to be present, we planned to explore and present possible causes.

\section{Assessment of reporting biases}

We attempted to avoid reporting biases by using a comprehensive search strategy that included searching for unpublished studies and searching trials registers.

\section{Data synthesis}

We planned to synthesise the data from the included studies within two key comparisons. 
Therapy interventions and training for sit-to-stand versus control or no intervention

We anticipated that this comparison might include data from studies comparing:

- augmented feedback interventions for sit-to-stand versus control or no augmented feedback;

- muscle strengthening exercise/programme for sit-to-stand versus control or no intervention;

- exercise/balance training programme aimed at improving sitto-stand versus control or no intervention;

- joint mobilisations for sit-to-stand versus control or no intervention;

- task-specific practice of sit-to-stand versus control or no interventions.

\section{Altered chair design or starting posture for sit-to-stand versus control or no intervention}

We anticipated that this comparison might include data from studies comparing:

- sit-to-stand from higher chair versus sit-to-stand from lower chair;

- sit-to-stand using arm rests versus sit-to-stand without arm rests;

- sit-to-stand from 'natural' starting position versus sit-to-stand from 'prescribed' starting position;

- sit-to-stand from one 'prescribed' starting position versus sit-tostand from another 'prescribed' starting position;

- sit-to-stand with eyes open versus sit-to-stand with eyes closed;

- sit-to-stand with shoes off versus sit-to-stand with shoes on

However, we found no studies suitable for inclusion within metaanalyses that investigated the effect of altered chair design or starting posture, and have therefore been unable to carry out this comparison.

We documented and reported information relating to usual care, including any treatment provided to participants in this group and the amount/intensity and duration of interventions.

\section{Subgroup analysis and investigation of heterogeneity}

If there were sufficient data (pre-stated as five or more studies within a comparison), we planned to carry out subgroup analyses to explore types of stroke (ischaemic versus haemorrhagic), time since onset of stroke (less than six months post-stroke versus more than six months post-stroke), initial dependency (Barthel score less than 15 or equivalent versus Barthel score of more than 15), and age (less than 75 years versus more than 75 years). Sufficient data were available to enable us to carry out a subgroup analysis to explore time since onset of stroke. In addition, we carried out subgroup analyses to explore the type of intervention and the duration/intensity of the intervention.

\section{Sensitivity analysis}

We completed sensitivity analyses based on the methodological quality of studies (method of randomisation, blinding of outcome assessor, intention-to-treat analysis, type of study). We carried out sensitivity analysis only if there were five or more studies within a comparison.

\section{RES U L T S}

\section{Description of studies}

\section{Results of the search}

Our search strategy identified 2255 titles and after the initial screening of titles and abstracts by one author (AP or CG) we eliminated 2157 irrelevant papers. We obtained the full text of the remaining 98 papers and after further assessment 66 studies did not meet the selection criteria and so we excluded them.

There was insufficient information to reach a decision about the inclusion of 18 additional studies (Atchison 1995; Camargos 2009; Chumbler 2011; Dean 2006; FFF 2010; Finestone 2012; Fraser 2012; Guttman 2011; Guttman 2012; Hirano 2010; Kerr 2012; Korner-Bitensky 2013; Lecours 2008; Moore 2012; Rodrigues-De-Paula 2010; Rose 2009; Zhong 2006; Zhu 2006), and attempts to contact the authors of these studies are ongoing (see Characteristics of studies awaiting classification). We also identified one ongoing trial that appears to be relevant for inclusion (ACTIV 2012) (see Characteristics of ongoing studies).

Thus we identified a total of 13 studies for inclusion in this review. (See Figure 1 for a summary flow diagram). 
Figure 1. Study flow diagram.

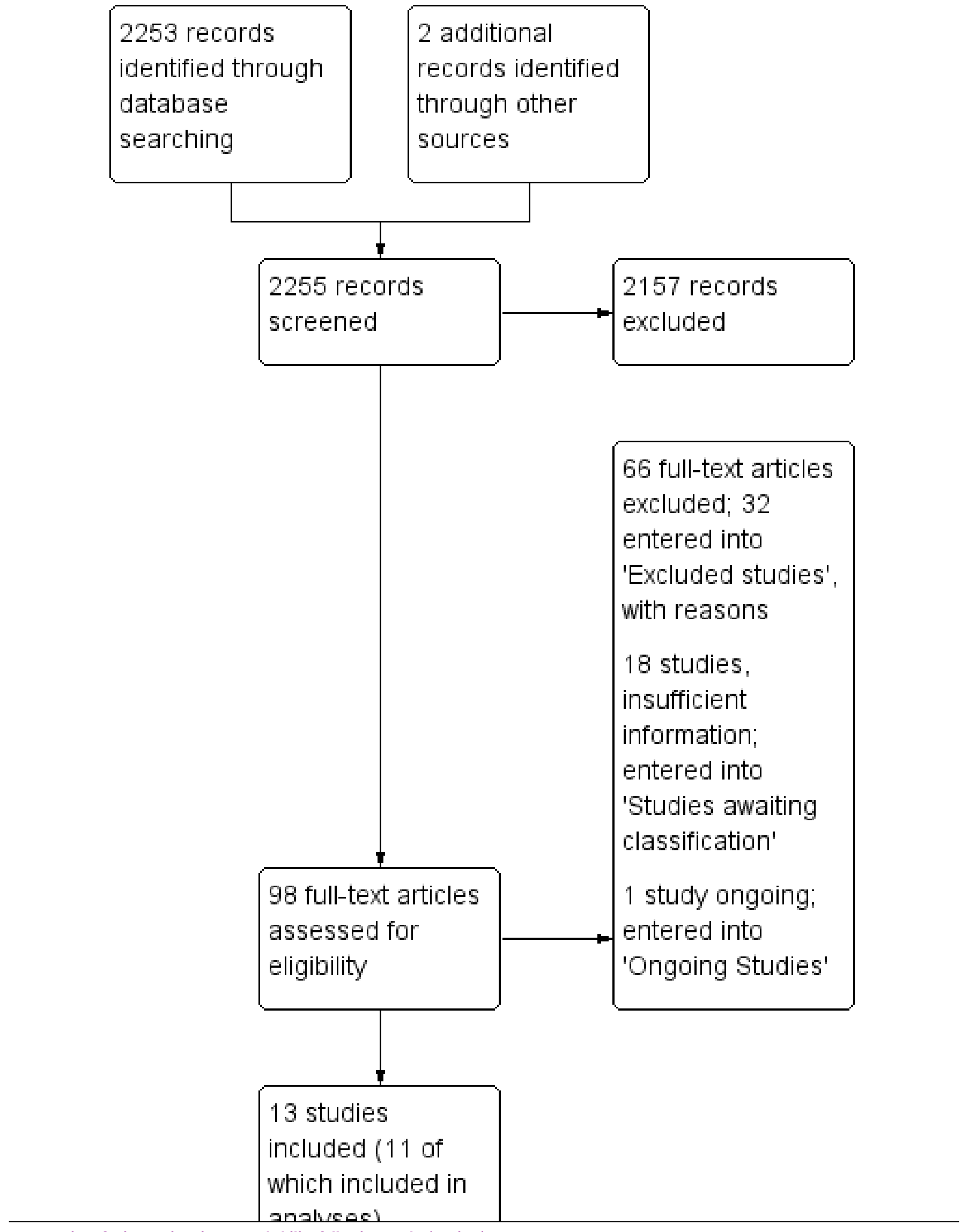




\section{Included studies}

Thirteen studies (603 participants) met the inclusion criteria for this review (Barreca 2004; Barreca 2007; Blennerhassett 2004; Britton 2008; Cheng 2001; Dean 2000; Dean 2007; Engardt 1993; FLASSH 2012; Hu 2013; Malouin 2009; Mead 2007; Tung 2010).

\section{Interventions studied}

Twelve of the 13 included studies investigated a type of therapy intervention or training for sit-to-stand. These included:

- six studies (276 participants) that investigated repetitive sit-tostand training (Barreca 2004; Barreca 2007; Britton 2008; Cheng 2001; Malouin 2009; Tung 2010);

- four studies (264 participants) that investigated an exercise training programme, which included sit-to-stand training (Blennerhassett 2004; Dean 2000; FLASSH 2012; Mead 2007);

- one study (12 participants) that included a training programme (sitting training) aimed to improve sit-to-stand (Dean 2007); and

- one study (42 participants) that investigated augmented feedback during sit-to-stand (Engardt 1993).

One of the included studies, with nine participants, investigated the effect of altered chair design or starting posture for sit-to-stand. This was a study comparing sit-to-stand with a cane and without a cane (Hu 2013).

Malouin 2009 included two repetitive sit-to-stand training intervention groups; one intervention combined repetitive sit-to-stand with cognitive training and the other intervention combined repetitive sit-to-stand with mental practice. We have included both of these intervention groups in our analyses, with the intervention including cognitive training entered as Malouin 2009a and the intervention including mental practice entered as Malouin 2009b. (Data from the control group were 'shared' between these 'studies', with half the number of control group participants allocated to each 'study').

Cheng 2001 provided both visual and auditory feedback as part of the repetitive sit-to-stand training. However, this study was comparing the intervention with a control group that was not doing repetitive sit-to-stand training; hence we agreed that this was an investigation of the effectiveness of a repetitive sit-to-stand training regime, and not an investigation of the effect of feedback.

FLASSH 2012 investigated an intervention programme that was specifically targeted at the reduction of falls in participants at high risk of falling. The exercise component of the multifactorial falls prevention programme might have included practice of sit-tostand; however, the intervention was individually tailored, and not all participants would have completed practice of sit-to-stand. We planned to explore the effect of including this study in a sensitivity analysis.

\section{Intensity and duration of interventions}

Most of the intervention periods lasted between 30 and 60 minutes each day delivered either three times per week (Barreca 2004; Barreca 2007; Dean 2000; Malouin 2009; Mead 2007; Tung 2010), or five times per week (Blennerhassett 2004; Britton 2008; Cheng 2001; Dean 2007), or between three and five times per week (FLASSH 2012). The exception was Engardt 1993, where the intervention lasted just 15 minutes, but was delivered three times each day (five days a week).

The study duration was either two weeks (Britton 2008; Dean 2007), three weeks (Cheng 2001), four weeks (Blennerhassett 2004; Dean 2000; Malouin 2009; Tung 2010), six weeks (Engardt 1993), or 12 weeks (Barreca 2007, Mead 2007). Barreca 2004 continued to deliver the intervention for the duration of the time that the participant was an in-patient. In FLASSH 2012, participants were given a home exercise programme, and adherence was measured for 12 months.

Hu 2013 was a repeated-measure design with no intervention period. Participants completed three trials of sit-to-stand in each of the two conditions, in a randomised order.

\section{Included participants}

Sample sizes in the included studies were generally low, ranging from 12 or fewer (Dean 2000; Dean 2007; Hu 2013; Malouin 2009), to 66 (Mead 2007), and 156 (FLASSH 2012).

Five of the studies included participants who were on average between 30 and 51 days post-stroke (Barreca 2004; Blennerhassett 2004; Britton 2008; Dean 2007; Engardt 1993); three studies included participants who were on average between 2.8 and 8 months post-stroke (Cheng 2001; FLASSH 2012; Hu 2013; Mead 2007); and three studies included participants who were on average more than one year post-stroke (Dean 2000; Malouin 2009; Tung 2010). Time after stroke is not stated for Barreca 2007.

Six of the studies only included participants who were already able to sit-to-stand independently (Britton 2008; Cheng 2001; Engardt 1993; Hu 2013; Malouin 2009; Tung 2010), and three required ability to walk independently (Blennerhassett 2004; Dean 2000; Mead 2007). In contrast Dean 2007 and Barreca 2004 included participants who had independent sitting balance (assessed using the sitting balance item of the Motor Assessment Scale for Stroke and the Postural Control item of the Chedoke McMaster Stroke Assessment respectively), but were not required to be able to sit-to-stand or walk independently. Barreca 2004 and Barreca 2007 excluded participants who were already able to sit-to-stand independently. This information was not provided for FLASSH 2012.

\section{Outcome measures}

Barreca 2004 measured outcome either at the time of discharge from hospital, or when a participant was first able to sit-to-stand independently. Eleven of the included studies all measured outcomes immediately after the end of the intervention. Seven of these studies also included a follow-up measure; this was at three weeks (Malouin 2009), two months (Dean 2000), six to seven months (Blennerhassett 2004; Cheng 2001; Dean 2007; Mead 2007), and 33 months (Engardt 1993). In FLASSH 2012 outcome was assessed 12 months after the implementation of the intervention programme.

\section{Primary outcomes}

Only two studies assessed our primary outcome of the ability to sitto-stand independently (Barreca 2004, Barreca 2007). In the majority of the other studies (all except Dean 2007), all participants were able to sit-to-stand independently prior to recruitment, meaning that this outcome was not appropriate as a measure of effect. 


\section{Secondary outcomes}

- Nine studies included a measure of time (time taken to sit-tostand: Britton 2008; Cheng 2001; Engardt 1993; Hu 2013; Mead 2007; Tung 2010; time taken to sit-to-walk: Blennerhassett 2004; Dean 2000; number of sit-to-stand repetitions in 30 seconds: FLASSH 2012). Data from FLASSH 2012 were multiplied by -1 as the measurement of number of sit-to-stand repetitions has a direction opposite to the measurement of time (i.e. decreased time is beneficial; increased number of repetitions is beneficial).

- Seven studies included a measure of lateral symmetry during sit-to-stand; including symmetry of weight distribution (Britton 2008; Dean 2000; Dean 2007; Engardt 1993; Hu 2013; Malouin 2009), and lateral movement of centre of pressure during sit-tostand (Cheng 2001).

- One study included a measure of peak vertical ground reaction forces during sit-to-stand (Cheng 2001).

- One study included a measure of the maximum anterior-posterior (A-P) movement of centre of pressure during sit-to-stand (Cheng 2001).

\section{Additional outcomes}

- Five studies reported the incidence of falls (Barreca 2004; Cheng 2001; Dean 2007; FLASSH 2012; Mead 2007). However, Dean 2007 only reported falls as an adverse event, rather than having a falls as a planned outcome measure.

- Two studies reported general functional ability, using the Functional Independence Measure (FIM) (FLASSH 2012; Mead 2007).

\section{Data used in analyses within this review}

Barreca 2007 is only reported as an abstract, and does not present data suitable for inclusion within the analyses in this review. We have attempted to contact the author of this study and will include these data in future updates of this review if we are able to obtain them. Hu 2013 is a repeated-measures, randomised, cross-over study and no data are available for before the cross-over, and therefore no data from this study are included within analyses.

Thus, data from 11 studies are included within this review (Barreca 2004; Blennerhassett 2004; Britton 2008; Cheng 2001; Dean 2000; Dean 2007; Engardt 1993; FLASSH 2012; Malouin 2009; Mead 2007; Tung 2010).

All analyses within this review have been carried out using outcomes measured immediately after the end of the intervention. The exceptions for this are Cheng 2001, where only follow-up (sixmonth) data were reported and FLASSH 2012, where data were only recorded at 12 months; we have pooled these follow-up data with the data from immediately after the end of the intervention for other studies (making the assumption that the follow-up data will be a conservative estimate of the data at the immediate end of the intervention), but have explored the effect of doing this using sensitivity analyses.

Cheng 2001 was the only study to include data for outcomes of peak vertical ground reaction force and anterior-posterior centre of pres- sure displacement. These data have been included within analyses in the comparison of intervention versus control (immediate outcomes). However, as noted above, these data actually pertain to six-month follow-up data.

Four studies reported follow-up data for a measure of time (Blennerhassett 2004; Cheng 2001; Dean 2000; Mead 2007), and three reported follow-up data for a measure of lateral symmetry (Cheng 2001; Dean 2000; Malouin 2009), but data were only available for a maximum of one study for the other outcome measures. We have therefore pooled follow-up data for the outcomes of time and lateral symmetry only. (Note: the data for Cheng 2001 are the same data as used in the analysis of immediate outcomes.)

As FLASSH 2012 investigated a falls prevention programme that may, or may not, have incorporated sit-to-stand exercise for individual participants, we planned to explore the effect of including this study with sensitivity analysis.

FLASSH 2012 reported median values, inter-quartile ranges and $P$ values for the differences between groups. The $P$ values were used to estimate a standard deviation for both groups, and the median values were entered in place of mean values. We had already planned to remove this study in a sensitivity analysis due to the study design (see above), so no further sensitivity analysis was planned to explore the use of these estimated data values.

\section{Excluded studies}

After two independent review authors assessed the full text of 98 papers, we excluded 66 of these studies. For 34 of these 66 excluded studies it was necessary to look at the full paper to determine whether repetitive sit-to-stand training was incorporated into another type of exercise or training intervention as insufficient details were provided in the abstract. Reasons for exclusion of the remaining 32 are listed in Characteristics of excluded studies; these studies either specifically investigate sit-to-stand or are focused on an intervention that the review authors considered was highly likely to involve sit-to-stand training. We identified several studies that investigated interventions that were of relevance to this review, often using a cross-over design, but the order of delivery of different conditions was not truly randomised. This excluded all the studies that we had identified investigating the effect of altered chair design or starting posture for sit-to-stand (e.g. Bjerlemo 2002; Brunt 2002; Roy 2006).

We had insufficient information to reach decisions about the inclusion or exclusion for a further 18 studies (see Characteristics of studies awaiting classification) and we identified one ongoing trial (ACTIV 2012).

\section{Risk of bias in included studies}

See Figure 2 for a summary of the risk of bias in included studies. We judged four studies to be at low risk of bias for all methodological parameters assessed (Blennerhassett 2004; Dean 2007; FLASSH 2012; Tung 2010). 
Figure 2. 'Risk of bias' summary: review authors' judgements about each risk of bias item for each included study.

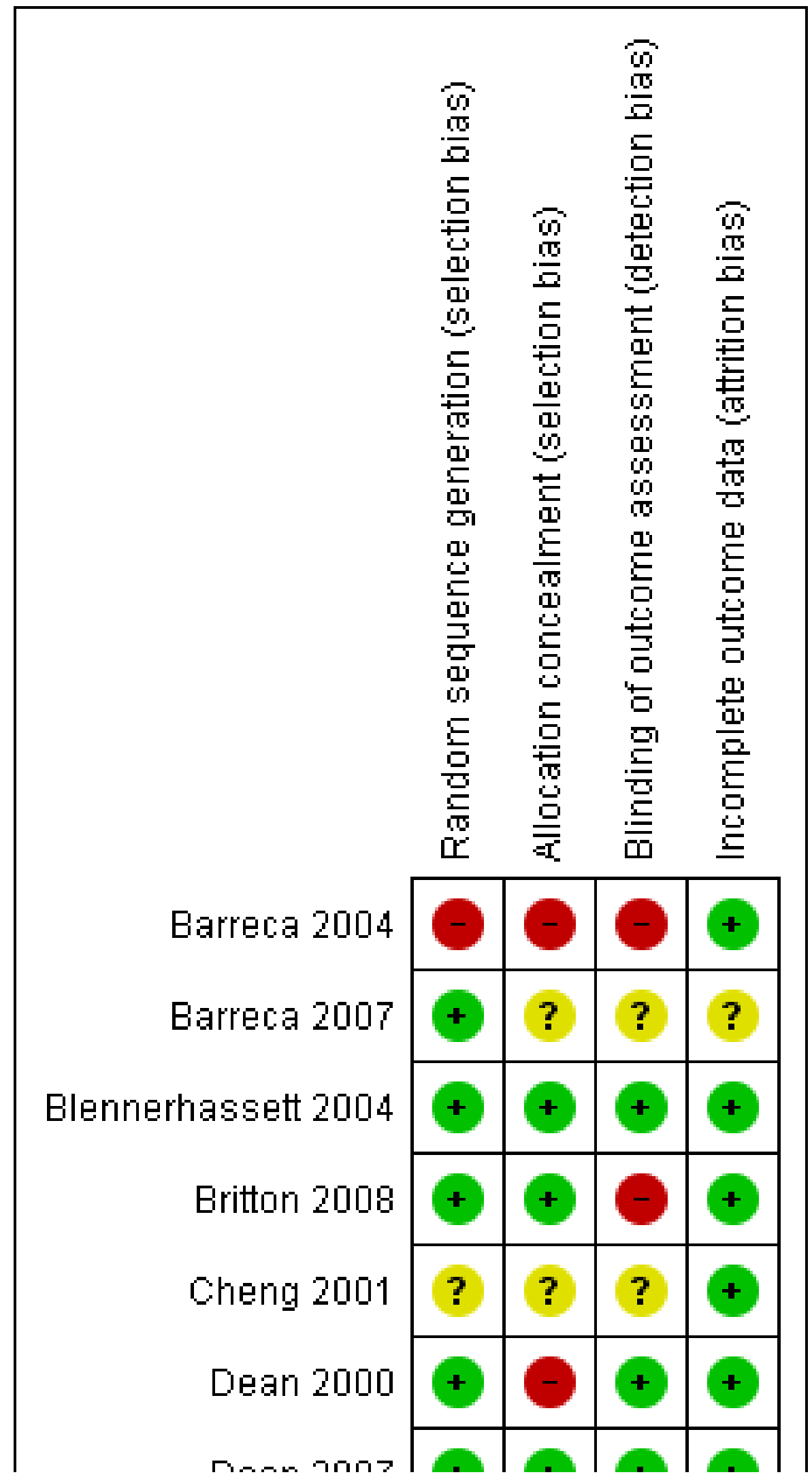


Figure 2. (Continued)

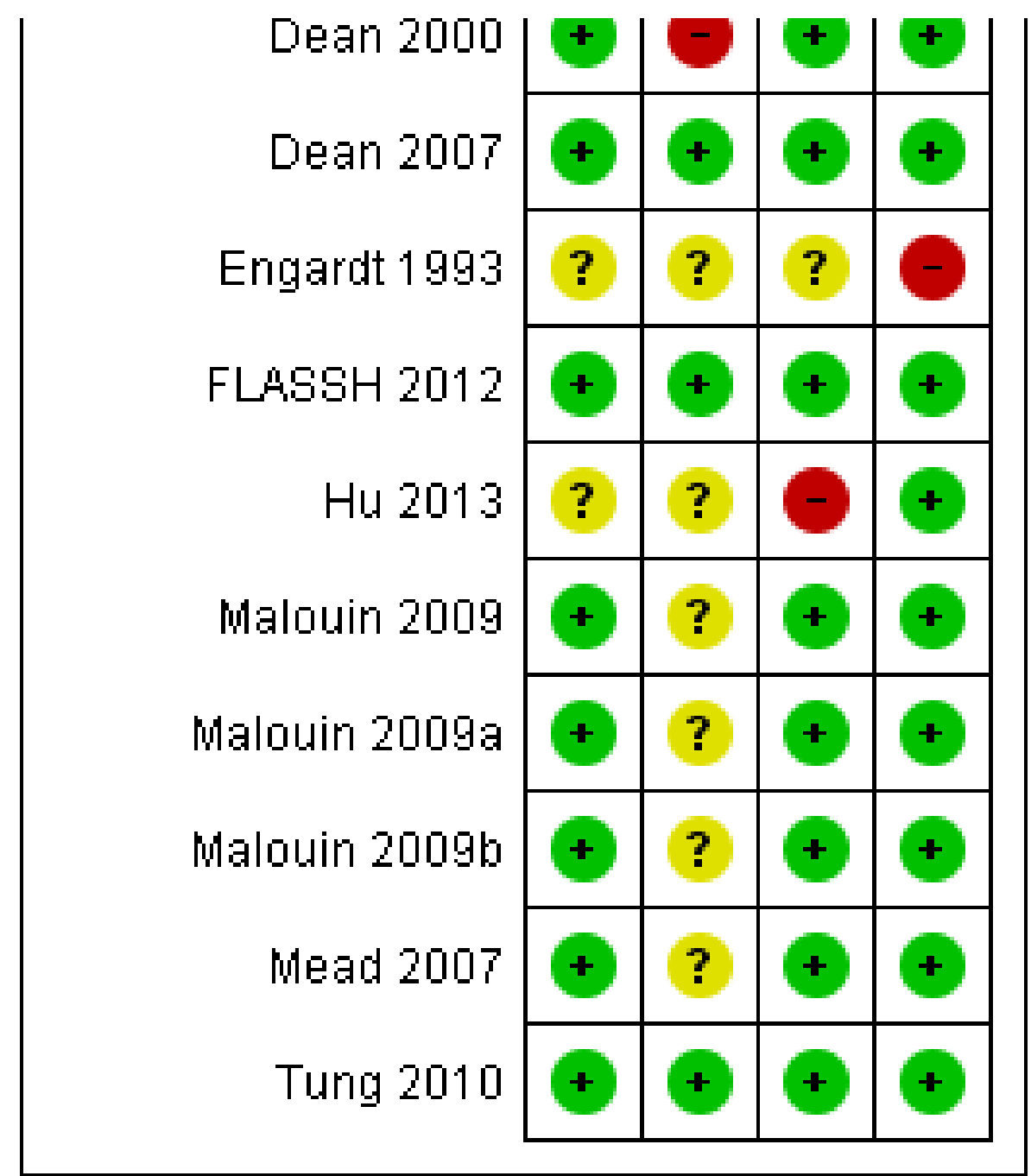


We judged five of the studies to be at high risk of bias for one or more methodological criteria. We assessed Barreca 2004 to be at high risk of bias for several methodological parameters, while we assessed the four other studies to be at high risk of bias for one methodological parameter: Britton 2008 failed to have a blinded outcome assessor, we considered Dean 2000 and Hu 2013 to have inadequate allocation concealment and we considered Engardt 1993 to have dealt with incomplete data inappropriately. In addition, we noted that Britton 2008 and Tung 2010 had unbalanced demographic variables between treatment groups. We also noted that the instruction to participants in Dean 2000 to sit-to-stand with equal weight distribution during baseline and post-intervention assessment might introduce some bias into the measurement of weightbearing symmetry compared with studies where this instruction was not given.

There were insufficient details to be certain of the risk of bias for several parameters for Barreca 2007, Cheng 2001 and Engardt 1993, and for allocation concealment for Malouin 2009 and Mead 2007.

\section{Effects of interventions}

See: Summary of findings for the main comparison

\section{Any therapy intervention or training for sit-to-stand versus control: immediate effect of intervention}

We included 10 studies in this comparison: five studies (164 participants) that investigated repetitive sit-to-stand training (Barreca 2004; Britton 2008; Cheng 2001; Malouin 2009; Tung 2010), four studies (264 participants) that investigated an exercise training programme that included sit-to-stand training (Blennerhassett 2004; Dean 2000; FLASSH 2012; Mead 2007), and one study (12 participants) that included a training programme (sitting training) aiming to improve sit-to-stand (Dean 2007).

\subsection{Ability to sit-to-stand independently}

Only one small study, judged to be at high risk of bias, assessed our primary outcome of ability to sit-to-stand independently (Barreca 2004, 48 participants). This study demonstrated a statistically significant effect of the intervention when compared with control (odds ratio (OR) 4.86, 95\% confidence interval (CI) 1.43 to 16.50 ) (Analysis 1.1).

\subsection{Time taken to sit-to-stand (or sit-to-walk)}

Seven studies (335 participants) measured the time to sit-to-stand (Britton 2008; Cheng 2001; Mead 2007; Tung 2010), or sit-to-walk (Blennerhassett 2004; Dean 2000), or number of sit-to-stands in a specified time (FLASSH 2012), and demonstrated a statistically significant effect of intervention when compared with control (standardised mean difference (SMD) $-0.34,95 \% \mathrm{Cl}-0.62$ to -0.06 ) with low heterogeneity $\left(I^{2}=29 \%\right)$ (Analysis 1.2$)$.

Sensitivity analysis to remove FLASSH 2012, as not all participants may have done sit-to-stand training, demonstrated that there was a more significant effect (SMD $-0.51,95 \% \mathrm{Cl}-0.79$ to -0.23 ) with no heterogeneity $\left(I^{2}=0 \%\right)$. There was no significant difference between the subgroup of studies measuring sit-to-stand time and those measuring sit-to-walk time $(P$ value $=0.75)$. Additional sensitivity analysis to explore the effect of removing Cheng 2001, as these data were follow-up data and not from immediately after the end of the intervention, demonstrated no change in the direction of the effect (SMD $-0.41,95 \% \mathrm{Cl}-0.73$ to -0.08 ).

\subsection{Lateral symmetry}

Five studies (105 participants) measured lateral symmetry by assessing either weight distribution (Britton 2008; Dean 2000; Dean 2007; Malouin 2009), or centre of pressure (Cheng 2001), and demonstrated a statistically significant effect of the intervention when compared with control (SMD $0.85,95 \% \mathrm{Cl} 0.38$ to 1.33 ) with little heterogeneity $\left(I^{2}=10 \%\right)$. The test for subgroup differences suggested that there was little difference between the subgroup assessing weight distribution and the subgroup assessing centre of pressure $(P$ value $=0.12)($ Analysis 1.3$)$

Sensitivity analysis to explore the effect of removing Dean 2000, as this study gave participants specific instructions to sit-to-stand with symmetrical weight distribution, did not impact on the significance of the results (SMD $0.80,95 \% \mathrm{Cl} 0.29$ to 1.30). Sensitivity analysis to explore the effect of removing Cheng 2001, as these data were follow-up data and not from immediately after the end of the intervention, demonstrated no change in the direction of the effect (SMD 1.19, 95\% Cl 0.55 to 1.84). However, removing Cheng 2001 from the analysis did reduce the heterogeneity from $\mathrm{I}^{2}=10 \%$ to $I^{2}=0 \%$.

\subsection{Peak vertical ground reaction force}

Only one study assessed peak vertical ground reaction force during sit-to-stand (Cheng 2001, 54 participants). This found no statistically significant effect of the intervention when compared with control (SMD - $0.02,95 \% \mathrm{Cl}-0.55$ to 0.52 ) (Analysis 1.4).

\subsection{Falls}

Five studies (319 participants) reported the number of participants falling during the intervention period (Barreca 2004; Cheng 2001; Dean 2007; FLASSH 2012; Mead 2007). Analysis suggests that there is no significant effect of the intervention when compared with control (OR 0.75, 95\% Cl 0.46 to 1.22). Removal of FLASSH 2012, as this study was specifically aimed at reduction of falls and included multifactorial falls prevention interventions, did not affect the direction of the result (OR $0.84,95 \% \mathrm{Cl} 0.41$ to 1.72 ) (Analysis 1.5).

Additional sensitivity analysis to explore the effect of removing Barreca 2004, as this study was assessed to be at high risk of bias, and Dean 2007, as falls were reported as an adverse event rather than an outcome, did not affect the direction of the result (OR $0.81,95 \%$ $\mathrm{Cl} 0.35$ to 1.87 ).

\subsection{Functional ability}

Two studies (196 participants) reported functional ability at the end of the intervention (FLASSH 2012; Mead 2007). There was no statistically significant effect of the intervention when compared with control (SMD $-0.24,95 \% \mathrm{Cl}-0.52$ to 0.04 ) (Analysis 1.6). Sensitivity analysis to remove FLASSH 2012 did not affect the result (SMD - 0.13 , $95 \% \mathrm{Cl}-0.62$ to 0.36 ).

\section{Any therapy intervention or training for sit-to-stand versus control: follow-up effects}

Due to availability of data we have pooled follow-up data for the outcomes of time and lateral symmetry only.

\subsection{Time taken to sit-to-stand (or sit-to-walk)}

Four studies (149 participants) reported follow-up data for a measure of time (Blennerhassett 2004; Cheng 2001; Dean 2000; Mead 
2007), and demonstrated a statistically significant effect of the intervention when compared with control (SMD $-0.45,95 \% \mathrm{Cl}-0.78$ to $-0.12)$ with no heterogeneity $\left(I^{2}=0 \%\right)$ (Analysis 2.1 ).

\subsection{Lateral symmetry}

Three studies (75 participants) reported follow-up data for a measure of lateral symmetry (Cheng 2001; Dean 2000; Malouin 2009), and demonstrated a statistically significant effect of the intervention when compared with control (SMD $0.59,95 \% \mathrm{Cl} 0.11$ to 1.07 ) with no heterogeneity $\left(I^{2}=0 \%\right)$ (Analysis 2.2 ).

\section{Subgroup analysis: type of intervention}

Three different types of therapy intervention or training for sit-tostand were included within the trials in Analysis 1. These interventions included repetitive sit-to-stand training (Barreca 2004; Britton 2008; Cheng 2001; Malouin 2009; Tung 2010), exercise training programmes that included sit-to-stand training (Blennerhassett 2004; Dean 2000; FLASSH 2012; Mead 2007), and a training programme (sitting training) aiming to improve sit-to-stand (Dean 2007). There were data available for more than five studies for the outcomes of 'Time' and 'Lateral symmetry'. We therefore carried out subgroup analyses to explore the effect of the type of intervention for these outcomes.

\subsection{Time taken to sit-to-stand (or sit-to-walk)}

Data were available from three studies investigating repetitive sitto-stand (Britton 2008; Cheng 2001; Tung 2010), and four investigating exercise programmes (Blennerhassett 2004; Dean 2000; FLASSH 2012; Mead 2007). Subgroup analysis suggested that there were no significant differences between subgroups of different types of intervention in time taken to sit-to-stand (or sit-to-walk) ( $P$ value $=0.19$ ). There remained no significant differences between subgroups when data from FLASSH 2012 were removed from the analysis $(P$ value $=0.69)($ Analysis 3.1$)$.

\subsection{Lateral symmetry}

Data were available from three studies investigating repetitive sitto-stand (Britton 2008; Cheng 2001; Malouin 2009); one investigating an exercise programme (Dean 2000), and one investigating sitting training aiming to improve sit-to-stand (Dean 2007). Subgroup analysis indicated that there were no significant differences between subgroups of different types of interventions in lateral symmetry during sit-to-stand ( $P$ value $=0.11$ ) (Analysis 3.2) .

\section{Subgroup analyses: duration and intensity of intervention}

We carried out subgroup analyses to explore the effect of interventions that were either delivered for a different number of weeks, or that were delivered for a different number of sessions per week, for the outcomes of 'Time' and 'Lateral symmetry'. These analyses indicated that there were no significant differences between subgroups for number of weeks or number of sessions per week for the outcome of 'Time' ( $P$ value $=0.68$ and $P$ value $=0.25$ respectively ) or 'Lateral symmetry' ( $P$ value $=0.81$ and $P$ value $=0.81$ respectively). We did not include data from FLASSH 2012 in this subgroup analysis as the duration and intensity was dependent on adherence by the participant (Analysis 4.1; Analysis 4.2; Analysis 4.3; Analysis 4.4).

\section{Subgroup analyses: time post-stroke}

We carried out subgroup analyses to explore the effect of including participants who were at different times post-stroke. We divided these, according to the descriptions of participants provided within studies, into 30 to 51 days post-stroke, 2.8 to 6 months post-stroke or more than one year post-stroke, and completed subgroup analyses for the outcomes of 'Time' and 'Lateral symmetry'. These analyses indicated that there were no significant differences between subgroups relating to time post-stroke for the outcomes of 'Time' ( $P$ value $=0.86)$ or 'Lateral symmetry' $(P$ value $=0.22)$ (Analysis 5.1; Analysis 5.2).

\section{Feedback versus no feedback}

One study (42 participants) investigated augmented feedback during sit-to-stand (Engardt 1993), comparing the effects of repetitive sit-to-stand training with auditory feedback of weight-bearing symmetry with repetitive sit-to-stand training with no auditory feedback. Data were available for the outcomes of 'Time' and 'Lateral symmetry'; analyses demonstrated no significant benefit of the feedback (SMD - $0.11,95 \% \mathrm{Cl}-0.82$ to 0.61 and SMD $0.53,95 \% \mathrm{Cl}-0.20$ to 1.26 respectively) (Analysis 6.1; Analysis 6.2).

\section{DISCUSSION}

\section{Summary of main results}

We identified 13 randomised controlled trials (RCTs) (603 participants) that investigated the effectiveness of interventions to improve sit-to-stand. Twelve of the studies compared a type of therapy intervention or training for sit-to-stand with a control intervention; one study investigated the effect of using a cane during sit-tostand. We included data from 11 RCTs (482 participants) in metaanalyses.

Only one of these studies (48 participants), which we judged to be at high risk of bias, reported our primary outcome of interest, ability to sit-to-stand independently, finding a significantly increased odds of achieving independent sit-to-stand in the intervention group. However, the majority of the RCTs (nine studies, 422 participants) included participants who were already able to sit-to-stand or walk independently, meaning that there is very little evidence relating to ability to achieve independent sit-to-stand. Rather, most evidence relates to improvements in sit-to-stand ability in people who are already independent.

Meta-analyses revealed that immediately after therapy interventions or training for sit-to-stand the time taken to sit-to-stand and the lateral symmetry (weight distribution between the legs or centre of pressure displacement) during sit-to-stand is significantly improved. Subgroup analyses found no evidence of significant subgroup differences between groups with different types of intervention, duration or intensity of intervention or of time post-stroke of included participants. Meta-analyses of follow-up data revealed that the immediate improvement in the time taken to sit-to-stand and the lateral symmetry (weight distribution between the legs) during sit-to-stand was maintained beyond the period of the intervention.

We found some limited evidence, from five RCTs, that the interventions did not have a significant effect on the number of falls. However, there were methodological issues with three of these RCTs, limiting the ability to generalise from this result. We identified very few trials that assessed the effect of sit-to-stand training on peak vertical ground reaction force (one study, 54 participants) and functional ability (two studies, 196 participants), providing very low and low quality evidence respectively in relation to these outcomes. 
In summary, this review has found insufficient evidence relating to our primary outcome of ability to sit-to-stand independently to reach any generalisable conclusions. However, we found moderate quality evidence that interventions to improve sit-to-stand have a significantly beneficial effect on secondary outcomes of time taken to sit-to-stand and lateral symmetry during sit-to-stand, in the population of people with stroke who were already able to sit-to-stand independently, with some evidence that this effect is maintained long-term.

\section{Overall completeness and applicability of evidence}

The evidence that has been pooled within analyses relates only to the population of people with stroke who are able to either sit-tostand or walk independently prior to the intervention. Thus this evidence is only applicable to improving ability in people with stroke who are able to sit-to-stand, and cannot be generalised to the population of people with stroke who are unable to sit-to-stand independently.

We primarily found RCTs investigating the effect of therapy interventions and training to improve sit-to-stand, and did not find any evidence relating to the effect of altered chair design and only one cross-over study investigating starting posture (use of a cane) for sit-to-stand. This review is therefore unable to reach any conclusions relating to the effect of different chair designs or starting postures during training of, or performance of, sit-to-stand.

Although our analyses include a low number of small studies, the results of the studies are consistent and there was relatively low heterogeneity for the analyses relating to the outcomes of time and lateral symmetry, increasing our confidence in the generalisability of this evidence.

\section{Quality of the evidence}

The sample sizes in the included studies were generally very low, ranging from 12 to 156 participants. We judged only four of the included studies to be at low risk of bias for all methodological criteria assessed, and we judged five studies to be at high risk of bias for at least one methodological criterion assessed. We judged one study to be at high risk of bias for more than one methodological feature; however, this study did not contribute any data to the key analyses relating to time or lateral symmetry.

\section{Potential biases in the review process}

We included studies that investigated exercise programmes that included sit-to-stand. There is the possibility that we may have failed to identify all RCTs of exercise programmes that included sit-tostand training. However, if the study included an outcome specific to sit-to-stand our search strategy ought to have been successful at identifying these studies. In some cases we identified RCTs of exercise programmes that did not explicitly state that the intervention was (or was not) aimed at improving sit-to-stand ability. As it is difficult to be certain about the absence of a statement, in these cases we therefore checked whether sit-to-stand had been assessed as an outcome. We excluded studies if there was no explicit statement of intent to improve sit-to-stand ability and there was no outcome related to sit-to-stand ability. Studies that we excluded on this basis are described in the Characteristics of excluded studies table as being excluded because "outcomes did not meet the criteria of this review".
We searched for studies that investigated the effect of altered chair design or starting posture for sit-to-stand. We found a number of studies that investigated sit-to-stand performance in people with stroke under a number of different conditions, including different chair heights and foot positions. Although some of these studies stated that there was some 'randomisation' of the order of different conditions, we judged that the order of the presentation of conditions was not truly randomised for all except one of these studies. It could be argued that one would not expect any carry-over in levels of performance of sit-to-stand between different conditions, and that therefore a truly randomised order of allocation of conditions is not a necessary criterion to achieve low risk of bias within these studies. Consequently, it may be unrealistic to expect to identify any RCTs investigating the effect of altered chair design or starting posture for sit-to-stand, as best evidence relating to chair design or starting posture may come from repeated-measures studies. We will need to consider whether, for future updates of this review, we continue to search for RCTs investigating chair design or starting posture within a single session.

\section{Agreements and disagreements with other studies or reviews}

There is a growing body of evidence from systematic reviews and meta-analyses of RCTs that effective rehabilitation components are high-intensity, repetitive and task-specific in nature (Langhorne 2009), and our review adds to this body of evidence. We are unaware of any previous systematic reviews focusing specifically on interventions to improve ability to sit-to-stand.

Our review is in agreement with a Cochrane review investigating the effect of repetitive task training to improve functional ability after stroke, which found a significant effect of repetitive task training on sit-to-stand outcomes (standardised mean difference (SMD) $0.35,95 \%$ confidence interval $(\mathrm{Cl}) 0.13$ to 0.56 ) (French 2007). The French 2010 Cochrane review included eight studies that had some measure of sit-to-stand ability; our review only included three of these eight studies (Barreca 2004; Blennerhassett 2004; Dean 2000). We excluded the other five studies from our review because the intervention was not specifically aimed at improving sit-to-stand ability; one at the full paper stage (Dean 1997), and four at the title/abstract stage (Howe 2005; Langhammer 2000; Salbach 2004; van Vliet 2005). Our review identified four RCTs of repetitive sitto-stand training that are not included in the French 2007 review; one study that does not appear to have been identified (Cheng 2001), and three that have been published after the date of the last search (Britton 2008; Malouin 2009; Tung 2010). Thus, our review is in agreement with the conclusions of the French 2007 review that repetitive training is beneficial for sit-to-stand. However, the advantages of our review are that our evidence is specific to interventions which are aimed at improving sit-to-stand, and that we have identified additional studies of repetitive sit-to-stand training.

\section{AUTHORS' CONCLUSIONS}

\section{Implications for practice}

The conclusions are limited by the low number of small studies included within this review. However, this review provides moderate quality evidence that therapy and training interventions that are specifically aimed at improving sit-to-stand may be effective at improving sit-to-stand time and performance (lateral symmetry), in people who are able to sit-to-stand independently after stroke, and 
that this effect may be sustained beyond the period of the intervention. This review thus adds to the body of evidence that repetitive task-specific training is beneficial within stroke rehabilitation.

There is insufficient evidence to make any conclusions about the effect of sit-to-stand training on global measures of functional ability after stroke.

The available studies suggest that effective interventions can either be specific repetitive training of sit-to-stand or exercise programmes that include repetitive sit-to-stand. The evidence is insufficient to make conclusions relating to the duration or intensity of training.

\section{Implications for research}

Further, appropriately powered, well-designed randomised controlled trials (RCTs) of sit-to-stand training are essential to confirm the results of this review, which are currently based on a low number of very small studies. Current evidence demonstrates benefits associated with repetitive sit-to-stand training, and there is now a need for RCTs that clearly investigate the effect of different durations and intensities of training. Future RCTs should include a mea- sure of global functional ability, and should include a follow-up outcome measure as well as an outcome measured immediately after the end of the intervention. Studies that explore methods of augmenting repetitive sit-to-stand training (e.g. the addition of feedback) would be beneficial.

Studies to investigate the effect of sit-to-stand training on people unable to sit-to-stand independently are required, as there is currently a lack of evidence relating to this population. Systematic reviews of the non-randomised evidence relating to the effect of seat design and starting posture are required, as this evidence potentially provides useful information relating to these issues.

\section{ACKNOWLEDGEMENTS}

We would like to thank Brenda Thomas, Cochrane Stroke Group Trials Search Co-ordinator, for her assistance in developing the search strategy; Paola Durando for assisting with literature searches; and Gillian Mead and Susan Lewis for providing data relating to the Mead 2007 trial. We are very grateful to everyone who provided peer-review on versions of this review; including Heather Goodare and another consumer reviewer who provided valuable comments. 


\section{RE F E R E N C E S}

\section{References to studies included in this review}

\section{Barreca 2004 \{published data only\}}

Barreca S, Sigouin CS, Lambert C, Ansley B. Effects of extra training on the ability of stroke survivors to perform an independent sit-to-stand: a randomized controlled trial. Journal of Geriatric Physical Therapy 2004;27:59-68.

\section{Barreca 2007 \{published data only\}}

Barreca SR, Masters L, Sigouin CS. Sit-to-stand training improves standing performance and quality of life in residents living in long-term care homes following a stroke: a cluster randomized controlled trial. Stroke 2007;38(2):474.

\section{Blennerhassett 2004 \{published data only\}}

Blennerhassett J, Dite W. Additional task-related practice improves mobility and upper limb function early after stroke: a randomized controlled trial. Australian Journal of Physiotherapy 2004;50:219-24.

\section{Britton 2008 \{published data only\}}

Britton E, Harris N, Turton A. An exploratory randomized controlled trial of assisted practice for improving sit-to-stand in stroke patients in the hospital setting. Clinical Rehabilitation 2008;22:458-68.

\section{Cheng 2001 \{published data only\}}

Cheng PT, Wu SH, Liaw MY, Wong AMK, Tang FT. Symmetrical body-weight distribution training in stroke patients and its effect on fall prevention. Archives of Physical Medicine and Rehabilitation 2001;82:1650-4.

\section{Dean 2000 \{published data only\}}

Dean CM, Richards CL, Malouin F. Task-related circuit training improves performance of locomotor tasks in chronic stroke: a randomized, controlled pilot trial. Archives of Physical Medicine and Rehabilitation 2000;81:409-17.

\section{Dean 2007 \{published data only\}}

Dean CM, Channon EF, Hall JM. Sitting training early after stroke improves sitting ability and quality and carries over to standing up but not to walking: a randomized controlled trial. Australian Journal of Physiotherapy 2007;53:97-102.

\section{Engardt 1993 \{published data only\}}

Engardt M, Ribbe T, Olsson E. Vertical ground reaction force feedback to enhance stroke patients' symmetrical body-weight distribution while rising/sitting down. Scandinavian Journal of Rehabilitation Medicine 1993;25:41-8.

\section{FLASSH 2012 \{published data only\}}

Batchelor F, Hill K, Mackintosh S, Said C, Fryer C, Whitehead C. Falls prevention after stroke: does adherence to exercise influence falls?. Neurorehabilitation and Neural Repair 2012;26(6):735.

* Batchelor FA, Hill KD, Mackintosh SF, Said CM, Whitehead CH. Effects of multifactorial falls prevention program for people with stroke returning home after rehabilitation: a randomized controlled trial. Archives of Physical Medicine and Rehabilitation 2012;93:1648-55.

\section{Hu 2013 \{published data only\}}

Hu P-T, Lin K-H, Lu T-W, Tang P-F, Hu M-H, Lai J-S. Effect of a cane on sit-to-stand transfer in subjects with hemiparesis. American Journal of Physical Medicine and Rehabilitation 2013;92:191-202.

\section{Malouin 2009 \{published data only\}}

Malouin F, Richards CL, Durand A, Doyon J. Added value of mental practice combined with a small amount of physical practice on the relearning of rising and sitting poststroke: a pilot study. Journal of Neurologic Physical Therapy 2009;33:195-202

Malouin 2009a \{published data only\}

Malouin F, Richards CL, Durand A, Doyon J. Added value of mental practice combined with a small amount of physical practice on the relearning of rising and sitting poststroke: a pilot study. Journal of Neurologic Physical Therapy 2009.;33:195-202.

\section{Malouin 2009b \{published data only\}}

Malouin F, Richards CL, Durand A, Doyon J. Added value of mental practice combined with a small amount of physical practice on the relearning of rising and sitting poststroke: a pilot study. Journal of Neurologic Physical Therapy 2009;33:195-202.

Mead 2007 \{published data only\}

Mead GE, Greig CA, Cunningham I, Lewis SJ, Dinan S, Saunders DH, et al. Stroke: a randomized trial of exercise or relaxation. Journal of the American Geriatrics Society 2007;55:892-9.

\section{Tung 2010 \{published data only\}} Tung FL, Yang YR, Lee CC, Wang RY. Balance outcomes after additional sit-to-stand training in subjects with stroke: a randomized controlled trial. Clinical Rehabilitation 2010;24:533-42.

\section{References to studies excluded from this review}

\section{Allison 2007 \{published data only\}}

Allison R, Dennett R. Pilot randomized controlled trial to assess the impact of additional supported standing practice on functional ability post stroke. Clinical Rehabilitation 2007:21:614-9.

\section{Anderson 1996 \{published data only\}}

Anderson D, Kurihara R, Pate P. Influence of trunk alignment on sit-to-stand transition of person with cerebellar hemorrhage. Neurology Report 1996;20(4):5-6

Bjerlemo 2002 \{published data only\}

Bjerlemo B, Johnels B, Kreuter M. The effect of two different arm positions on body weight distribution when rising from 
sitting to standing in stroke patients. Physiotherapy Theory and Practice 2002;18:33-41.

\section{Boyne 2011 \{published data only\}}

Boyne P, Israel S, Dunning K. Speed-dependent body weight supported sit-to-stand training in chronic stroke: a case series. Journal of Neurologic Physical Therapy 2011;35(4):178-84.

Briere 2010 \{published data only\}

Briere A, Lauziere S, Gravel D, Nadeau S. Perception of weightbearing distribution during sit-to-stand tasks in hemiparetic and healthy individuals. Stroke 2010;41:1704-8.

\section{Brunt 2002 \{published data only\}}

Brunt D, Greenberg B, Wankadia S, Trimble MA, Shechtman O. The effect of foot placement on sit to stand in healthy young subjects and patients with hemiplegia. Archives of Physical Medicine and Rehabilitation 2002;83:924-9.

\section{Burns 1999 \{published data only\}}

Burns DC, Wheeler LE, Pierson-Carey C, Brown DA. Increased weight acceptance with external loading during sit-to-stand in people with stroke induced hemiparesis. Neurology Report 1999;23(5):206.

\section{Chen 2010 \{published data only\}}

Chen HB, Wei TS, Chang LW. Postural influence on stand-to-sit leg load sharing strategies and sitting impact forces in stroke patients. Gait and Posture 2010;32:576-80.

\section{Dean 1997 \{published data only\}}

Dean CM, Shepherd RB. Task-related training improves performance of seated reaching tasks after stroke. A randomized controlled trial. Stroke 1997;28:722-8.

\section{Duclos 2008 \{published data only\}}

Duclos C, Nadeau S, Lecours J. Lateral trunk displacement and stability during sit-to-stand transfer in relation to foot placement in patients with hemiparesis. Neurorehabilitation and Neural Repair 2008;22:715-22.

\section{Engardt 1995 \{published data only\}}

Engardt M, Knutsson E, Jonsson M, Sternhag M. Dynamic muscle strength training in stroke patients: effects on knee extension torque, electromyographic activity, and motor function. Archives of Physical Medicine and Rehabilitation 1995;76:419-25.

\section{Flynn 2007 \{published data only\}}

Flynn H. An investigation into the influence of sit-to-stand repetitions in acute rehabilitation. Physiotherapy 2007;93 Suppl 1:S398.

\section{Fowler 1996 \{published data only\}}

Fowler V, Carr J. Auditory feedback: effects on vertical force production during standing up following stroke. International Journal of Rehabilitation Research 1996;19:265-9.

Fujikura 2012 \{published data only\}

Fujikura M, Fujii H, Kafuku T, Kimura Y, Fukuda E. Sit-tostand from a toilet seat by hemiplegic subjects using a one- point cane. Physical and Occupational Therapy in Geriatrics 2012;30(2):150-64.

Giuliani 1993 \{published data only\}

* Giuliani CA, Light KE, Rose DK. The effect of an isokinetic exercise program on gait patterns in patients with hemiparesis. Neurology Report 1993;17(4):23-4.

Giuliani CA, Light KE, Rose DK. The effect of an isokinetic exercise program on the performance of sit-to-stand in patients with hemiparesis. Proceedings of the Forum on Physical Therapy Issues Related to Cerebrovascular Accidents. Combined Sections Meeting, APTA. San Francisco, 1992:49-54.

Rose DK, Giuliani CA, Light KE. The immediate effects of isokinetic exercise on temporal-distance characteristics of selfselected and fast hemiplegic gait. Proceedings of the Forum on Physical Therapy Issues Related to Cerebrovascular Accidents. Combined Sections Meeting, APTA. San Francisco, 1992:37-42.

\section{Goldman 2011 \{published data only\}}

Goldman AJ, Buster TW, Taylor AP, Ediger MJ, Shu Y, Burnfield JM. Muscle demands of device assisted versus clinician assisted sit-to-stand transfers: implications for stroke rehabilitation. Stroke 2011;42(3):e326.

\section{Helbostad 2004 \{published data only\}}

Helbostad JL, Sletvold O, Moe-Nilssen R. Effects of home exercises and group training on functional abilities in homedwelling older persons with mobility and balance problems. A randomized study. Aging Clinical and Experimental Research 2004;16:113-21.

\section{Hesse 1998 \{published data only\}}

Hesse S, Schauer M, Perterson M, Jahnke M. Sit-to-stand manoeuvre in hemiparetic patients before and after a 4week rehabilitation programme. Scandinavian Journal of Rehabilitation Medicine 1998;30:81-6.

\section{Janssen 2010 \{published data only\}}

Janssen W, Bussmann J, Selles R, Koudstaal P, Ribbers G, Stam H. Recovery of the sit-to-stand movement after stroke: a longitudinal cohort study. Neurorehabilitation and Neural Repair 2010;24:763-9.

\section{Kluding 2004 \{published data only\}}

Kluding P, Zipp GP. Effect of ankle joint mobilization on ankle mobility and sit-to-stand in subjects with hemiplegia. Journal of Neurological Physical Therapy 2004;28(2):72-83.

\section{Kluding 2005 \{published data only\}}

Kluding P, Santos M. Changes in sit-to-stand following ankle joint mobilizations in subjects with hemiplegia (abstract). Journal of Neurologic Physical Therapy 2005;29(4):210-1.

\section{Li 2005 \{published data only\}}

Li H-F, Wang J-H, Feng J-C, Gao F. Application of motor relearning therapy in the early rehabilitation of stroke: a randomized controlled comparison. Zhongguo Linchuang Kanfu 2005;9(29):1-3. 
Malouin 2004 \{published data only\}

Malouin F, Richards CL, Doyon J, Desrosiers J, Belleville S. Training mobility tasks after stroke with combined mental and physical practice: a feasibility study. Neurorehabilitation and Neural Repair 2004;18(2):66-75.

\section{McClellan 2004 \{published data only\}}

McClellan R, Ada L. A six-week, resource-efficient mobility program after discharge from rehabilitation improves standing in people affected by stroke: placebo-controlled, randomised trial. Australian Journal of Physiotherapy 2004;50:163-7.

\section{Mercer 2001 \{published data only\}}

Mercer VS, Baker I, Piner S, Templar A. Effects of an external versus an internal attentional focus on lower extremity weight bearing during sit-to-stand in subjects who are post-stroke. Neurology Report 2001;25(4):139.

\section{Monger 2002 \{published data only\}}

Monger C, Carr JH, Fowler V. Evaluation of a home-based exercise training programme to improve sit-to-stand in patients with chronic stroke. Clinical Rehabilitation 2002;16:361-7.

\section{Noh 2008 \{published data only\}}

Noh DK, Lim JY, Shin HI, Paik NJ. The effect of aquatic therapy on postural balance and muscle strength in stroke survivors - randomized controlled pilot trial. Clinical Rehabilitation 2008;22:966-76.

\section{Oh 2010 \{published data only\}}

Oh DW, Kim JS, Kim SY, Yoo EY, Jeon HS. Effect of motor imagery training on symmetrical use of knee extensors during sitto-stand and stand-to-sit tasks in post-stroke hemiparesis. Neurorehabilitation 2010;26:307-15.

\section{Rocha 2010 \{published data only\}}

Rocha A, Knabben RJ, Michaelsen SM. Non-paretic lower limb constraint with a step decreases the asymmetry of vertical forces during sit-to-stand at two seat heights in subjects with hemiparesis. Gait and Posture 2010;32:457-63.

\section{Roy 2006 \{published data only\}}

Roy G, Nadeau S, Gravel D, Malouin F, McFadyen BJ, Piotte F. The effect of foot position and chair height on the asymmetry of vertical forces during sit-to-stand and stand-to-sit tasks in individuals with hemiparesis. Clinical Biomechanics 2006;21:585-93.

\section{Shepherd 1996 \{published data only\}}

Shepherd RB, Carr JH, Dean C. The effect of visual feedback on the performance of standing up following stroke. Proceedings of the 1st Australasian Biomechanics Conference. Sydney, Australia, 1-2 February 1996:96-7.

\section{Sherrington 2008 \{published data only\}}

Sherrington C, Pamphlett PI, Jacka JA, Olivetti LM, Nugent JA, Hall JM, et al. Group exercise can improve participants' mobility in an outpatient rehabilitation setting: a randomized controlled trial. Clinical Rehabilitation 2008;22(6):493-502.

\section{References to studies awaiting assessment}

Atchison 1995 \{published data only\}

Atchison JW, Simpson L, Knapp L, Oeffinger D, Mainous A. Increased isotonic quadricep strength following stroke with a six-week exercise program. Archives of Physical Medicine and Rehabilitation 1995;76(11):1041.

\section{Camargos 2009 \{published data only\}}

Camargos ACR, Rodrigues-de-Paula-Goulart F, TeixeiraSalmela LF. The effects of foot position on the performance of the sit-to-stand movement with chronic stroke subjects. Archives of Physical Medicine and Rehabilitation 2009;90:314-9.

\section{Chumbler 2011 \{published data only\}}

Chumbler NR, Roudebush RL, Morey MC, Griffiths P, Quigley P, Rose DK, et al. The effects of a stroke telerehabilitation in-home intervention on function and disability: preliminary results of a randomized clinical trial. Stroke 2011;42(3):e76-7.

\section{Dean 2006 \{published data only\}}

* Dean CM, Rissel C, Sherrington C, Sharkey M, Cumming R, Lord SR, et al. Weight-bearing exercise improves mobility in stroke survivors and may prevent falls in faster walkers. Neurorehabilitation and Neural Repair 2012;26(6):730-1.

Dean CM, Rissel C, Sherrington C, Sharkey M, Cumming RG, Lord SR, et al. Exercise to enhance mobility and prevent falls after stroke: the Community Stroke Club Randomized Trial. Neurorehabilitation and Neural Repair 2012;26(9):1046-57.

\section{FFF 2010 \{published data only\}}

Fleck RJ, Richardson J, Hladysh G, McBay C, Elizabeth M, Thorlakson R, et al. FIT for FUNCTION community stroke wellness program: a pilot randomized controlled trial. Stroke 2012;43(11):e120.

\section{Finestone 2012 \{published data only\}}

Finestone HM, Svelstrup H, Bilodeau M, Taillon-Hobson A, McEwan D, Tseng L. Virtual reality exercise training for stroke rehabilitation inpatients. Stroke 2012;43(11):e155.

\section{Fraser 2012 \{published data only\}}

Fraser J, Mansfield A, Wong J, Middleton L, Inness EL, Mcllroy WE. Evaluating the impact of subacute aerobic training groups during inpatient stroke rehabilitation on levels of fitness activity post-discharge. Stroke 2012;43(11):e146.

\section{Guttman 2011 \{published data only\}}

Guttman A, Burstin A, Brown R, Brill S, Dickstein R. Motor imagery practice for improving sit-to-stand and reach-to-grasp in individuals with post-stroke hemiparesis. Journal of the Israeli Physical Therapy Society 2011;13:37.

Guttman 2012 \{published data only\}

Guttman A, Burstin A, Brown R, Bril S, Dickstein R. Motor imagery practice for improving sit to stand and reaching to grasp in individuals with poststroke hemiparesis. Topics in Stroke Rehabilitation 2012;19(4):306-19. 
Hirano 2010 \{published data only\}

Hirano Y, Maeshima S, Osawa A, Nishio D, Ikeda M, Baba M, et al. Voluntary training with family members has an effect for stroke patients with severe hemiplegia. Cerebrovascular Diseases 2012;34 Suppl 1(49):Abst.OP-89.

Kerr 2012 \{published data only\}

Kerr A, Cooke EV, Rowe P, Clark A, Pomeroy V. The effects of different physical therapy interventions on restoring fluency of sit-to-stand early after stroke. Randomised controlled trial. International Journal of Stroke 2012;7 Suppl 2:49.

Korner-Bitensky 2013 \{published data only\}

Korner-Bitensky N, Clemson L. Randomized pilot trial of usual care versus LIFE (lifestyle intervention using functional exercise to reduce falls) in those with mild stroke. Stroke 2013;44:Abst.ATP319.

\section{Lecours 2008 \{published data only\}}

Lecours J, Nadeau S, Gravel D, Teixera-Salmela L. Interactions between foot placement, trunk frontal position, weight-bearing and knee moment asymmetry at seat-off during rising from a chair in healthy controls and persons with hemiparesis. Journal of Rehabilitation Medicine 2008;40:200-7.

\section{Moore 2012 \{published data only\}}

* Moore SA, Jakovljevic DJ, Ford GA, Rochester L, Trenell MI. The effect of a community exercise intervention on physiological and physical function following stroke: a randomised controlled trial. Cerebrovascular Diseases 2012;33 Suppl 2:850-1.

Moore Sa, Jakovljevic DG, Ford GA, Rochester L, Trenell MI. The effect of a community exercise intervention on physiological and physical function following stroke: a randomized controlled trial. International Journal of Stroke 2012;7 Suppl 2(76):Abst 179.

\section{Rodrigues-De-Paula 2010 \{published data only\}}

Rodrigues-De-Paula F, Filgueiras S, Teixeira-Salmela LF. Verbal instructions for sit-to-stand movement in hemiparetic subjects. Canadian Journal of Neurological Sciences 2010;37:S102.

\section{Rose 2009 \{published data only\}}

Rose D, Duncan P, Paris T, Wu S, Behrman A, Crews E. Promoting functional improvement in post-acute stroke: the importance of repetition and progression. Stroke 2009;40:e253.

\section{Zhong 2006 \{published data only\}}

Zhong M, Mo H, Liu H, et al. Evidence-based nursing on early rehabilitation of cerebral infarction patients with hemiplegia. Chinese Nursing Research 2006;20:393-5.

\section{Zhu 2006 \{published data only\}}

Zhu J, Liao L, Chen S, et al. Influence of rehabilitative nursing intervention on activities of daily living of senile cerebral apoplexy patients. Chinese Nursing Research 2006;20:890-2.

\section{References to ongoing studies}

ACTIV 2012 \{published data only\}

Taylor D. Telerehabilitation to improve outcomes for people with stroke: the ACTIV trial. Australian New Zealand Clinical Trials Registry (ANZCTR) http://www.anzctr.org.au/ 2012.

\section{Additional references}

\section{Alexander 2000}

Alexander NB, Galecki AT, Nyquist LV, Hofmeyer MR, Grunawalt JC, Grenier ML, et al. Chair and bed rise performance in ADL-impaired congregate housing residents. Journal of the American Geriatric Society 2000;48:526-33.

\section{Cheng 1998}

Cheng PT, Liaw MY, Wong MK, Tang FT, Lee MY, Lin PS. The sit-to-stand movement in stroke patients and its correlation with falling. Archives of Physical Medicine and Rehabilitation 1998;79:1043-6.

\section{Durward 1994}

Durward BR. The Biomechanical Assessment of Stroke Patients in Rising to Stand and Sitting Down [PhD Thesis]. Glasgow: University of Strathclyde, 1994.

\section{Engardt 1992}

Engardt M, Olsson E. Body weight bearing whilst rising and sitting down in patients with stroke. Scandinavian Journal of Rehabilitation Medicine 1992;24:67-74.

\section{French 2007}

French B, Thomas LH, Leathley MJ, Sutton CJ, McAdam J, Forster $A$, et al. Repetitive task training for improving functional ability after stroke. Cochrane Database of Systematic Reviews 2007, Issue 4. [DOI: 10.1002/14651858.CD006073.pub2]

\section{French 2010}

French B, Thomas L, Leathley M, Sutton C, McAdam J, Forster A, et al. Does repetitive task training improve functional activity after stroke? A Cochrane systematic review and meta-analysis. Journal of Rehabilitation Medicine 2010;42:9-14.

\section{Hatano 1976}

Hatano S. Experience from a multicentre stroke register: a preliminary report. Bulletin of the World Health Organization 1976;54:541-33.

\section{Higgins 2011}

Higgins JPT, Green S (editors). Cochrane Handbook for Systematic Reviews of Interventions Version 5.1.0 [updated March 2011]. The Cochrane Collaboration, 2011. Available from www.cochrane-handbook.org.

\section{Howe 2005}

Howe TE, Taylor I, Finn P, Jones H. Lateral weight transference exercises following acute stroke: a preliminary study of clinical effectiveness. Clinical Rehabilitation 2005;19:45-53. 


\section{Langhammer 2000}

Langhammer B, Stanghelle JK. Bobath or Motor Relearning Programme? A comparison of two different approaches of physiotherapy in stroke rehabilitation: a randomized controlled study. Clinical Rehabilitation 2000;14:361-9.

\section{Langhorne 2009}

Langhorne P, Coupar F, Pollock A. Motor recovery after stroke: a systematic review. Lancet Neurology 2009;8:741-54.

\section{RevMan 2012 [Computer program]}

The Nordic Cochrane Centre, The Cochrane Collaboration. Review Manager (RevMan). Version 5.2. Copenhagen: The Nordic Cochrane Centre, The Cochrane Collaboration, 2012.

\section{CHARACTERISTICS OF STUDIES}

Characteristics of included studies [ordered by study ID]

\section{Salbach 2004}

Salbach NM, Mayo NE, Wood-Dauphinee S, Hanley JA, Richards CL, Côte R. A task-orientated intervention enhances walking distance and speed in the first year post stroke: a randomized controlled trial. Clinical Rehabilitation 2004;18:509-19.

\section{van Vliet 2005}

Van Vliet PM, Lincoln NB, Foxall A. Comparison of Bobath based and movement science based treatment for stroke: a randomised controlled trial. Journal of Neurology, Neurosurgery and Psychiatry 2005;76:503-8.

* Indicates the major publication for the study

\section{Barreca 2004}

\begin{tabular}{ll}
\hline Methods & Block RCT \\
\hline Participants & Canada \\
& 48 participants: 23 control, 25 intervention \\
& Inclusion criteria: between the ages of 18 and 90, medically stable, postural control of stage 3 or greater \\
& on the CMSA, failed the third item of the CMSA stage 4 postural control \\
& Exclusion criteria: none stated \\
& Mean age control group: 70 years \\
& Mean time since stroke onset control group: 31 days \\
& Mean age intervention group: 67 years \\
& Mean time since stroke onset intervention group: 30 days
\end{tabular}

Intervention group: usual care + STS training. Usual care: rehabilitation 3 times a week for 45 minutes consisting of strengthening exercises, repetitive training, functional training in standing, electrical stimulation and recreational therapy. STS training: extra sessions of STS practice 3 times a week for 45 minutes conducted in groups of 6 to 7 participants. STS practice from a variety of seat surfaces and seat heights. Participants attempted to complete 3 sets of 5 repetitions of STS

Control group: usual care (as above) + recreational therapy 3 times a week for 45 minutes. Recreational therapy: participants remained seated in wheelchairs and participated in activities such as pet therapy, information sessions and interactive word and picture games

Outcomes

Outcomes measured at discharge from rehabilitation unit or when participant was able to perform STS independently as described below

Outcome measures: ability to STS independently (ability to stand twice from a 16-inch mat surface without the use of arms on 2 consecutive days), number of STSs over the test period, incidence of falls

Additional outcomes included: satisfaction with general health status and quality of life (Dartmouth Primary Care Cooperative Project COOP scores)

Notes

No difference in baseline characteristics

No withdrawals from intervention 
Barreca 2004 (Continued)

Potential other risk of bias: before the study nurses working on the wards were taught a STS protocol, signs were posted in participants' rooms to remind them to record their STSs. These features are likely to have had an impact on 'usual care' to participants in both groups

\section{Risk of bias}

Bias Authors' judgement Support for judgement

Random sequence genera- High risk tion (selection bias)

\begin{abstract}
"On the basis of the flip of a coin, eligible participants admitted consecutively to the stroke units during the first 4-month period of the study were assigned to the conventional practice group. Eligible participants admitted consecutively to rehabilitation during the next 4 months were assigned to the extra practice group. This sequence of block randomisation (i.e. assigned participants to either a conventional or extra practice group) was conducted 3 times in total."
\end{abstract}

Therefore, the only randomisation that occurred was the random allocation of the first "block" - randomisation did not occur at the individual patient level

\begin{tabular}{ll}
\hline $\begin{array}{l}\text { Allocation concealment } \\
\text { (selection bias) }\end{array}$ & High risk
\end{tabular} $\begin{aligned} & \text { The blocked allocation was not concealed, and recruiting researchers were } \\
& \text { aware of the allocated treatment }\end{aligned}$

Blinding of outcome as- High risk sessment (detection bias) All outcomes Participants, staff and family members were asked to click a counter each time a STS action was done. The number was recorded by a physiotherapy assistant daily

"A research physiotherapist, blind to the study, tested the participants' STS movement once a week"

The method of recording the number of STSs is potentially open detection bias, especially as the staff and family were not blinded to the allocated group

Incomplete outcome data Low risk $\quad$ No drop-outs reported
(attrition bias)

All outcomes

\section{Barreca 2007}

$\begin{array}{ll}\text { Barreca } 2007 & \\ \text { Methods } & \text { RC }\end{array}$

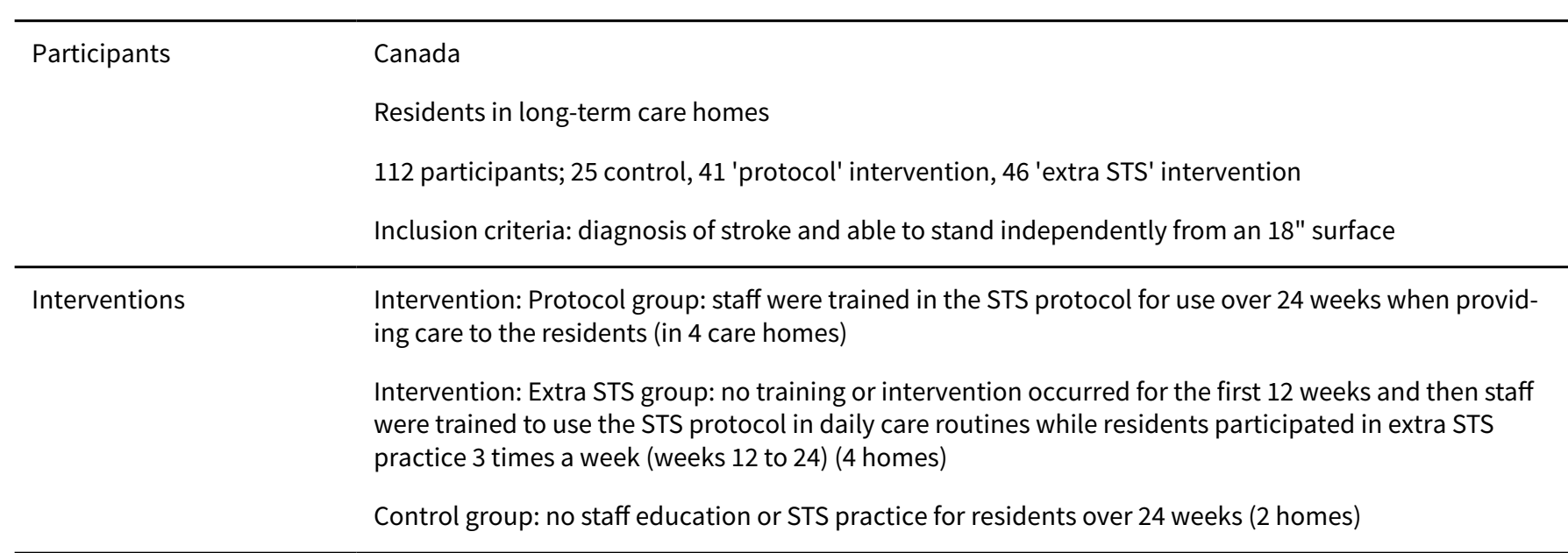


Barreca 2007 (Continued)

Ability to stand independently from 20 " surface

Notes Abstract only. No data suitable for inclusion within analyses

(Attempting to contact authors to seek data for future updates of this review)

\section{Risk of bias}

\begin{tabular}{lll}
\hline Bias & Authors' judgement & Support for judgement \\
\hline $\begin{array}{l}\text { Random sequence genera- } \\
\text { tion (selection bias) }\end{array}$ & Low risk & $\begin{array}{l}\text { "The homes were stratified according to size, years of operation, and existing } \\
\text { resident programming and randomised" }\end{array}$ \\
\hline $\begin{array}{l}\text { Allocation concealment } \\
\text { (selection bias) }\end{array}$ & Unclear risk & No information provided \\
\hline $\begin{array}{l}\text { Blinding of outcome as- } \\
\text { sessment (detection bias) } \\
\text { All outcomes }\end{array}$ & Unclear risk & No information provided \\
\hline $\begin{array}{l}\text { Incomplete outcome data } \\
\text { (attrition bias) } \\
\text { All outcomes }\end{array}$ & Unclear risk & No information provided \\
\hline
\end{tabular}

\section{Blennerhassett 2004}

\begin{tabular}{|c|c|}
\hline Methods & $\mathrm{RCT}$ \\
\hline \multirow[t]{9}{*}{ Participants } & Australia \\
\hline & Rehabilitation centre \\
\hline & 30 participants: 15 control, 15 intervention \\
\hline & $\begin{array}{l}\text { Inclusion criteria: ability to walk } 10 \text { metres with close supervision (with or without aids), ability to pro- } \\
\text { vide informed consent }\end{array}$ \\
\hline & $\begin{array}{l}\text { Exclusion criteria: deteriorating medical condition, independent community ambulators as defined by } \\
\text { a score of } 6 \text { on the Functional Ambulation Classification and the ability to walk further than } 300 \text { metres } \\
\text { in the } 6 \text { Minute Walk Test }\end{array}$ \\
\hline & Mean age control: $56.3(10.5)$ years \\
\hline & Mean time since stroke onset control: 50.1 (49.2) days \\
\hline & Mean age intervention: 53.9 (19.8) years \\
\hline & Mean time since stroke onset intervention: 36 (25.1) days \\
\hline \multirow[t]{2}{*}{ Interventions } & $\begin{array}{l}\text { Intervention group: conventional rehabilitation + mobility task practice. Conventional rehabilitation } \\
\text { was based on the movement science approach of Carr and Shepherd. Mobility task practice was a cir- } \\
\text { cuit of } 10 \text { five-minute workstations with up to } 4 \text { participants in each session. Activities included warm- } \\
\text { up, endurance using stationary bikes and treadmills, repetitive STS practice, step-ups, obstacle course, } \\
\text { walking, standing balance, stretching and strengthening. Conventional rehabilitation was provided for } \\
1 \text { hour a day, } 5 \text { days a week. Mobility task practice was provided } 1 \text { hour a day, } 5 \text { days a week for } 4 \text { weeks }\end{array}$ \\
\hline & $\begin{array}{l}\text { Control group: conventional rehabilitation (as described above) + upper limb exercises. Upper limb ex- } \\
\text { ercises consisted of a circuit of } 10 \text { five-minute workstations with up to } 4 \text { participants in each session. } \\
\text { Activities included a warm-up on the arm ergometer followed by tasks to improve reach and grasp, }\end{array}$ \\
\hline
\end{tabular}


Blennerhassett 2004 (Continued)

hand-eye co-ordination activities, stretching and strengthening. Conventional rehabilitation was provided for 1 hour a day, 5 days a week. Upper limb exercise was provided 1 hour a day, 5 days a week for 4 weeks

\begin{tabular}{|c|c|}
\hline \multirow[t]{3}{*}{ Outcomes } & $\begin{array}{l}\text { Outcomes measured at baseline, immediately following training and } 6 \text { months following the end of } \\
\text { training }\end{array}$ \\
\hline & Outcome measures: Timed Up and Go \\
\hline & Additional outcomes: 6 Minute Walk Test; Step Test and measures of upper limb ability \\
\hline Notes & - \\
\hline
\end{tabular}

\section{Risk of bias}

\begin{tabular}{lll}
\hline Bias & Authors' judgement & Support for judgement \\
\hline $\begin{array}{l}\text { Random sequence genera- } \\
\text { tion (selection bias) }\end{array}$ & Low risk & $\begin{array}{l}\text { Drawing of a pre-sealed opaque envelope that specified allocation (drawn by } \\
\text { someone independent from the study) }\end{array}$ \\
\hline $\begin{array}{l}\text { Allocation concealment } \\
\text { (selection bias) }\end{array}$ & Low risk & $\begin{array}{l}\text { Treating physiotherapists were not told of group allocation but may have } \\
\text { found out through interaction with participants during treatment }\end{array}$ \\
\hline $\begin{array}{l}\text { Blinding of outcome as- } \\
\text { sessment (detection bias) } \\
\text { All outcomes }\end{array}$ & Low risk & $\begin{array}{l}\text { Blinded to group allocation, previous test results and not involved in treat- } \\
\text { ment of participants }\end{array}$ \\
\hline $\begin{array}{l}\text { Incomplete outcome data } \\
\text { (attrition bias) } \\
\text { All outcomes }\end{array}$ & Low risk & No participants dropped out or were lost to follow-up \\
\hline
\end{tabular}

Britton 2008

\begin{tabular}{ll}
\hline Methods & RCT \\
\hline Uarticipants & Rehabilitation wards \\
& 18 participants: 9 control, 9 intervention \\
Inclusion criteria: able to STS without using hands for support and requiring 'stand by' supervision, un- & able to perform more than 3 STSs in 10 seconds, impaired upper limb function due to stroke \\
& Exclusion criteria: confused state, medically unfit, unable to provide informed consent, unable to STS \\
independently prior to stroke & Mean age control: 63 (10.6) years \\
Mean time since stroke onset control: 40.2 (32.1) days & Mean age intervention: 68.4 (13.3) years \\
Mean time since stroke onset intervention: 50.8 (35.2) days & $\begin{array}{l}\text { Intervention group: routine physiotherapy and occupational therapy + STS practice. STS practice con- } \\
\text { sisted of repetitive STS practice with emphasis on improving technique including proper foot place- } \\
\text { ment, speed and affected limb weight-bearing. A balance performance monitor provided visual feed- } \\
\text { back and the session was carried out by a physiotherapy assistant to provide verbal feedback. Seat }\end{array}$ \\
\hline Interventions
\end{tabular}


Britton 2008 (Continued)

height and surface was varied during practice. Participants were encouraged to maximise the number of STS repetitions. Strengthening exercises of the lower limbs were performed when participants fatigued before the end of a session. STS practice was performed 5 days a week, 30 minutes each day for a total of 2 weeks

Control group: routine physiotherapy and occupational therapy + sedentary arm therapy. Sedentary arm therapy consisted of arm and hand exercises or stretch positioning. Arm therapy was performed 5 days a week, 30 minutes each day for a total of 2 weeks

\begin{tabular}{ll}
\hline Outcomes & $\begin{array}{l}\text { Outcomes measured at baseline, } 1 \text { and } 2 \text { two weeks after baseline } \\
\text { Outcome measures included: duration of STS, peak vertical ground reaction force of the affected limb, } \\
\text { number of STSs in } 1 \text { minute }\end{array}$ \\
\hline Notes & Unclear if groups were the same at baseline \\
& $\begin{array}{l}\text { Statistical analysis only performed on measures at baseline and } 1 \text { week post-baseline due to loss of } \\
\text { participants at } 2 \text { weeks post-baseline. } 4 \text { participants in the control group were unavailable at } 2 \text { weeks } \\
\text { post-baseline measures due to discharge from hospital and staff shortages, } 1 \text { participant in the inter- } \\
\text { vention group was unavailable at } 2 \text { weeks post-baseline due to discharge from hospital }\end{array}$ \\
& $\begin{array}{l}\text { Potential other risk of bias: differences in demographics of treatment groups: "The mean age and time } \\
\text { since stroke were substantially less for the control group. Left hemiparesis was predominant in the ex- } \\
\text { perimental group while the control group had a more even distribution of left- and right-sided weak- } \\
\text { ness." }\end{array}$
\end{tabular}

\section{Risk of bias}

\begin{tabular}{lll}
\hline Bias & Authors' judgement & Support for judgement \\
\hline $\begin{array}{l}\text { Random sequence genera- } \\
\text { tion (selection bias) }\end{array}$ & Low risk & Predetermined sequence of group allocation, randomly drawn from a bag \\
& "Group allocation was revealed after the baseline assessment, by reference to \\
a pseudo random sequence of 20 allocations that controlled for a balance of \\
numbers between groups. The sequence was drawn up, before the beginning \\
of the trial, by putting 20 tickets into a paper bag; ten tickets had 'experimen- \\
tal' and ten 'control' written on them. A person who was independent of the \\
study pulled the tickets blindly, one at a time, from the bag. The resulting se- \\
quence was held by a secretary who was unaware of any features about the \\
patient when asked for the group allocation of participants."
\end{tabular}

\begin{tabular}{lll}
\hline $\begin{array}{l}\text { Allocation concealment } \\
\text { (selection bias) }\end{array}$ & Low risk & See above \\
\hline $\begin{array}{l}\text { Blinding of outcome as- } \\
\text { sessment (detection bias) } \\
\text { All outcomes }\end{array}$ & High risk & $\begin{array}{l}\text { "The assessor was not blind to the group allocation, however the outcomes } \\
\text { selected minimized value judgements and instructions and recording proce- } \\
\text { dures were standardized as much as possible. To establish reliability of the } \\
\text { kinematic analysis, a second assessor independently checked a sample of } 35 \\
\text { measurements." }\end{array}$ \\
\hline $\begin{array}{l}\text { Incomplete outcome data } \\
\text { (attrition bias) }\end{array}$ & Low risk & $\begin{array}{l}5 / 18 \text { participants were lost to follow-up at the 2-week assessment (2 due to } \\
\text { discharge and 3 due to staff shortages). However, there were no incomplete } \\
\text { outcome data at } 1 \text { week, so these data are reported (and not the } 2 \text { week out- } \\
\text { comes) }\end{array}$ \\
\hline
\end{tabular}

Cheng 2001

Methods RCT


Cheng 2001 (Continued)

Participants
Taiwan

Hospital-based rehabilitation setting

54 participants: 24 control, 30 intervention

Inclusion criteria: stroke onset 2 to 4 months prior to start of study, no arthritis or fractures of lower extremities, medically stable, able to understand and follow instructions, able to stand-up independently and walk with or without a cane

Exclusion criteria: Parkinson's disease, cerebellar or pontine lesion, significant cognitive deficit, evidence of a peripheral neuropathy

Mean age control group: 63.1 (7.8) years

Mean time since stroke onset control group: 2.9 (1.2) months

Mean age intervention group: 62.3 (8) years

Mean time since stroke onset intervention group: 2.8 (1.4) months

Interventions

Intervention group: conventional stroke rehabilitation + standing symmetry training + repetitive STS training. Conventional stroke rehabilitation consisted of neuromuscular facilitation, functional electrical stimulation and mat exercises. Standing postural symmetry training: participants stood in front of a height adjustable work table (biofeedback trainer) with a mirror and weight-bearing sensors to provide visual and auditory feedback. Participants pushed and pulled a weight loaded box while maintaining symmetry of upright standing using the visual and auditory feedback. Repetitive STS training: participants performed the STS and stand-to-sit task as symmetrically as possible using visual and auditory feedback provided by the biofeedback trainer. Participants performed 30 minutes of standing training and 20 minutes of STS training each day with a 15 minute rest between the 2 types of training. Total training period was 5 days a week for 3 weeks

Control group: conventional stroke rehabilitation as described above plus other therapeutic exercises. Total training period was 5 days a week for 3 weeks

Outcomes Outcomes measured at baseline, immediately following training and 6 months post-training. Values only reported at 6 months post-training

Outcome measures: duration of STS, weight-bearing asymmetry, peak vertical ground reaction force, lateral centre of pressure displacement during STS, anteroposterior centre of pressure displacement during STS, number of falls in each group between post-training and 6-month follow-up

Notes

No difference in baseline characteristics

No withdrawals from intervention

Data presented were measured at 6 months post-training. NB - paper states: "The first 8 patients in our training group received immediate post training testing after completing the 3 weeks to determine whether the training program was effective in improving STS performance in stroke patients. The results showed significant improvement in comparison with pre-training testing results. Their STS performance in the immediate post training testing appeared to be better than performances in the 6-month follow-up testing. However, there was no significant difference between 3-week retesting and 6-month follow-up testing."

Only data from the 6-month follow-up were presented in the paper

\section{Risk of bias}

Bias Authors' judgement Support for judgement

Random sequence genera- Unclear risk Method of randomisation not reported. ("The patients were randomly divided tion (selection bias) into control and training groups") 
Cheng 2001 (Continued)

\begin{tabular}{l}
$\begin{array}{l}\text { Allocation concealment } \\
\text { (selection bias) }\end{array} \quad$ Unclear risk No information provided \\
\hline
\end{tabular}

\begin{tabular}{lll}
$\begin{array}{l}\text { Blinding of outcome as- } \\
\text { sessment (detection bias) } \\
\text { All outcomes }\end{array}$ & Unclear risk & Not indicated \\
\hline $\begin{array}{l}\text { Incomplete outcome data } \\
\text { (attrition bias) }\end{array}$ & Low risk & No drop-outs reported \\
All outcomes & &
\end{tabular}

Dean 2000

\begin{tabular}{ll}
\hline Methods & RCT \\
\hline Participants & Rehabilitation centre \\
& 12 participants: 6 control, 6 intervention \\
& Inclusion criteria: first stroke resulting in hemiplegia, at least 3 months since stroke onset, discharged \\
from all rehabilitation services, able to walk 10 metres independently with or without mobility aid, able & to attend rehabilitation centre 3 times per week for 4 weeks \\
& Exclusion criteria: any medical condition preventing participation in a training programme \\
& Mean age control group: 62.3 (6.6) years \\
& Mean time since stroke onset control group: 1.3 (0.9) years \\
& Mean age intervention group: 66.2 (7.7) years \\
& Mean time since stroke onset intervention group: 2.3 (0.7) years \\
\end{tabular}

Interventions Intervention group: group circuit training including practice at 10 work stations and walking races/relays. Workstations were designed to strengthen muscles of the affected leg in a functionally relevant way and provide practice of locomotor related tasks. The 10 workstations included: seated reaching promoting weight-bearing of the affected limb, repetitive STS practice from various chair heights, stepping forward, backward and sideways onto blocks of various heights, standing heel lifts, standing balance exercises, knee flexion/extension exercise, STS with short walk and return to chair, treadmill walking, walking over various terrains and obstacles and walking over slopes and stairs. 2 physiotherapists supervised each class; for the STS workstation they ensured that the height of the seat was set to a level which promoted used of affected lower-limb muscles and discouraged used of maladaptive (compensatory) behaviours. Training sessions lasted 1 hour, 3 times per week for 4 weeks

Control group: group exercise class, training was similar to experimental group but workstations were designed to improve function of the affected upper limb. Training sessions lasted 1 hour, 3 times per week for 4 weeks

Outcomes

Outcomes assessed at baseline and following the 4 weeks of training and at 2-month follow-up. (Data from immediately after training was used for analyses)

Outcome measures: peak vertical ground reaction force through the affected limb during STS, Timed Up and Go

Additional outcomes: gait speed, 6 Minute Walk Test, step test, movement profiles, moments of force and mechanical powers of the affected limb hip, knee and ankle 
Dean 2000 (Continued)

Notes
Participants were asked to stand up from sitting with their weight equally distributed when assessing the peak vertical ground reaction force through the affected limb

Only the Timed Up and Go was assessed at the 2-month follow-up, not peak vertical ground reaction force

\section{Risk of bias}

\section{Bias}

Random sequence genera- Low risk tion (selection bias)

\section{Authors' judgement Support for judgement}

Participants matched according to walking speed. "Subjects in each pair were randomly assigned to the experimental or control group. The randomisation process involved drawing two cards, one with subjects' names, and the other with the group allocation from two separate boxes. The cards were drawn by a person independent of the study."

\begin{tabular}{|c|c|c|}
\hline $\begin{array}{l}\text { Allocation concealment } \\
\text { (selection bias) }\end{array}$ & High risk & $\begin{array}{l}\text { Training sessions were conducted by one of the study authors. Progression of } \\
\text { exercises in each group was also conducted by one of the study authors }\end{array}$ \\
\hline
\end{tabular}

\begin{tabular}{lll}
\hline $\begin{array}{l}\text { Blinding of outcome as- } \\
\text { sessment (detection bias) } \\
\text { All outcomes }\end{array}$ & Low risk & Blinded to participant allocation, however blinding may have been unmasked \\
\hline $\begin{array}{l}\text { Incomplete outcome data } \\
\text { (attrition bias) }\end{array}$ & Low risk & $\begin{array}{l}1 \text { participant from each group dropped out prior to start of training. } 1 \text { partici- } \\
\text { pant withdrew after training and before post-training testing due to unrelated } \\
\text { illness. } 1 \text { participant lost to follow-up assessment }\end{array}$ \\
\hline
\end{tabular}

Dean 2007

\begin{tabular}{ll}
\hline Methods & RCT \\
\hline
\end{tabular}

Participants

\author{
Australia \\ Rehabilitation centre \\ 12 participants: 6 control, 6 intervention \\ evidence of left neglect, ability to understand instructions \\ Exclusion criteria: none reported \\ Mean age control group: 74 (12) years \\ Mean time since stroke onset control group: 37 (23) days \\ Mean age intervention group: 60 (7) years \\ Mean time since stroke onset intervention group: 21 (8) days
}

Inclusion criteria: diagnosis of first stroke resulting in hemiplegia within previous 3 months, no orthopaedic problems that would interfere with reaching, no visual problems that would interfere with reaching and picking up an object, score of at least 3 on Item 3 (sitting balance) of the Motor Assessment Scale for Stroke, ability to reach with the unaffected arm a distance equal to $140 \%$ of arm's length, no major cognitive or perceptual problems identified with the mental status questionnaire, no
Intervention group: conventional rehabilitation + sitting training. Sitting training consisted of reaching tasks beyond arm's length using the unaffected hand with focus on smooth co-ordinated movement, appropriate loading of the affected foot, and preventing maladaptive strategies such as widening the base of support. Sitting training was performed 5 days a week for 2 weeks with 30 minutes each session 
Dean 2007 (Continued)

Control group: conventional rehabilitation + sham sitting training. Sham sitting training consisted of confined reaching tasks within $50 \%$ of arm's length and focused on improving attention. Sham sitting training was performed 5 days a week for 2 weeks with 30 minutes each session

Outcomes measured at baseline, after 2 weeks of training and at 6-month follow-up

Outcome measures: peak vertical ground reaction force of the affected limb during STS

Additional outcomes: maximum reach and gait speed

Adverse events: 1 fall (slip off the stool) was reported during the training. This has been included as a

"fall" within meta-analysis

Notes

The intervention studied was sitting training and did not involve training of STS. However, a stated research question for this study was "Does completion of a 2-week sitting training protocol have carry over benefits to standing up and walking?"

\section{Risk of bias}

Bias Authors' judgement Support for judgement

Random sequence genera- Low risk tion (selection bias)

"Randomisation was concealed from the recruiter and assessor by using sealed opaque envelopes containing the allocation, which was generated earlier by a person independent of the study using random number tables, blocked to ensure equal numbers of experimental and control participants. The third author remained blinded to group allocation and collected the outcome measures post training and six months later."

\begin{tabular}{lll}
\hline $\begin{array}{l}\text { Allocation concealment } \\
\text { (selection bias) }\end{array}$ & Low risk & Concealed from recruiter and assessor \\
\hline $\begin{array}{l}\text { Blinding of outcome as- } \\
\text { sessment (detection bias) } \\
\text { All outcomes }\end{array}$ & Low risk & $\begin{array}{l}\text { Concealed from recruiter and assessor. "The collection of some outcome mea- } \\
\text { sures required two persons, one of whom was not blinded. To reduce bias, the } \\
\text { blinded assessor (third author) gave all instructions and measured outcomes } \\
\text { which were not collected by the computer." }\end{array}$ \\
\hline
\end{tabular}

Incomplete outcome data Low risk (attrition bias)

Only 9 participants were available for follow-up testing at 6 months. Inten-

All outcomes tion-to-treat analysis was used

\section{Engardt 1993}

\begin{tabular}{|c|c|}
\hline Methods & $\mathrm{RCT}$ \\
\hline \multirow[t]{6}{*}{ Participants } & Sweden \\
\hline & Inpatient rehabilitation setting \\
\hline & 42 participants: 20 control, 20 intervention \\
\hline & $\begin{array}{l}\text { Inclusion criteria: } 1 \text { week to } 3 \text { months post-stroke onset, able to understand and follow instructions, } \\
\text { adequate hearing, able to stand up independently }\end{array}$ \\
\hline & $\begin{array}{l}\text { Exclusion criteria: normal motor function of the lower limbs, presence of ataxia when standing-up, se- } \\
\text { vere cognitive deficits }\end{array}$ \\
\hline & Mean age control group: 65.1 (9.0) years \\
\hline
\end{tabular}


Engardt 1993 (Continued)

Mean age intervention group: 64.6 (6.7) years

Mean time since stroke onset intervention group: 38 (18) days
Intervention group 1: conventional physiotherapy + repetitive STS training with auditory feedback of weight-bearing symmetry, participants were instructed to place equal weight on both feet when rising to stand (instructed to put equal weight on both feet). Training period was 6 weeks in duration with 15 minute sessions, 3 times a day, 5 days a week

Intervention group 2: conventional physiotherapy + repetitive STS training with no auditory feedback of weight-bearing symmetry, participants were instructed to place equal weight on both feet when rising to stand. Training period was 6 weeks in duration with 15 minute sessions, 3 times a day, 5 days a week

Outcomes Outcomes assessed at baseline and after 6 weeks of training. A follow-up study reports follow-up data taken at a mean of 33 months post-training (for $16 / 20$ and 14/20 participants respectively)

Outcomes measures: time, weight-bearing symmetry, Barthel Index. Means and standard deviations reported for weight-bearing symmetry. Medians and range reported for Barthel Index. Only weight-bearing symmetry included within meta-analyses

Additional outcomes: Fugl-Meyer Assessment, Motor Assessment Scale, muscular tone of the quadriceps, hamstrings, adductors and triceps surae

Notes

In the Engardt 1993 publication weight-bearing symmetry was "computed as the ratio between the time integrals of the vertical forces of the paretic and non-paretic leg, where 1.0 equals symmetrical body-weight distribution". However, in the Engardt 1994 publication for a follow-up study weight-bearing is reported as percentage body weight on affected side (for immediately post-training as well as at 33 months post-training). These data are used within analyses. Time to STS is also reported in the follow-up study. Data reported in the follow-up study come from only those participants who were included at the 33-month follow-up

\section{FLASSH 2012}

\begin{tabular}{ll}
\hline Methods & Multicentre RCT \\
\hline Participants & Australia \\
\hline
\end{tabular}


FLASSH 2012 (Continued)

Intervention in patients' homes

156 participants; 85 control, 71 intervention

Inclusion criteria: "aged 45 years or more, had been discharged home after rehabilitation, and were at high risk of falls. A person was determined to have high falls risk if he/she either had fallen during hospital admission or had a Step Test worse leg score of less than 7, or a Berg Balance Scale score of less than 49, because these variables have been shown to predict multiple falls in the first 6 months after discharge from stroke rehabilitation."

Exclusion criteria: "Those discharged to residential care facilities or with homes more than 100 kilometres from study sites were ineligible."

Interventions

Intervention group: usual care + falls prevention programme. Usual care was provided by treating health professionals: "Typically, following discharge from rehabilitation, this included referral for ongoing therapy (physiotherapy and occupational therapy) and follow-up by their general medical practitioner". A multifactorial, individually tailored falls prevention programme was provided by a physiotherapist. This consisted of the following: (1) individualised home exercise programme prescribed by a physiotherapist and based on the Otago Exercise Programme, (2) falls risk minimisation strategies based on general and stroke-specific risk factors identified in the baseline assessment, (3) education (written and verbal) for participant and carer about identified falls risk factors and risk minimisation, (4) injury risk minimisation strategies

The Otago Exercise Programme comprised a 30 to 40-minute home exercise session, 3 to 5 times weekly. Exercises were selected from: (1) warm-up exercises: head/neck movements, back extension, trunk movements, ankle movements, (2) strength and balance exercises: knee extension/flexion, hip abduction, heel raise/toe raise, knee bends, backward walk, walk and turn, sideways walk, heel-toe stand, heel-toe walk, one-leg stand, heel walking/toe walking, heel-toe backward walk, STS, stair walking

Control group: "Participants in the control group received usual care with their treating health professionals, and research staff made no attempt to limit their access to any care. In addition, we provided control participants with the falls prevention booklet as above."

Mean age control group: 72.2 (9.9) years

Mean time since stroke onset control group: 3.1 (1.9) months

Mean age intervention group: 70.8 (11.4) years

Mean time since stroke onset intervention group: 3.0 (1.6) months

Outcomes Falls rates, proportion of fallers, injurious falls

Leg strength - STS test

Gait speed

Balance (Step Test)

Human Activity Profile

Functional Independence Measure

Fear of falling

Falls risk

Notes

The intervention programme was specifically targeted at the reduction of falls in participants at high risk of falling. The exercise component of the multifactorial falls prevention programme may include practice of STS; however the intervention was individually tailored, and not all participants will have completed practice of STS. We planned to explore the effect of including this study in a sensitivity analysis. 
FLASSH 2012 (Continued)

Risk of bias

\begin{tabular}{lll}
\hline Bias & Authors' judgement & Support for judgement \\
\hline $\begin{array}{l}\text { Random sequence genera- } \\
\text { tion (selection bias) }\end{array}$ & Low risk & $\begin{array}{l}\text { "Computer-generated random allocation sequence concealed from all re- } \\
\text { searchers in opaque envelopes." }\end{array}$ \\
\hline $\begin{array}{l}\text { Allocation concealment } \\
\text { (selection bias) }\end{array}$ & Low risk & "Staff independent of the study undertook sequence and concealment." \\
\hline $\begin{array}{l}\text { Blinding of outcome as- } \\
\text { sessment (detection bias) }\end{array}$ & Low risk & "The physiotherapists conducting baseline and the follow-up assessment \\
$\begin{array}{l}\text { All outcomes } \\
\text { Incomplete outcome data } \\
\text { (attrition bias) }\end{array}$ & Low risk & $\begin{array}{l}\text { "144 (92\%) had at least } 1 \text { month of fall data available for analysis. Twelve addi- } \\
\text { All outcomes }\end{array}$ \\
\hline
\end{tabular}

Hu 2013

\begin{tabular}{|c|c|}
\hline Methods & Repeated-measures design; cross-over with random assignment to condition \\
\hline \multirow[t]{6}{*}{ Participants } & Taiwan \\
\hline & 9 participants \\
\hline & $\begin{array}{l}\text { Inclusion criteria: people with stroke who had: (1) ability to perform STS transfer under supervision } \\
\text { without assistive device and without orthosis, (2) ambulation with an assistive device (such as hold- } \\
\text { ing the parallel bars, quad cane or regular cane) in the rehabilitation ward or at home, and (3) ability to } \\
\text { maintain an independent stance for at least } 60 \text { seconds }\end{array}$ \\
\hline & $\begin{array}{l}\text { Exclusion criteria: (1) having other neurologic or orthopedic conditions that would interfere with STS } \\
\text { transfer and stance, (2) inability to understand and follow instructions }\end{array}$ \\
\hline & Mean age participants: 61.1 (12.83) years \\
\hline & Mean time since stroke onset: 7.35 (11.86) months \\
\hline \multirow[t]{3}{*}{ Interventions } & Intervention 1: STS without use of a cane, by placing their arms along the side of the body \\
\hline & Intervention 2: STS with a cane, by putting the non-paretic or dominant hand on the regular cane \\
\hline & All participants completed 3 trials in each condition \\
\hline \multirow[t]{4}{*}{ Outcomes } & STS time \\
\hline & Joint moment \\
\hline & Symmetry index \\
\hline & EMG activity \\
\hline Notes & Data are presented for whole group only; first-phase data only not available \\
\hline
\end{tabular}

\section{Risk of bias}


Hu 2013 (Continued)

Random sequence genera- Unclear risk No details provided
tion (selection bias)

Allocation concealment $\quad$ Unclear risk $\quad$ No details provided
(selection bias)

\begin{tabular}{lll}
\hline Blinding of outcome as- & High risk & Blinding of assessor not possible, due to repeated nature of study design \\
sessment (detection bias)
\end{tabular}

All outcomes

Incomplete outcome data Low risk

No long-term treatment, therefore no drop-outs

(attrition bias)

All outcomes

Malouin 2009

\begin{tabular}{ll}
\hline Methods & RCT \\
\hline Participants & Canada \\
Rehabilitation centre \\
12 participants: 4 control, 3 intervention (1), 5 intervention (2) \\
Inclusion criteria: between age 30 and 80 years, first stroke, more than 3 months since stroke onset, \\
residual limb loading asymmetry, able to STS without using hands, able to understand and follow in- \\
structions, ability to engage in motor imagery \\
Exclusion criteria: lesions in the cerebellum or midbrain, conditions causing pain in the lower limbs, \\
presence of knee or ankle contracture, joint replacement, severe aphasia or perceptual problems, cog- \\
nitive impairment or other neurological condition
\end{tabular}

Mean age control: $61.8(9.5)$ years

Mean time since stroke onset control: 2.4 (2.0) years

Mean age intervention (1): $61.0(8.5)$ years

Mean time since stroke onset intervention (1): 3.5 (2.9) years

Mean age intervention (2): $61.3(7.2)$ years

Mean time since stroke onset intervention: 2.4 (1.8) years

Interventions

Intervention group 1: repetitive STS practice + cognitive practice. Repetitive practice of STS was performed with focus on loading of the affected limb and constraints were used such as seat height to increase task difficulty. Cognitive practice consisted of mental activities unrelated to the STS task. Sessions held 3 times a week for 4 weeks

Intervention group 2: repetitive STS practice + mental practice. Repetitive practice of STS was performed with focus on loading of the affected limb and constraints were used such as seat height to increase task difficulty. Mental practice consisted of mental repetitions of the STS task for 1 hour each session. Sessions held 3 times a week for 4 weeks

Control group: no physical or cognitive practice

Outcomes

Outcomes assessed at baseline, post-training and 3 weeks following the end of training

Outcome measures: vertical ground reaction force of the affected limb from seat-off to the end of the task, Timed Up and Go (only measured at baseline) 
Malouin 2009 (Continued)

Vertical ground reaction force was presented graphically for individual patients in each of the 3 treatment groups. Graphs were measured, and means and standard deviations calculated from these measured figures. The measurements were checked by an independent review author

\begin{tabular}{ll}
\hline Notes & 3 groups were included in this study \\
RCT with unequal group allocation
\end{tabular}

\section{Risk of bias}

\begin{tabular}{lll}
\hline Bias & Authors' judgement & Support for judgement \\
\hline $\begin{array}{l}\text { Random sequence genera- } \\
\text { tion (selection bias) }\end{array}$ & Low risk & Participants were randomly assigned using a random numbers table \\
\hline $\begin{array}{l}\text { Allocation concealment } \\
\text { (selection bias) }\end{array}$ & Unclear risk & Not indicated \\
\hline $\begin{array}{l}\text { Blinding of outcome as- } \\
\text { sessment (detection bias) } \\
\text { All outcomes }\end{array}$ & Low risk & "The analyses were carried out by a research assistant unaware of the group \\
\hline $\begin{array}{l}\text { Incomplete outcome data } \\
\text { (attrition bias) } \\
\text { All outcomes }\end{array}$ & Low risk & assignment." \\
\hline
\end{tabular}

Malouin 2009a

\begin{tabular}{ll}
\hline Methods See Malouin 2009 \\
\hline Participants
\end{tabular}

Participants See Malouin 2009

Malouin 2009a refers to only the comparison between 1 intervention group (STS plus cognitive practice) and control, i.e. from 7 participants: 4 control, 3 intervention

Mean age control: $61.8(9.5)$ years

Mean time since stroke onset control: 2.4 (2.0) years

Mean age intervention: $61.0(8.5)$ years

Mean time since stroke onset intervention: 3.5 (2.9) years

Interventions Intervention group: repetitive STS practice + cognitive practice. Repetitive practice of STS was performed with focus on loading of the affected limb and constraints were used such as seat height to increase task difficulty. Cognitive practice consisted of mental activities unrelated to the STS task. Sessions held 3 times a week for 4 weeks

Control group: no physical or cognitive practice

\begin{tabular}{ll}
\hline Outcomes & See Malouin 2009 \\
\hline Notes & $\begin{array}{l}\text { To prevent 'double-counting' within analyses of Malouin 2009a and Malouin 2009b, only half the num- } \\
\text { ber of control group participants are assigned to each study; i.e. control group } n=2\end{array}$ \\
\hline
\end{tabular}

\section{Risk of bias}


Malouin 2009a (Continued)

\begin{tabular}{lll} 
Bias & Authors' judgement & Support for judgement \\
\hline $\begin{array}{l}\text { Random sequence genera- } \\
\text { tion (selection bias) }\end{array}$ & Low risk & Participants were randomly assigned using a random numbers table \\
\hline $\begin{array}{l}\text { Allocation concealment } \\
\text { (selection bias) }\end{array}$ & Unclear risk & Not indicated \\
\hline $\begin{array}{l}\text { Blinding of outcome as- } \\
\text { sessment (detection bias) } \\
\text { All outcomes }\end{array}$ & Low risk & $\begin{array}{l}\text { "The analyses were carried out by a research assistant unaware of the group } \\
\text { assignment." }\end{array}$ \\
\hline $\begin{array}{l}\text { Incomplete outcome data } \\
\text { (attrition bias) }\end{array}$ & Low risk & None reported \\
All outcomes & &
\end{tabular}

Malouin 2009b

\begin{tabular}{|c|c|}
\hline Methods & See Malouin 2009 \\
\hline \multirow[t]{6}{*}{ Participants } & See Malouin 2009 \\
\hline & $\begin{array}{l}\text { Malouin } 2009 \mathrm{~b} \text { refers to only the comparison between } 1 \text { intervention group (STS plus mental practice) } \\
\text { and control, i.e. from } 9 \text { participants: } 4 \text { control, } 5 \text { intervention }\end{array}$ \\
\hline & Mean age control: $61.8(9.5)$ years \\
\hline & Mean time since stroke onset control: 2.4 (2.0) years \\
\hline & Mean age intervention: $61.3(7.2)$ years \\
\hline & Mean time since stroke onset intervention: 2.4 (1.8) years \\
\hline \multirow[t]{2}{*}{ Interventions } & $\begin{array}{l}\text { Intervention group: repetitive STS practice + mental practice. Repetitive practice of STS was performed } \\
\text { with focus on loading of the affected limb and constraints were used such as seat height to increase } \\
\text { task difficulty. Mental practice consisted of mental repetitions of the STS task for } 1 \text { hour each session. } \\
\text { Sessions held } 3 \text { times a week for } 4 \text { weeks }\end{array}$ \\
\hline & Control group: no physical or cognitive practice \\
\hline
\end{tabular}

\begin{tabular}{ll}
\hline Outcomes & See Malouin 2009 \\
\hline Notes & $\begin{array}{l}\text { To prevent 'double-counting' within analyses of Malouin 2009a and Malouin 2009b, only half the num- } \\
\text { ber of control group participants are assigned to each study; i.e. control group } \mathrm{n}=2\end{array}$ \\
\hline
\end{tabular}

\section{Risk of bias}

\begin{tabular}{lll}
\hline Bias & Authors' judgement & Support for judgement \\
\hline $\begin{array}{l}\text { Random sequence genera- } \\
\text { tion (selection bias) }\end{array}$ & Low risk & Participants were randomly assigned using a random numbers table \\
\hline $\begin{array}{l}\text { Allocation concealment } \\
\text { (selection bias) }\end{array}$ & Unclear risk & Not indicated \\
\hline $\begin{array}{l}\text { Blinding of outcome as- } \\
\text { sessment (detection bias) }\end{array}$ & Low risk & $\begin{array}{l}\text { "The analyses were carried out by a research assistant unaware of the group } \\
\text { assignment." }\end{array}$ \\
\hline
\end{tabular}


Malouin 2009b (Continued)

All outcomes

Incomplete outcome data Low risk None reported
(attrition bias)

All outcomes

Mead 2007

Methods Randomised exploratory trial. ("Aims were to determine the feasibility of key parts of the trial and to assess the effect of exercise training on important outcomes")

UK
Rehabilicipants
66 participants: 34 control, 32 intervention
Inclusion criteria: independently ambulatory, living in central or South Edinb
phasia or confusion and no medical contraindications to exercise training
Exclusion criteria: none reported
Mean age control: 71.7 (9.6) years
Mean time since stroke onset control: 147.5 days (range 78.8 to 235.5 days)
Mean age intervention: 72 (10.4) years
Mean time since stroke onset intervention: 171 days (range 55 to 287 days)

Interventions

Intervention group: exercise training including endurance and resistance exercises. Training sessions included the following: 15 to 20-minute warm-up, cycle ergometry, raising and lowering an exercise ball, shuttle walking, standing chest press, stair climbing and descending, upper back strengthening, triceps extension, pole lifting exercise, repetitive STS practice resisted by body mass, progressing from 4 to 10 repetitions. Training sessions were held 3 times a week for 12 weeks

Control group: relaxation exercises focused on attention control. Exercises were performed in sitting and included deep breathing and muscle relaxation techniques with no muscle contraction. Training sessions were held 3 times a week for 12 weeks

Outcomes Outcomes were measured at baseline, at the end of the 12 -week training period and at 7 months after baseline testing

Outcome measures included: duration of STS, the Rivermead Mobility Index and the Functional independence measure

Additional outcomes: Nottingham Extended ADLs, functional reach, Medical Outcomes Study 36-item short from questionnaire, Hospital Anxiety and Depression scores, bilateral leg extensor power, walking speed, walking economy, Timed Up and Go

Notes

Data are presented as adjusted means and confidence intervals within published paper. Authors supplied individual patient data for relevant time point (end of training) for outcomes of STS time, Rivermead Mobility Index and the Functional Independence Measure and means and standard deviations were computed using Excel. Functional Independence Measure was used as measure of functional ability

\section{Risk of bias}


Mead 2007 (Continued)

$\begin{array}{ll}\text { Random sequence genera- } \quad \text { Low risk } & \text { "Randomisation was by the trial coordinator or principal investigator (not by } \\ \text { tion (selection bias) } & \text { the outcome assessors) via a secure Internet randomisation service." }\end{array}$

$\begin{array}{ll}\begin{array}{l}\text { Allocation concealment } \\ \text { (selection bias) }\end{array} & \begin{array}{l}\text { "Patients were blinded to the underlying hypothesis by reiterating the possible } \\ \text { benefits of both interventions." }\end{array}\end{array}$

\begin{tabular}{|c|c|c|}
\hline $\begin{array}{l}\text { Blinding of outcome as- } \\
\text { sessment (detection bias) } \\
\text { All outcomes }\end{array}$ & Low risk & $\begin{array}{l}\text { "Outcome assessors were blinded by asking patients not to discuss their allo- } \\
\text { cated intervention." }\end{array}$ \\
\hline
\end{tabular}

\begin{tabular}{|c|c|c|}
\hline $\begin{array}{l}\text { Incomplete outcome data } \\
\text { (attrition bias) }\end{array}$ & Low risk & $\begin{array}{l}\text { Few missing data - less than } 3 \% \text { of data were missing for the Functional Inde- } \\
\text { pendence Measure and 5\% for STS time }\end{array}$ \\
\hline
\end{tabular}

Tung 2010

\begin{tabular}{|c|c|}
\hline Methods & $\mathrm{RCT}$ \\
\hline \multirow[t]{9}{*}{ Participants } & Taiwan \\
\hline & Rehabilitation medical centre \\
\hline & 32 participants: 16 control, 16 intervention \\
\hline & $\begin{array}{l}\text { Inclusion criteria: first cerebrovascular accident with unilateral motor deficits, Berg balance score of } \\
\text { less than } 50 \text {, ability to independently stand up from sitting, medically stable, ability to understand and } \\
\text { follow instructions }\end{array}$ \\
\hline & $\begin{array}{l}\text { Exclusion criteria: medical condition preventing participation, deep sensory deficits, presence of hem- } \\
\text { ineglect }\end{array}$ \\
\hline & Mean age control group: 52.7 (14.1) years \\
\hline & Mean time since stroke onset control group: 12.8 (12.3) months \\
\hline & Mean age intervention group: 51 (12.1) years \\
\hline & Mean time since stroke onset intervention group: 26.9 (16) months \\
\hline
\end{tabular}

Interventions Intervention group: 30 minutes general physiotherapy +15 minutes of STS training. General physiotherapy consisted of balance training, gait training, strengthening exercises for the lower extremities and activities of daily living training. STS training consisted of repetitive practice of the STS task with variation in knee angle (75 to 105 degrees of flexion) and floor surface (hard or spongy floor surface). Study duration was 4 weeks, with 3 sessions per week of 45 minutes each

Control group: 30 minutes of general physiotherapy as described above. Study duration was 4 weeks, with 3 sessions per week of 30 minutes each

Outcomes Outcomes measured at baseline and within 3 days of finishing the 4-week training period

Outcome measures: duration of STS

Additional outcomes: standing balance (weight distribution in standing), dynamic balance (limits of stability test), Berg Balance Scale, lower extremity extensor strength 
Tung 2010 (Continued)

\section{Bias Authors' judgement Support for judgement}

Random sequence genera- Low risk tion (selection bias)

Single-blind randomised controlled study. "The block randomisation (with block size of 4) was used to assign subjects to either experimental or control group by an independent person who selected a sealed envelope 30 minutes before beginning the intervention. The sealed envelopes contained the group of the patient and they were filled at random."

\begin{tabular}{|c|c|c|}
\hline $\begin{array}{l}\text { Allocation concealment } \\
\text { (selection bias) }\end{array}$ & Low risk & Only blinded to post-training outcome assessor \\
\hline $\begin{array}{l}\text { Blinding of outcome as- } \\
\text { sessment (detection bias) } \\
\text { All outcomes }\end{array}$ & Low risk & Post-training outcome assessor blinded to group allocation \\
\hline $\begin{array}{l}\text { Incomplete outcome data } \\
\text { (attrition bias) } \\
\text { All outcomes }\end{array}$ & Low risk & No drop-outs reported \\
\hline
\end{tabular}

ADLs: activities of daily living

EMG: electromyographic

CMSA: Chedoke McMaster Stroke Assessment

$\mathrm{RCT}$ : randomised controlled trial

STS: sit-to-stand

Characteristics of excluded studies [ordered by study ID]

\begin{tabular}{|c|c|}
\hline Study & Reason for exclusion \\
\hline Allison 2007 & Intervention and outcomes did not meet criteria of this review \\
\hline Anderson 1996 & Single participant design \\
\hline Bjerlemo 2002 & Not a RCT \\
\hline Boyne 2011 & Not a RCT \\
\hline Briere 2010 & Not a RCT \\
\hline Brunt 2002 & Not a RCT \\
\hline Burns 1999 & Not a RCT \\
\hline Chen 2010 & Not a RCT \\
\hline Dean 1997 & Study not aimed at improving STS \\
\hline Duclos 2008 & Not a RCT \\
\hline Engardt 1995 & Not a RCT \\
\hline Flynn 2007 & $\begin{array}{l}\text { Communication with the author confirmed that this study did not include participants with } \\
\text { stroke }\end{array}$ \\
\hline Fowler 1996 & Not a RCT \\
\hline
\end{tabular}




\begin{tabular}{|c|c|}
\hline Study & Reason for exclusion \\
\hline Fujikura 2012 & Not a RCT \\
\hline Giuliani 1993 & Not a RCT \\
\hline Goldman 2011 & Not a RCT \\
\hline Helbostad 2004 & Study was not specific to people with stroke \\
\hline Hesse 1998 & Not a RCT \\
\hline Janssen 2010 & Not a RCT \\
\hline Kluding 2004 & Not a RCT \\
\hline Kluding 2005 & Intervention was not STS \\
\hline Li 2005 & Outcomes did not meet criteria of this review \\
\hline Malouin 2004 & Not a RCT \\
\hline McClellan 2004 & Outcomes did not meet criteria of this review \\
\hline Mercer 2001 & Not a RCT \\
\hline Monger 2002 & Single participant design \\
\hline Noh 2008 & Intervention did not meet criteria of this review \\
\hline Oh 2010 & Not a RCT \\
\hline Rocha 2010 & Not a RCT \\
\hline Roy 2006 & Not a RCT \\
\hline Shepherd 1996 & Not a RCT \\
\hline Sherrington 2008 & $\begin{array}{l}\text { Participants: older adults. } 52 \% \text { of included participants had neurological deficits: but not } \\
\text { stated if these were stroke or other deficits }\end{array}$ \\
\hline
\end{tabular}

RCT: randomised controlled trial

STS: sit-to-stand

Characteristics of studies awaiting assessment [ordered by study ID]

Atchison 1995

\begin{tabular}{ll}
\hline Methods & RCT \\
\hline Participants & USA \\
& 27 participants: 15 control, 12 intervention \\
\hline Interventions & Intervention group: 3 sets of 16 to 20 repetitions of a prescribed quadriceps exercise \\
& Study duration was 18 exercise sessions over 6 weeks (3 sessions per week)
\end{tabular}


Atchison 1995 (Continued)

Control group: not indicated

Outcomes Outcomes measured at baseline and the 6-week training period

Outcome measures: Timed Up and Go

Notes

Results were not significant but they found a trend for the exercise group to have a greater increase in speed

It remains unclear if the aim of the study was to improve STS performance

Camargos 2009

\begin{tabular}{|c|c|}
\hline Methods & Cross-sectional, cross-over design \\
\hline \multirow[t]{6}{*}{ Participants } & Brazil \\
\hline & 12 participants: all intervention \\
\hline & $\begin{array}{l}\text { Inclusion criteria: only } 1 \text { episode of stroke, over } 60 \text { years of age, weakness or spasticity on the af- } \\
\text { fected side, able to rise from sitting without using hands, no evidence of receptive aphasia }\end{array}$ \\
\hline & $\begin{array}{l}\text { Exclusion criteria: evidence of musculoskeletal injury, neurological disease other than stroke or } \\
\text { any auditory or visual deficits that would prevent data collection }\end{array}$ \\
\hline & Mean age: 68 (7.14) years \\
\hline & Mean time since stroke onset: 7.67 (3.99) years \\
\hline Interventions & $\begin{array}{l}\text { Intervention: } 4 \text { foot positions tested: (1) spontaneous position (no instructions given to participant } \\
\text { regarding foot placement), (2) symmetric position (both ankles were positioned at the same level } \\
\text { with an ankle dorsiflexion angle between } 10 \text { and } 15 \text { degrees), (3) asymmetric } 1 \text { (affected leg placed } \\
\text { half a foot length behind the unaffected leg), (4) asymmetric } 2 \text { (unaffected leg placed half a foot } \\
\text { length behind the affected leg). The spontaneous position was always tested first followed by ran- } \\
\text { dom presentation of the remaining positions }\end{array}$ \\
\hline Outcomes & Outcome measures: duration of STS, weight-bearing symmetry \\
\hline \multirow[t]{2}{*}{ Notes } & $\begin{array}{l}\text { Results were significant for an increased time to complete the STS task with the } 2 \text { asymmetrical } \\
\text { foot conditions compared with the spontaneous foot position, time to complete the task with the } \\
\text { symmetric foot position was not different from the spontaneous foot position. Results were not sig- } \\
\text { nificant for weight-bearing symmetry }\end{array}$ \\
\hline & $\begin{array}{l}\text { This study used a randomised cross-over design; results from the first step of the cross-over design } \\
\text { are needed for inclusion in the review }\end{array}$ \\
\hline
\end{tabular}

Chumbler 2011

\begin{tabular}{ll}
\hline Methods & Prospective, randomised trial \\
\hline Participants & 48 participants: 23 control, 25 intervention \\
& Inclusion criteria: stroke within preceding 24 months \\
& Exclusion criteria: not reported \\
& Mean age of all participants: 67.6 years
\end{tabular}


Chumbler 2011 (Continued)

Interventions

Intervention group received telerehabilitation

Telerehabilitation included 3 one-hour videotaped visits, 5 telephone calls and communication via an in-home messaging telehealth device over 3 months instructing participants in functionally based neurorehabilitation exercises and adaptive strategies. Neurorehabilitation exercises included chair raises, sitting balance and standing balance. Adaptive strategies included tub and shower transfers

Control group received usual care

Usual care consisted of routine rehabilitation with no attempts by the study personnel to influence the self care activities or physical functioning

Outcomes Outcomes measured at baseline and following 3 months of treatment

Outcome measures: Functional Independence Measure

Notes

A secondary aim of this study was to determine the effect of telerehabilitation on disability; it remains unclear if this aim included changes to STS performance

Dean 2006

\begin{tabular}{ll}
\hline Methods & RCT \\
\hline Participants & Stroke \\
\hline Interventions & $\begin{array}{l}\text { Weekly exercise class (45 minutes for } 40 \text { weeks })+ \text { home exercise programme }(30 \text { minutes, } 5 \text { days } \\
\text { per week) for } 12 \text { months versus weekly upper limb + cognitive exercise class + home upper limb }+ \\
\text { cognition exercise }\end{array}$ \\
\hline Outcomes & Falls prevention, mobility and physical activity \\
\hline Notes & Unclear if intervention includes STS. Full report required \\
\hline
\end{tabular}

\section{FFF 2010}

\begin{tabular}{ll}
\hline Methods & RCT \\
\hline Participants & Stroke \\
\hline Interventions & $\begin{array}{l}\text { 12-week community-based wellness programme (Fit For Function) of exercise (2 hours per week) } \\
\text { and self management education sessions versus control in community-based stroke patients }\end{array}$ \\
\hline Outcomes & Mobility, balance, strength, community reintegration \\
\hline Notes & Unclear whether intervention includes STS. Full report required \\
\hline
\end{tabular}

Finestone 2012

Methods RCT


Finestone 2012 (Continued)

Participants Stroke inpatients

\begin{tabular}{ll}
\hline Interventions & Virtual reality (VR) exercise therapy while standing versus VR exercises while sitting (10 to 12 ses- \\
sions of 20 to 30 minutes) in stroke patients undergoing inpatient rehabilitation
\end{tabular}

Outcomes Berg Balance Scale, Functional Independence Measure, Chedoke McMaster Stroke Assessment, Timed Up and Go, 2 minute walk test, centre of pressure, Ottawa Sitting Scale

Notes Not clear if this intervention involves STS

Fraser 2012

\begin{tabular}{ll}
\hline Methods & RCT \\
\hline Participants & Inpatient stroke \\
\hline Interventions & Aerobic fitness training \\
\hline Outcomes & Physical activity \\
\hline Notes & Unclear if intervention included STS. Full report required \\
\hline
\end{tabular}

\section{Guttman 2011}

\begin{tabular}{|c|c|}
\hline Methods & Cross-over intervention \\
\hline \multirow[t]{5}{*}{ Participants } & Israel \\
\hline & 13 participants \\
\hline & Inclusion criteria: chronic stroke \\
\hline & Exclusion criteria: not reported \\
\hline & Mean age of all participants: 68.9 (4.9) years \\
\hline \multirow[t]{4}{*}{ Interventions } & 2 interventions were included \\
\hline & Intervention 1: mental practice of STS \\
\hline & Intervention 2: mental practice of reach and grasp \\
\hline & Both groups practised for 4 weeks and then 'crossed over' to practise the second intervention \\
\hline \multirow[t]{2}{*}{ Outcomes } & $\begin{array}{l}\text { Outcomes measures were assessed during } 1 \text { week of baseline testing and then twice before and } \\
\text { twice following each practice session }\end{array}$ \\
\hline & Outcome measures: duration of STS, weight-bearing symmetry \\
\hline Notes & $\begin{array}{l}\text { Results were significant for global STS duration and not significant for weight distribution. It re- } \\
\text { mains unclear if participants were randomly allocated into the } 2 \text { groups. In addition, results from } \\
\text { the first step of the cross-over design are needed for inclusion in the review }\end{array}$ \\
\hline
\end{tabular}


Guttman 2012

\begin{tabular}{ll}
\hline Methods & Cross-over (unclear if randomised) \\
\hline Participants & Chronic stroke \\
\hline Interventions & Motor imagery of STS, cross-over motor imagery of reaching \\
\hline Outcomes & Speed of STS and weight distribution \\
\hline Notes & $\begin{array}{l}\text { July } 2013 \text { - tried to contact author for the } 2011 \text { abstract (with no response) to determine if partici- } \\
\text { pants were randomly allocated to type of mental imagery practice at start of study }\end{array}$ \\
\hline
\end{tabular}

Hirano 2010

\begin{tabular}{ll}
\hline Methods & RCT \\
\hline Participants & Stroke patients admitted to convalescent rehabilitation ward \\
\hline Interventions & Self directed physiotherapy training with family participation (family training) versus control \\
\hline Outcomes & Unclear \\
\hline Notes & Not clear if intervention included STS, or if outcomes are relevant. Full report required
\end{tabular}

\section{Kerr 2012}

\begin{tabular}{ll}
\hline Methods & RCT \\
\hline Participants & Stroke \\
\hline Interventions & Conventional physical therapy or conventional physical therapy + functional strength training \\
\hline Outcomes & Weight-bearing symmetry \\
\hline Notes & $\begin{array}{l}\text { Communication with study author confirmed that the trial is complete and did include STS. How- } \\
\text { ever, analysis of STS data is ongoing. Inclusion of this study will be assessed when data analysis is } \\
\text { complete and a report of this is available }\end{array}$ \\
\hline
\end{tabular}

Korner-Bitensky 2013

\begin{tabular}{ll}
\hline Methods & RCT \\
\hline Participants & Stroke (mild) \\
\hline Interventions & $\begin{array}{l}\text { Home-based falls prevention programme (LIFE - Lifestyle Intervention using Functional Exercise) } \\
\text { while performing common daily activities versus structured balance and lower limb strengthening } \\
\text { exercises versus gentle exercises in patients at high risk of falls }\end{array}$ \\
\hline Outcomes & Falls \\
\hline Notes & Not clear if intervention included STS. Full report required \\
\hline
\end{tabular}


Lecours 2008

\begin{tabular}{|c|c|}
\hline Methods & Cross-sectional, cross-over design \\
\hline \multirow[t]{5}{*}{ Participants } & 17 participants \\
\hline & $\begin{array}{l}\text { Inclusion criteria: more than } 6 \text { months post-stroke, able to stand up and sit down independently } \\
\text { without using arms and hands, able to tolerate } 2 \text { hours of testing with appropriate rest periods, } \\
\text { residual muscular weakness and motor impairment of the affected lower limb resulting in a score } \\
\text { of less than } 6 \text { on the Chedoke McMaster Stroke Assessment }\end{array}$ \\
\hline & $\begin{array}{l}\text { Exclusion criteria: cognitive impairment, cerebellar involvement, any musculoskeletal disorder of } \\
\text { neurological disorder other than stroke }\end{array}$ \\
\hline & Mean age: $49.7(11.3)$ years \\
\hline & Mean time since stroke onset: $3.2(2.3)$ years \\
\hline Interventions & $\begin{array}{l}\text { Intervention: } 3 \text { foot positions were tested: (1) spontaneous position (no instructions provided to } \\
\text { participant regarding foot placement), (2) symmetrical position (both ankles were placed in } 15 \text { de- } \\
\text { grees of ankle dorsiflexion), ( } 3 \text { ) asymmetrical position (the affected ankle was placed in } 15 \text { degrees } \\
\text { of ankle dorsiflexion and half a foot length behind the unaffected ankle). The spontaneous position } \\
\text { was always tested first followed by random presentation of the remaining positions }\end{array}$ \\
\hline Outcomes & Outcome measures: weight-bearing symmetry \\
\hline Notes & $\begin{array}{l}\text { Results were significant for weight-bearing symmetry with the asymmetrical foot position com- } \\
\text { pared with the spontaneous and symmetrical foot positions. This study performed a randomised } \\
\text { cross-over design; results from the first step of the cross-over design are needed for inclusion in the } \\
\text { review }\end{array}$ \\
\hline
\end{tabular}

\section{Moore 2012}

\begin{tabular}{ll}
\hline Methods & RCT \\
\hline Participants & Ambulant chronic stroke patients \\
\hline Interventions & Community exercise intervention (3 x 1-hour sessions for 19 weeks) versus control (stretching) \\
\hline Outcomes & Physiological and physical function \\
\hline Notes & Unclear if intervention includes STS. Full report required \\
\hline
\end{tabular}

Rodrigues-De-Paula 2010

\begin{tabular}{ll}
\hline Methods & Not reported \\
\hline Participants & 12 participants \\
& Age range was 65 to 75 years \\
\hline Interventions & $\begin{array}{l}\text { Participants performed STS using } 3 \text { different verbal instructions including (1) stand up as fast as } \\
\text { you can, (2) stand up as fast as you can with your body weight distributed on both legs, (3) stand up } \\
\text { as fast as you can with your body weight distributed on the weakest leg }\end{array}$ \\
\hline
\end{tabular}


Rodrigues-De-Paula 2010 (Continued)

Outcomes Outcome measures: duration of STS and weight-bearing symmetry

Notes $\quad$ Results were significant for duration of STS, performing the task with instruction 3 resulted in the greatest movement time compared with instructions 1 and 2 . Results were not significant for weight-bearing symmetry. It remains unclear if the sequence of verbal instructions was randomised with each participant

\section{Rose 2009}

\begin{tabular}{ll}
\hline Methods & Not reported \\
\hline Participants & 180 participants: 108 control, 72 intervention \\
& Inclusion criteria: not reported \\
& Exclusion criteria: not reported
\end{tabular}

Interventions

Intervention group received circuit training physical therapy that emphasised repetition and progression. Circuit training physical therapy consisted of 1.5 hours of treatment, the content of treatment included transfers, bed mobility, sitting and standing balance, STS and gait practice. Circuit training physical therapy consisted of $4 \times 15$-minute functional task stations that focused on progression with increasing the number of repetitions or task difficulty. The remaining 30 minutes of treatment time was allotted to family training and equipment assessment

Control group received standard physical therapy. Standard physical therapy consisted of 1.5 hours of treatment, the content of treatment included transfers, bed mobility, sitting/standing balance, STS and gait practice. Standard physical therapy was delivered according to the treatment plan developed by the therapist

Outcomes $\begin{aligned} & \text { Outcomere measured at admission and discharge } \\ & \text { Outcome measures included the Functional Independence Measure }\end{aligned}$

Notes

Results were not significant for the Functional Independence Measure. It remains unclear if participants were randomly allocated to each group

\section{Zhong 2006}

\begin{tabular}{ll}
\hline Methods & RCT \\
\hline Participants & Stroke \\
\hline Interventions & Rehabilitation (nursing - includes STS training) \\
\hline Outcomes & Unclear \\
\hline Notes & Further information required \\
\hline
\end{tabular}

\section{Zhu 2006}

Methods

RCT 
Zhu 2006 (Continued)

\begin{tabular}{ll} 
Participants & Acute stroke patient \\
\hline Interventions & Early rehabilitative nursing care including Bobath and Rood training versus control \\
\hline Outcomes & Activities of daily living \\
\hline Notes & Appears to include STS. Further details required \\
\hline
\end{tabular}

RCT: randomised controlled trial

STS: sit to stand

Characteristics of ongoing studies [ordered by study ID]

\section{ACTIV 2012}

Trial name or title

Telerehabilitation to improve outcomes for people with stroke: The ACTIV trial

RCT, with blinded outcome assessor

Methods RCT, with blinded outcome assessor

Participants

Stroke: "Have had a first ever stroke of haemorrhagic or ischaemic origin. Are over the age of 20 years, have been discharged from their District Health Board, inpatient, outpatient and community physiotherapy services to live in their own home (participants involved in other forms of therapy such as OT, Tai Chi or community exercise programs will not be excluded). Have medical clearance from their GP to participate in a low to moderate level activity programme. Score at least 3 on a telephone cognitive screening questionnaire (Callahan et al 2002). Have a limitation in physical function of leg, arm or both and have had their stroke less than 18 months ago"

Target sample size: 96

Interventions

"A six month intervention comprising four face to face physiotherapy sessions (consisting of exercises working towards a specific goal), five telephone calls and 1-2 text messages per week, to encourage continuation of the prescribed exercise plan. Each physiotherapy intervention will be approximately 45 minutes in duration and will occur at baseline, after 2 weeks, 12 weeks and 24 weeks. The phone calls will be approximately 20 minutes in duration and will occur at 1 week, 4 weeks, 8 weeks, 16 weeks and 20 weeks. The treating physiotherapist makes the phone calls and discusses whether the exercises have been managed and how the participant is working towards their goal. They discuss any barriers to exercise completion and make suggestions to modify the programme if problems are occurring. The exercises will consist of simple functional exercises such as sit to stand, walking and balance, which directly pertain to achieving the desired goal. The therapist and participant between them will agree on when the exercises will be done, including how many, what level of difficulty and any safety concerns. The participant will then do the exercises in their own home."

Outcomes Physical function (physical subcomponent of Stroke Impact Scale)

Dynamic balance

Grip strength

Changes in health outcomes

Admission rates

Cost-effectiveness

Experience and satisfaction 
ACTIV 2012 (Continued)

Contact information

Denise Taylor (PI), AUT University 90 Akoranga Dr Northcote Auckland 1142 OR Private Bag 92006

Auckland

Email: detaylor@aut.ac.nz

\section{Notes}

$-$

RCT: randomised controlled trial

\section{DATA AND ANALYSES}

\section{Comparison 1. Any intervention versus control (immediate outcomes)}

\begin{tabular}{|c|c|c|c|c|}
\hline Outcome or subgroup title & $\begin{array}{l}\text { No. of } \\
\text { studies }\end{array}$ & $\begin{array}{l}\text { No. of } \\
\text { partici- } \\
\text { pants }\end{array}$ & Statistical method & Effect size \\
\hline 1 Ability to sit-to-stand independently & 1 & 48 & Odds Ratio (M-H, Random, 95\% Cl) & $4.86[1.43,16.50]$ \\
\hline 2 Time & 7 & 335 & $\begin{array}{l}\text { Std. Mean Difference (IV, Random, } \\
95 \% \mathrm{CI})\end{array}$ & $-0.34[-0.62,-0.06]$ \\
\hline 2.1 Time taken to sit-to-stand & 4 & 164 & $\begin{array}{l}\text { Std. Mean Difference (IV, Random, } \\
95 \% \mathrm{CI})\end{array}$ & $-0.49[-0.80,-0.18]$ \\
\hline 2.2 Time taken to sit-to-walk (up and go) & 2 & 39 & $\begin{array}{l}\text { Std. Mean Difference (IV, Random, } \\
95 \% \mathrm{CI} \text { ) }\end{array}$ & $-0.61[-1.25,0.04]$ \\
\hline $\begin{array}{l}\text { 2.3 Number of sit-to-stands in specified } \\
\text { time }\end{array}$ & 1 & 132 & $\begin{array}{l}\text { Std. Mean Difference (IV, Random, } \\
95 \% \mathrm{CI})\end{array}$ & $0.05[-0.29,0.40]$ \\
\hline 3 Lateral symmetry & 6 & 105 & $\begin{array}{l}\text { Std. Mean Difference (IV, Random, } \\
95 \% \mathrm{CI})\end{array}$ & $0.85[0.38,1.33]$ \\
\hline $\begin{array}{l}3.1 \text { Weight distribution (\% on affected } \\
\text { side) }\end{array}$ & 5 & 51 & $\begin{array}{l}\text { Std. Mean Difference (IV, Random, } \\
95 \% \mathrm{Cl})\end{array}$ & $1.19[0.55,1.84]$ \\
\hline 3.2 Centre of pressure & 1 & 54 & $\begin{array}{l}\text { Std. Mean Difference (IV, Random, } \\
95 \% \mathrm{CI})\end{array}$ & $0.52[-0.03,1.06]$ \\
\hline 4 Peak vertical ground reaction force & 1 & 54 & $\begin{array}{l}\text { Std. Mean Difference (IV, Random, } \\
95 \% \mathrm{CI})\end{array}$ & $-0.02[-0.55,0.52]$ \\
\hline 5 Falls (number of participants falling) & 5 & 319 & Odds Ratio (M-H, Fixed, 95\% Cl) & $0.75[0.46,1.22]$ \\
\hline 6 Functional ability & 2 & 196 & $\begin{array}{l}\text { Std. Mean Difference (IV, Random, } \\
95 \% \mathrm{CI})\end{array}$ & $-0.24[-0.52,0.04]$ \\
\hline
\end{tabular}


Analysis 1.1. Comparison 1 Any intervention versus control (immediate outcomes), Outcome 1 Ability to sit-to-stand independently.

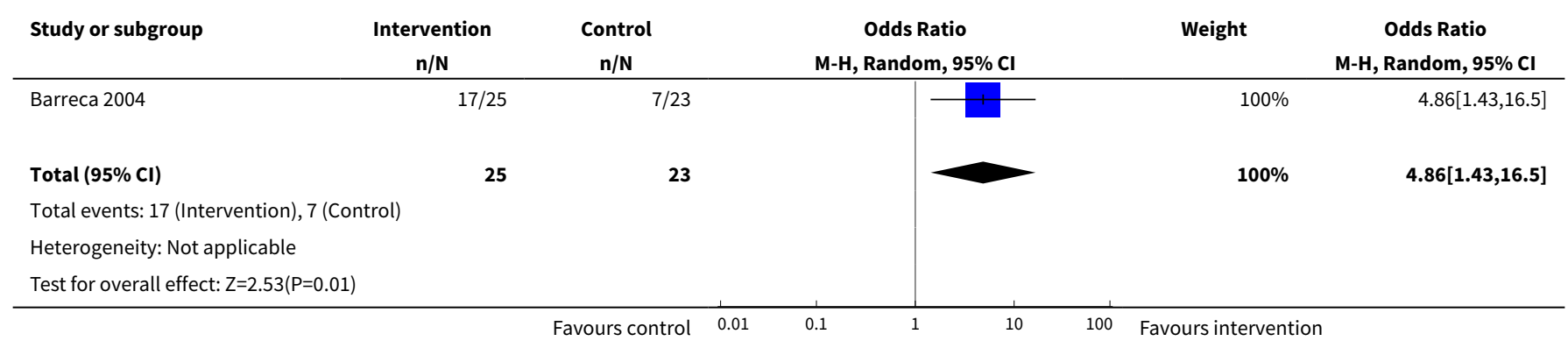

Analysis 1.2. Comparison 1 Any intervention versus control (immediate outcomes), Outcome 2 Time.

\begin{tabular}{|c|c|c|c|c|c|c|c|}
\hline \multirow[t]{2}{*}{ Study or subgroup } & \multicolumn{2}{|c|}{ Intervention } & \multicolumn{2}{|c|}{ Control } & \multirow{2}{*}{$\begin{array}{c}\text { Std. Mean Difference } \\
\text { Random, } 95 \% \mathrm{Cl}\end{array}$} & \multirow[t]{2}{*}{ Weight } & \multirow{2}{*}{$\begin{array}{c}\text { Std. Mean Difference } \\
\text { Random, } 95 \% \mathrm{Cl} \\
\end{array}$} \\
\hline & $\mathbf{N}$ & Mean(SD) & $\mathbf{N}$ & Mean(SD) & & & \\
\hline \multicolumn{8}{|c|}{ 1.2.1 Time taken to sit-to-stand } \\
\hline Britton 2008 & 9 & $1.2(0.3)$ & 9 & $1.3(0.4)$ & $\longrightarrow$ & $7.74 \%$ & $-0.27[-1.2,0.66]$ \\
\hline Cheng 2001 & 30 & $2.7(1.1)$ & 24 & $3.9(1.8)$ & 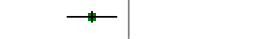 & $16.84 \%$ & $-0.81[-1.37,-0.25]$ \\
\hline Mead 2007 & 29 & $1.1(0.6)$ & 31 & $1.4(1.1)$ & $\rightarrow$ & $18.98 \%$ & $-0.36[-0.87,0.15]$ \\
\hline Tung 2010 & 16 & $2.1(0.7)$ & 16 & $2.5(1.4)$ & $\longrightarrow$ & $12.26 \%$ & $-0.35[-1.05,0.35]$ \\
\hline Subtotal $\star \star \star$ & 84 & & 80 & & & $55.82 \%$ & $-0.49[-0.8,-0.18]$ \\
\hline \multicolumn{8}{|c|}{ Heterogeneity: $\operatorname{Tau}^{2}=0 ; \mathrm{Chi}^{2}=1.92, \mathrm{df}=3(\mathrm{P}=0.59) ; \mathrm{I}^{2}=0 \%$} \\
\hline \multicolumn{8}{|c|}{ Test for overall effect: $Z=3.06(P=0)$} \\
\hline \multicolumn{8}{|c|}{ 1.2.2 Time taken to sit-to-walk (up and go) } \\
\hline Blennerhassett 2004 & 15 & $11.5(3.8)$ & 15 & $19.1(14.4)$ & 千 & $11.21 \%$ & $-0.7[-1.44,0.04]$ \\
\hline Dean 2000 & 5 & $19.5(14.1)$ & 4 & $26.1(25.4)$ & & $4.11 \%$ & $-0.3[-1.62,1.03]$ \\
\hline \multicolumn{8}{|c|}{ Heterogeneity: $\mathrm{Tau}^{2}=0 ; \mathrm{Chi}^{2}=0.27, \mathrm{df}=1(\mathrm{P}=0.6) ; \mathrm{I}^{2}=0 \%$} \\
\hline \multicolumn{8}{|c|}{ Test for overall effect: $Z=1.84(P=0.07)$} \\
\hline \multicolumn{8}{|c|}{ 1.2.3 Number of sit-to-stands in specified time } \\
\hline FLASSH 2012 & 57 & $-7.6(3.7)$ & 75 & $-7.8(3.7)$ & & $28.85 \%$ & $0.05[-0.29,0.4]$ \\
\hline Subtotal $\star \star \star ~$ & 57 & & 75 & & & $28.85 \%$ & $0.05[-0.29,0.4]$ \\
\hline \multicolumn{8}{|c|}{ Heterogeneity: Not applicable } \\
\hline \multicolumn{8}{|c|}{ Test for overall effect: $Z=0.31(P=0.76)$} \\
\hline Total $\star \star \star$ & 161 & & 174 & & $>$ & $100 \%$ & $-0.34[-0.62,-0.06]$ \\
\hline \multicolumn{8}{|c|}{ Heterogeneity: $\mathrm{Tau}^{2}=0.04 ; \mathrm{Chi}^{2}=8.48, \mathrm{df}=6(\mathrm{P}=0.2) ; \mathrm{I}^{2}=29.27 \%$} \\
\hline \multicolumn{8}{|c|}{ Test for overall effect: $\mathrm{Z}=2.4(\mathrm{P}=0.02)$} \\
\hline \multicolumn{8}{|c|}{ Test for subgroup differences: $\mathrm{Chi}^{2}=6.29, \mathrm{df}=1(\mathrm{P}=0.04), \mathrm{I}^{2}=68.19 \%$} \\
\hline
\end{tabular}


Analysis 1.3. Comparison 1 Any intervention versus control (immediate outcomes), Outcome 3 Lateral symmetry.

\begin{tabular}{|c|c|c|c|c|c|c|c|}
\hline \multirow[t]{2}{*}{ Study or subgroup } & \multicolumn{2}{|c|}{ Intervention } & \multicolumn{2}{|c|}{ Control } & \multirow{2}{*}{$\begin{array}{c}\text { Std. Mean Difference } \\
\text { Random, } 95 \% \mathrm{Cl}\end{array}$} & \multirow[t]{2}{*}{ Weight } & \multirow{2}{*}{$\begin{array}{c}\text { Std. Mean Difference } \\
\text { Random, } 95 \% \mathrm{Cl}\end{array}$} \\
\hline & $\mathbf{N}$ & Mean(SD) & $\mathbf{N}$ & Mean(SD) & & & \\
\hline \multicolumn{8}{|c|}{ 1.3.1 Weight distribution ( $\%$ on affected side) } \\
\hline Britton 2008 & 9 & $42.5(6.9)$ & 9 & $33.4(8.4)$ & $\div$ & $19.29 \%$ & $1.13[0.11,2.14]$ \\
\hline Dean 2000 & 5 & $62.2(7.8)$ & 4 & $46.6(9.6)$ & & $7.98 \%$ & $1.61[-0.04,3.26]$ \\
\hline Dean 2007 & 6 & $61(7)$ & 6 & $45(7)$ & & $9.16 \%$ & $2.11[0.58,3.64]$ \\
\hline Malouin 2009a & 3 & $43.7(3.4)$ & 2 & $39.6(7.4)$ & & $5.77 \%$ & $0.58[-1.37,2.53]$ \\
\hline 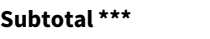 & 28 & & 23 & & & $50.08 \%$ & $1.19[0.55,1.84]$ \\
\hline \multicolumn{8}{|c|}{ Heterogeneity: $\mathrm{Tau}^{2}=0 ; \mathrm{Chi}^{2}=3.12, \mathrm{df}=4(\mathrm{P}=0.54) ; \mathrm{I}^{2}=0 \%$} \\
\hline \multicolumn{8}{|c|}{ Test for overall effect: $Z=3.62(P=0)$} \\
\hline \multicolumn{8}{|c|}{ 1.3.2 Centre of pressure } \\
\hline Cheng 2001 & 30 & $-7.8(4.2)$ & 24 & $-10(4.2)$ & + & $49.92 \%$ & $0.52[-0.03,1.06]$ \\
\hline \multicolumn{8}{|c|}{ Heterogeneity: Not applicable } \\
\hline \multicolumn{8}{|c|}{ Test for overall effect: $Z=1.85(P=0.06)$} \\
\hline 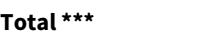 & 58 & & 47 & & & $100 \%$ & $0.85[0.38,1.33]$ \\
\hline \multicolumn{8}{|c|}{ Heterogeneity: $\mathrm{Tau}^{2}=0.04 ; \mathrm{Chi}^{2}=5.57, \mathrm{df}=5(\mathrm{P}=0.35) ; \mathrm{I}^{2}=10.21 \%$} \\
\hline \multicolumn{8}{|c|}{ Test for overall effect: $Z=3.5(P=0)$} \\
\hline Test for subgroup dif & $5, \mathrm{df}=$ & $P=0.12), I^{2}=5 \mathrm{C}$ & & & & & \\
\hline
\end{tabular}

Analysis 1.4. Comparison 1 Any intervention versus control (immediate outcomes), Outcome 4 Peak vertical ground reaction force.

\begin{tabular}{|c|c|c|c|c|c|c|c|}
\hline \multirow[t]{2}{*}{ Study or subgroup } & \multicolumn{2}{|c|}{ Intervention } & \multicolumn{2}{|c|}{ Control } & \multirow{2}{*}{$\begin{array}{c}\text { Std. Mean Difference } \\
\text { Random, } 95 \% \mathrm{Cl}\end{array}$} & \multirow[t]{2}{*}{ Weight } & \multirow{2}{*}{$\begin{array}{c}\text { Std. Mean Difference } \\
\text { Random, } 95 \% \mathrm{Cl}\end{array}$} \\
\hline & $\mathbf{N}$ & Mean(SD) & $\mathbf{N}$ & Mean(SD) & & & \\
\hline Cheng 2001 & 30 & $107.4(6.2)$ & 24 & $107.5(5)$ & & $100 \%$ & $-0.02[-0.55,0.52]$ \\
\hline Total $\star \star \star ~$ & 30 & & 24 & & & $100 \%$ & $-0.02[-0.55,0.52]$ \\
\hline \multicolumn{8}{|c|}{ Heterogeneity: Not applicable } \\
\hline Test for overall effect & & & & & & & \\
\hline
\end{tabular}

Analysis 1.5. Comparison 1 Any intervention versus control (immediate outcomes), Outcome 5 Falls (number of participants falling).

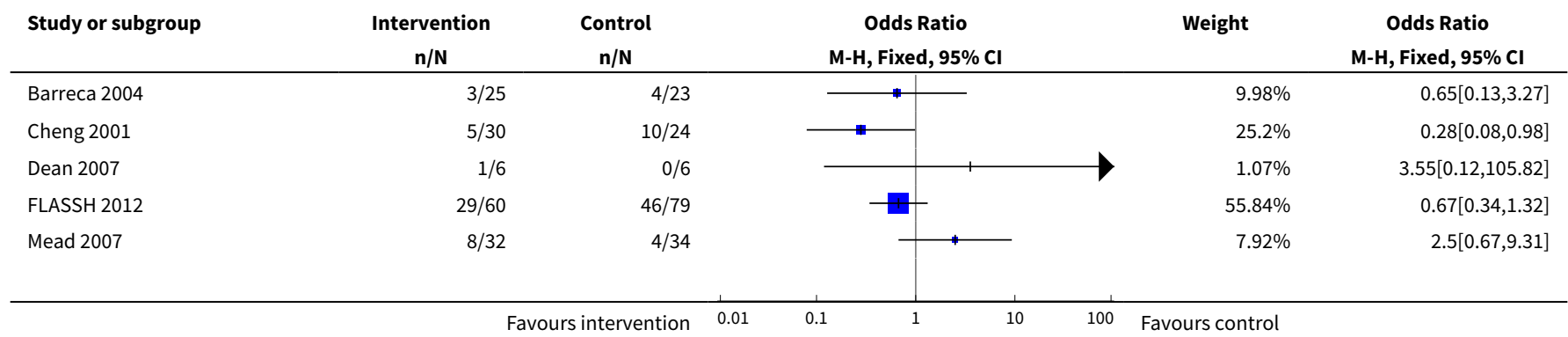




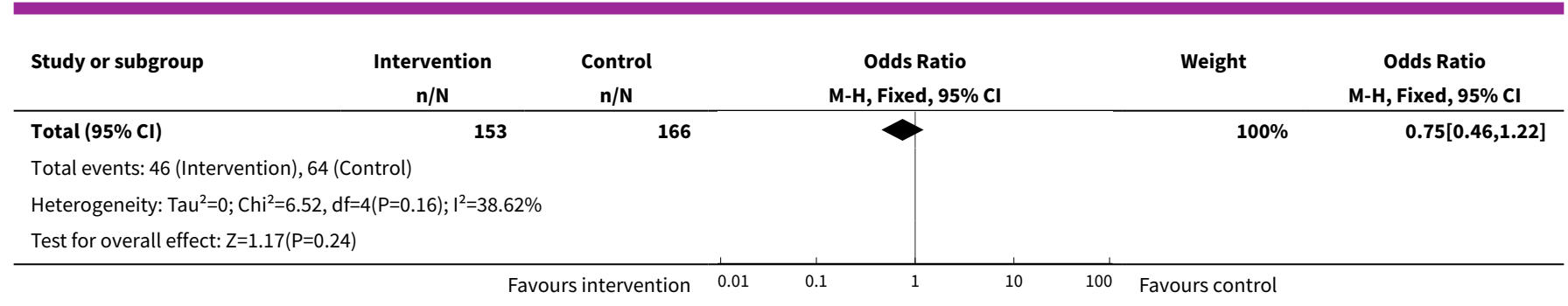

Analysis 1.6. Comparison 1 Any intervention versus control (immediate outcomes), Outcome 6 Functional ability.

\begin{tabular}{|c|c|c|c|c|c|c|c|}
\hline \multirow[t]{2}{*}{ Study or subgroup } & \multicolumn{2}{|c|}{ Intervention } & \multicolumn{2}{|c|}{ Control } & \multirow{2}{*}{$\begin{array}{c}\text { Std. Mean Difference } \\
\text { Random, } 95 \% \mathrm{Cl}\end{array}$} & \multirow[t]{2}{*}{ Weight } & \multirow{2}{*}{$\begin{array}{c}\text { Std. Mean Difference } \\
\text { Random, } 95 \% \mathrm{Cl}\end{array}$} \\
\hline & $\mathbf{N}$ & Mean(SD) & $\mathbf{N}$ & $\operatorname{Mean}(S D)$ & & & \\
\hline FLASSH 2012 & 57 & $114(3.4)$ & 75 & $115(3.4)$ & + & $66.76 \%$ & $-0.3[-0.64,0.05]$ \\
\hline Mead 2007 & 31 & $116.9(7.4)$ & 33 & $117.7(4.9)$ & $\rightarrow$ & $33.24 \%$ & $-0.13[-0.62,0.36]$ \\
\hline 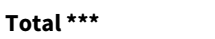 & 88 & & 108 & & & $100 \%$ & $-0.24[-0.52,0.04]$ \\
\hline \multicolumn{8}{|c|}{ Heterogeneity: Tau $^{2}=0 ; \mathrm{Chi}^{2}=0.3, \mathrm{df}=1(\mathrm{P}=0.58) ; \mathrm{I}^{2}=0 \%$} \\
\hline
\end{tabular}

Comparison 2. Any intervention versus control (follow-up outcomes)

\begin{tabular}{lllll}
\hline Outcome or subgroup title & $\begin{array}{l}\text { No. of } \\
\text { studies }\end{array}$ & $\begin{array}{l}\text { No. of } \\
\text { partici- } \\
\text { pants }\end{array}$ & Statistical method & Effect size \\
\hline 1 Time & 4 & 149 & $\begin{array}{l}\text { Std. Mean Difference (IV, Random, } \\
95 \% \text { CI) }\end{array}$ & $-0.45[-0.78,-0.12]$ \\
\hline 1.1 Follow-up after less than 6 months & 1 & 8 & $\begin{array}{l}\text { Std. Mean Difference (IV, Random, } \\
95 \% \text { Cl) }\end{array}$ & $-0.15[-1.54,1.24]$ \\
\hline 1.2 Follow-up after 6 months or more & 3 & 141 & $\begin{array}{l}\text { Std. Mean Difference (IV, Random, } \\
95 \% \text { Cl) }\end{array}$ & $-0.48[-0.88,-0.08]$ \\
\hline 2 Lateral symmetry & & & $\begin{array}{l}\text { Std. Mean Difference (IV, Random, } \\
95 \% \text { Cl) }\end{array}$ & 0.59 [0.11, 1.07] \\
\hline 2.1 Follow-up after less than 6 months & 2 & 12 & $\begin{array}{l}\text { Std. Mean Difference (IV, Random, } \\
95 \% \text { CI) }\end{array}$ & $0.35[-0.96,1.65]$ \\
\hline 2.2 Follow-up after 6 months or more & 2 & 63 & $\begin{array}{l}\text { Std. Mean Difference (IV, Random, } \\
95 \% \text { CI) }\end{array}$ & $0.79[-0.16,1.74]$ \\
\hline
\end{tabular}


Analysis 2.1. Comparison 2 Any intervention versus control (follow-up outcomes), Outcome 1 Time.

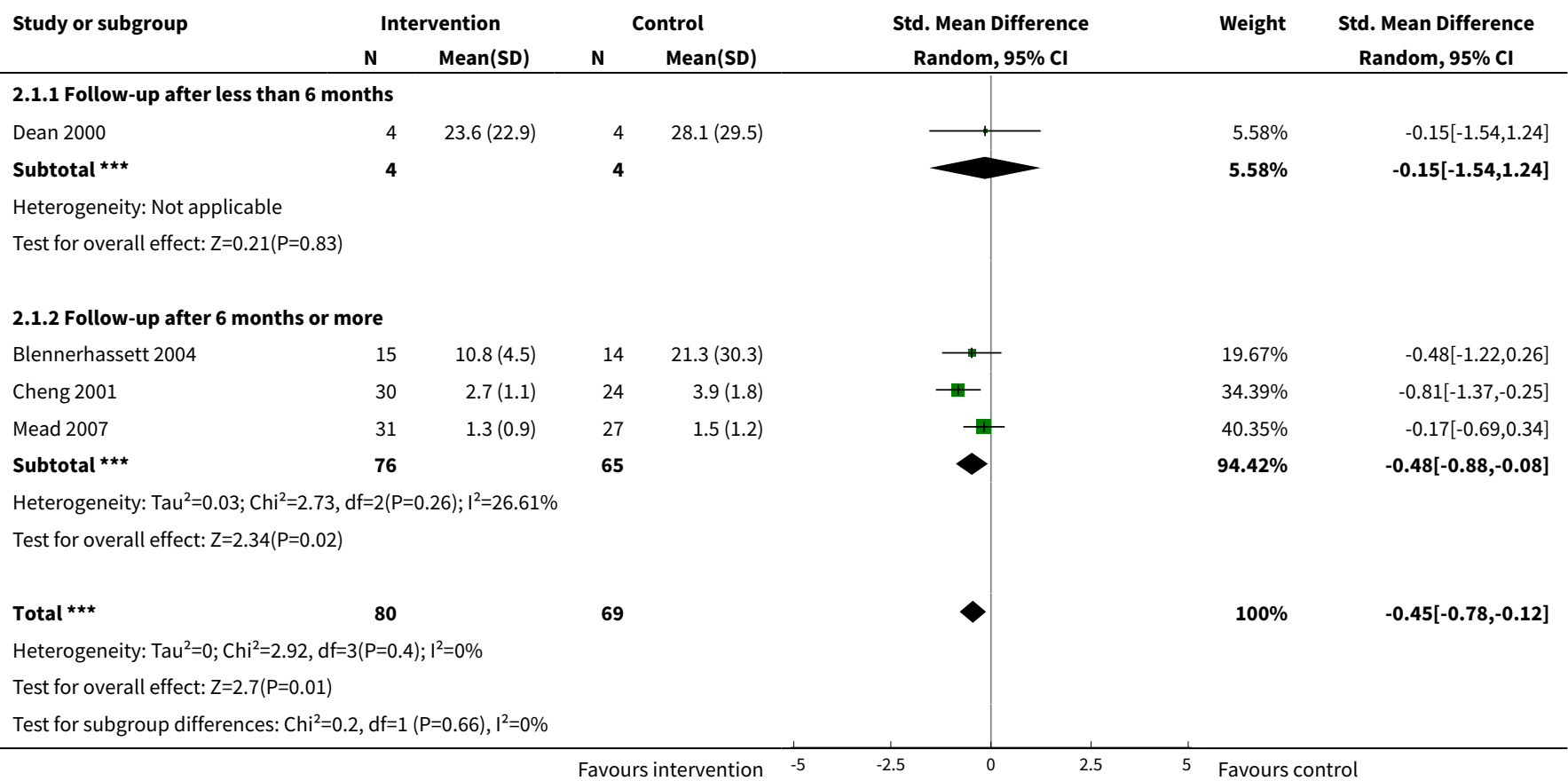

\section{Analysis 2.2. Comparison 2 Any intervention versus control (follow-up outcomes), Outcome 2 Lateral symmetry.}

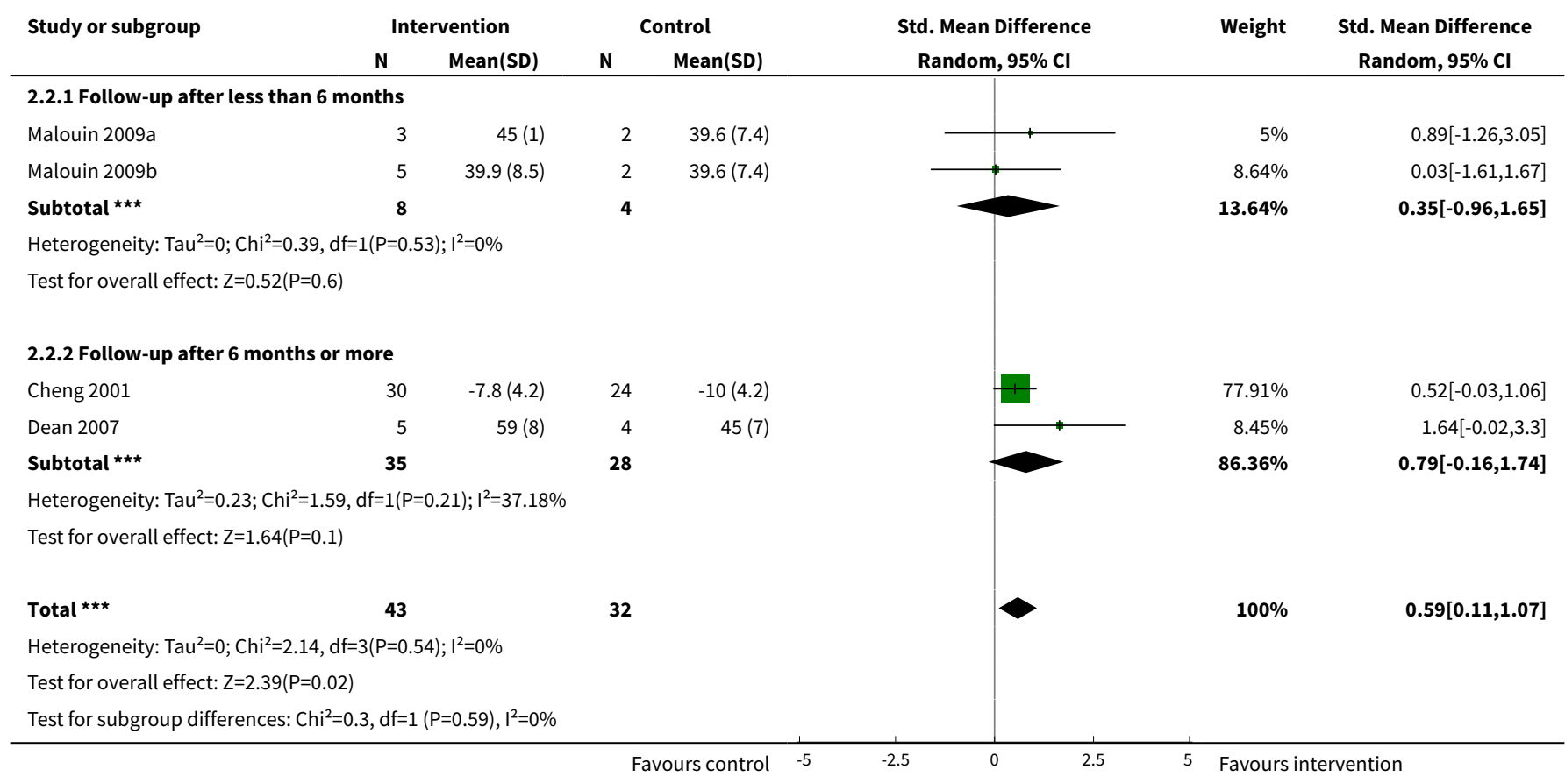


Comparison 3. Subgroup analysis: type of intervention

\begin{tabular}{llllll}
\hline Outcome or subgroup title & $\begin{array}{l}\text { No. of } \\
\text { studies }\end{array}$ & $\begin{array}{l}\text { No. of } \\
\text { partici- } \\
\text { pants }\end{array}$ & Statistical method & Effect size \\
\hline 1 Time & 7 & 335 & Std. Mean Difference (IV, Random, 95\% Cl) & $-0.34[-0.62,-0.06]$ \\
\hline 1.1 Repetitive sit-to-stand & 3 & 104 & Std. Mean Difference (IV, Random, 95\% Cl) & $-0.57[-0.96,-0.17]$ \\
\hline 1.2 Exercise programme & 4 & 231 & Std. Mean Difference (IV, Random, 95\% Cl) & $-0.22[-0.56,0.12]$ \\
\hline 2 Lateral symmetry & 6 & 105 & Std. Mean Difference (IV, Random, 95\% Cl) & $0.85[0.38,1.33]$ \\
\hline 2.1 Repetitive sit-to-stand & 4 & 84 & Std. Mean Difference (IV, Random, 95\% CI) & $0.62[0.18,1.07]$ \\
\hline 2.2 Exercise programme & 1 & 9 & Std. Mean Difference (IV, Random, 95\% Cl) & $1.61[-0.04,3.26]$ \\
\hline 2.3 Sitting training & 1 & 12 & Std. Mean Difference (IV, Random, 95\% Cl) & $2.11[0.58,3.64]$ \\
\hline
\end{tabular}

Analysis 3.1. Comparison 3 Subgroup analysis: type of intervention, Outcome 1 Time.

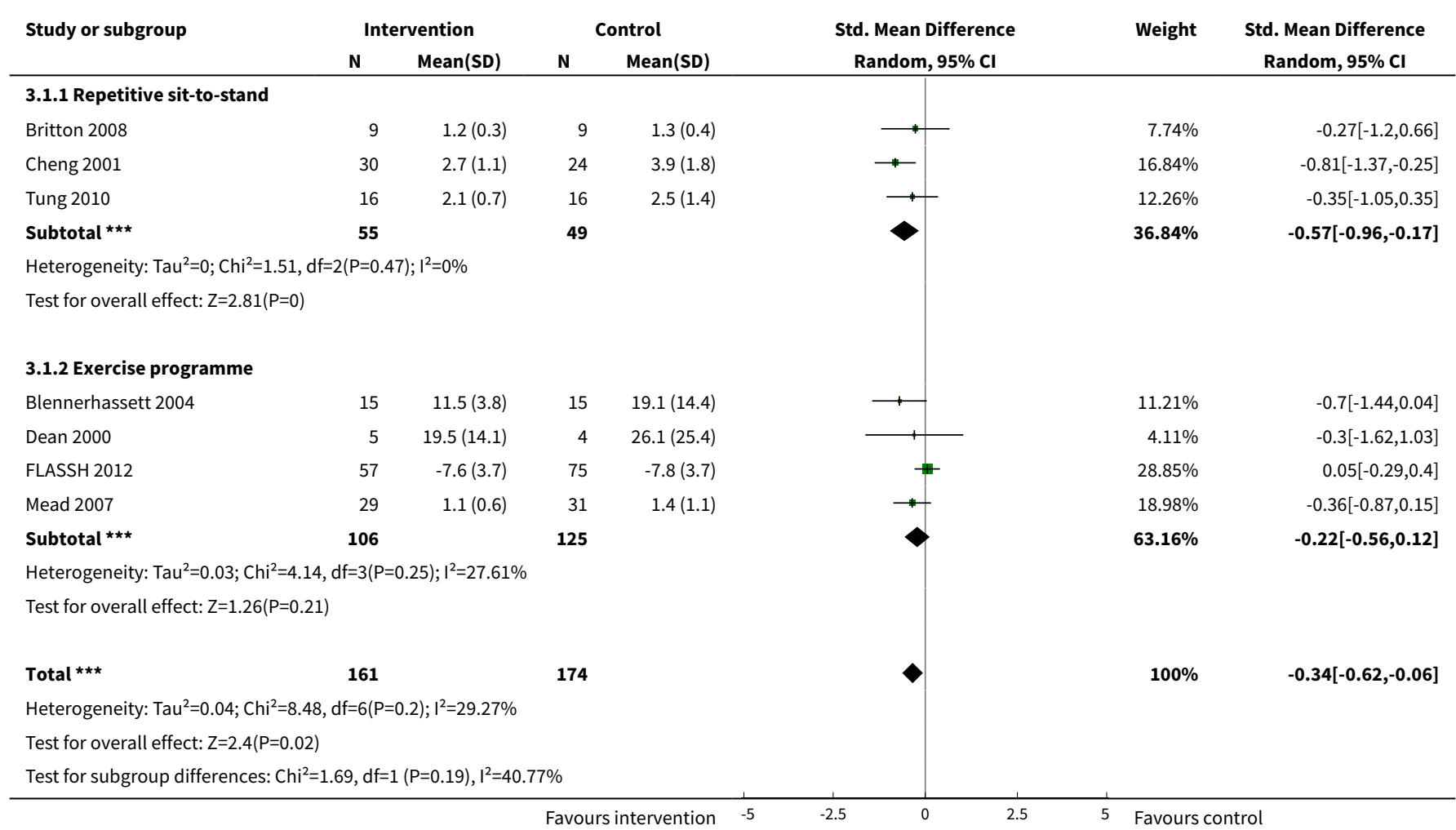


Analysis 3.2. Comparison 3 Subgroup analysis: type of intervention, Outcome 2 Lateral symmetry.

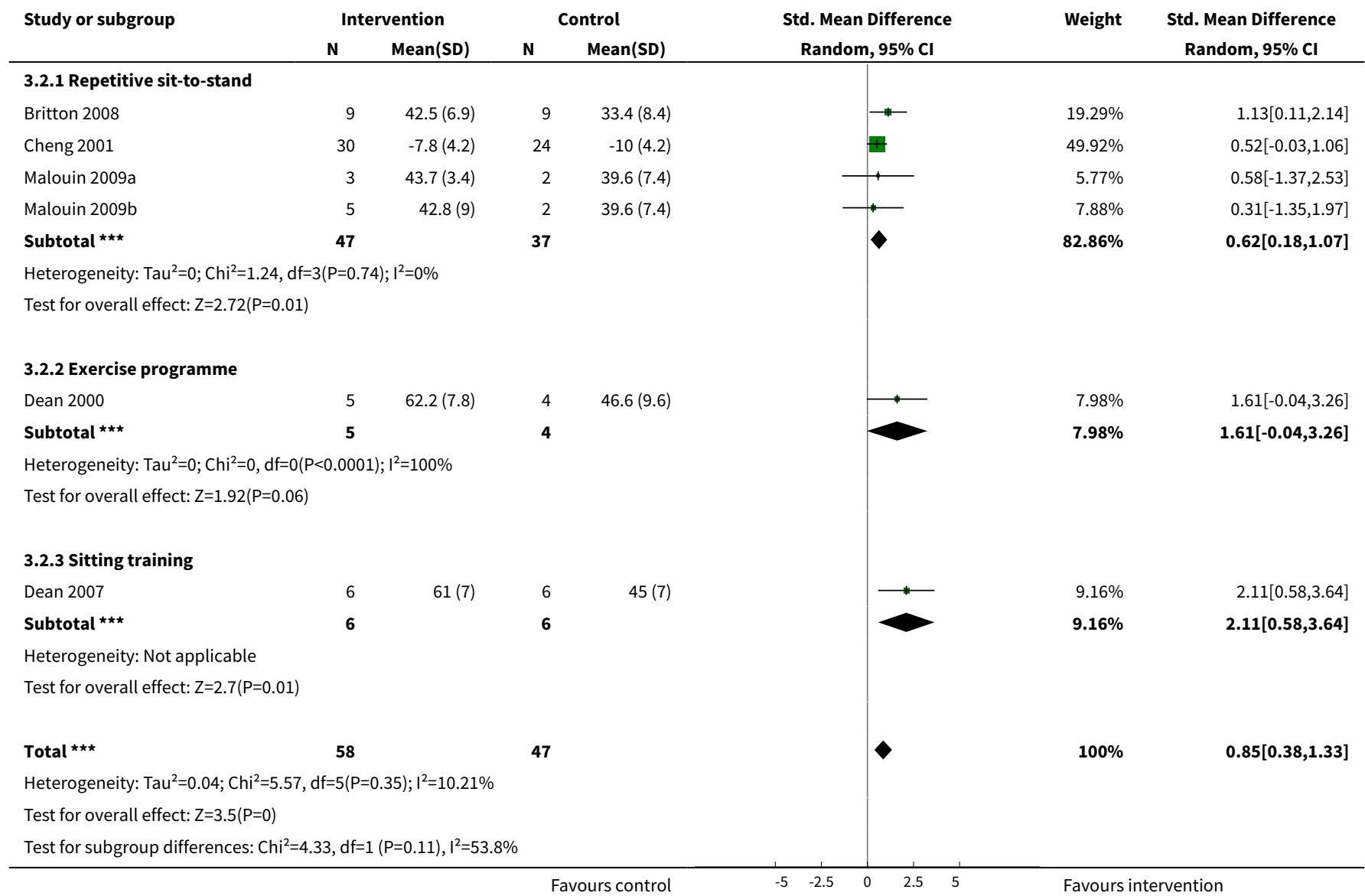

\section{Comparison 4. Subgroup analysis: duration and intensity of intervention}

\begin{tabular}{llllll}
\hline Outcome or subgroup title & $\begin{array}{l}\text { No. of } \\
\text { studies }\end{array}$ & $\begin{array}{l}\text { No. of } \\
\text { partici- } \\
\text { pants }\end{array}$ & Statistical method & Effect size \\
\hline 1 Weeks of intervention: Time & 6 & 203 & Std. Mean Difference (IV, Random, 95\% Cl) & $-0.51[-0.79,-0.23]$ \\
\hline 1.12 to 3 weeks & 2 & 72 & Std. Mean Difference (IV, Random, 95\% Cl) & $-0.67[-1.15,-0.19]$ \\
\hline 1.24 weeks & 3 & 71 & Std. Mean Difference (IV, Random, 95\% Cl) & $-0.49[-0.96,-0.01]$ \\
\hline 1.312 weeks & 1 & 60 & Std. Mean Difference (IV, Random, 95\% Cl) & $-0.36[-0.87,0.15]$ \\
\hline 2 Sessions per week: Time & 6 & 203 & Std. Mean Difference (IV, Random, 95\% Cl) & $-0.51[-0.79,-0.23]$ \\
\hline 2.13 sessions per week & 3 & 101 & Std. Mean Difference (IV, Random, 95\% Cl) & $-0.35[-0.74,0.04]$ \\
\hline 2.25 sessions per week & 3 & 102 & Std. Mean Difference (IV, Random, 95\% Cl) & $-0.68[-1.08,-0.28]$ \\
\hline $\begin{array}{l}3 \text { Weeks of intervention: Lateral } \\
\text { symmetry }\end{array}$ & 6 & 105 & Std. Mean Difference (IV, Random, 95\% Cl) & $0.85[0.38,1.33]$ \\
\hline
\end{tabular}




\begin{tabular}{lllll}
\hline Outcome or subgroup title & $\begin{array}{l}\text { No. of } \\
\text { studies }\end{array}$ & $\begin{array}{l}\text { No. of } \\
\text { partici- } \\
\text { pants }\end{array}$ & Statistical method & Effect size \\
\hline 3.12 to 3 weeks & 3 & 84 & Std. Mean Difference (IV, Random, 95\% Cl) & $1.02[0.21,1.83]$ \\
\hline 3.24 weeks & 3 & 21 & Std. Mean Difference (IV, Random, 95\% Cl) & $0.86[-0.14,1.86]$ \\
\hline $\begin{array}{l}\text { 4 Sessions per week: Lateral } \\
\text { symmetry }\end{array}$ & 6 & 105 & Std. Mean Difference (IV, Random, 95\% Cl) & $0.85[0.38,1.33]$ \\
\hline 4.13 sessions per week & 3 & 21 & Std. Mean Difference (IV, Random, 95\% Cl) & $0.86[-0.14,1.86]$ \\
\hline 4.25 sessions per week & 3 & 84 & Std. Mean Difference (IV, Random, 95\% Cl) & $1.02[0.21,1.83]$ \\
\hline
\end{tabular}

Analysis 4.1. Comparison 4 Subgroup analysis: duration and intensity of intervention, Outcome 1 Weeks of intervention: Time.

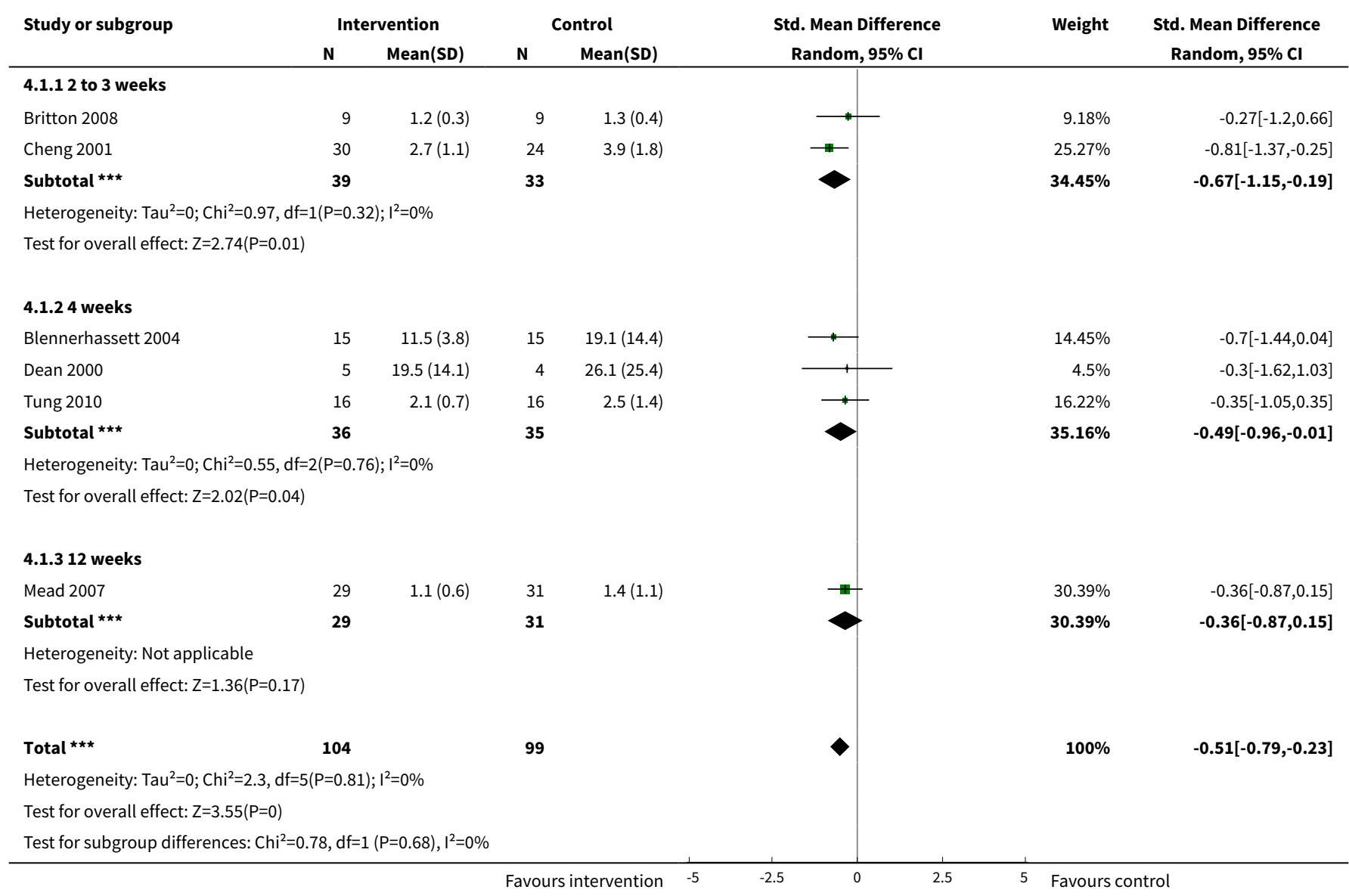


Analysis 4.2. Comparison 4 Subgroup analysis: duration and intensity of intervention, Outcome 2 Sessions per week: Time.

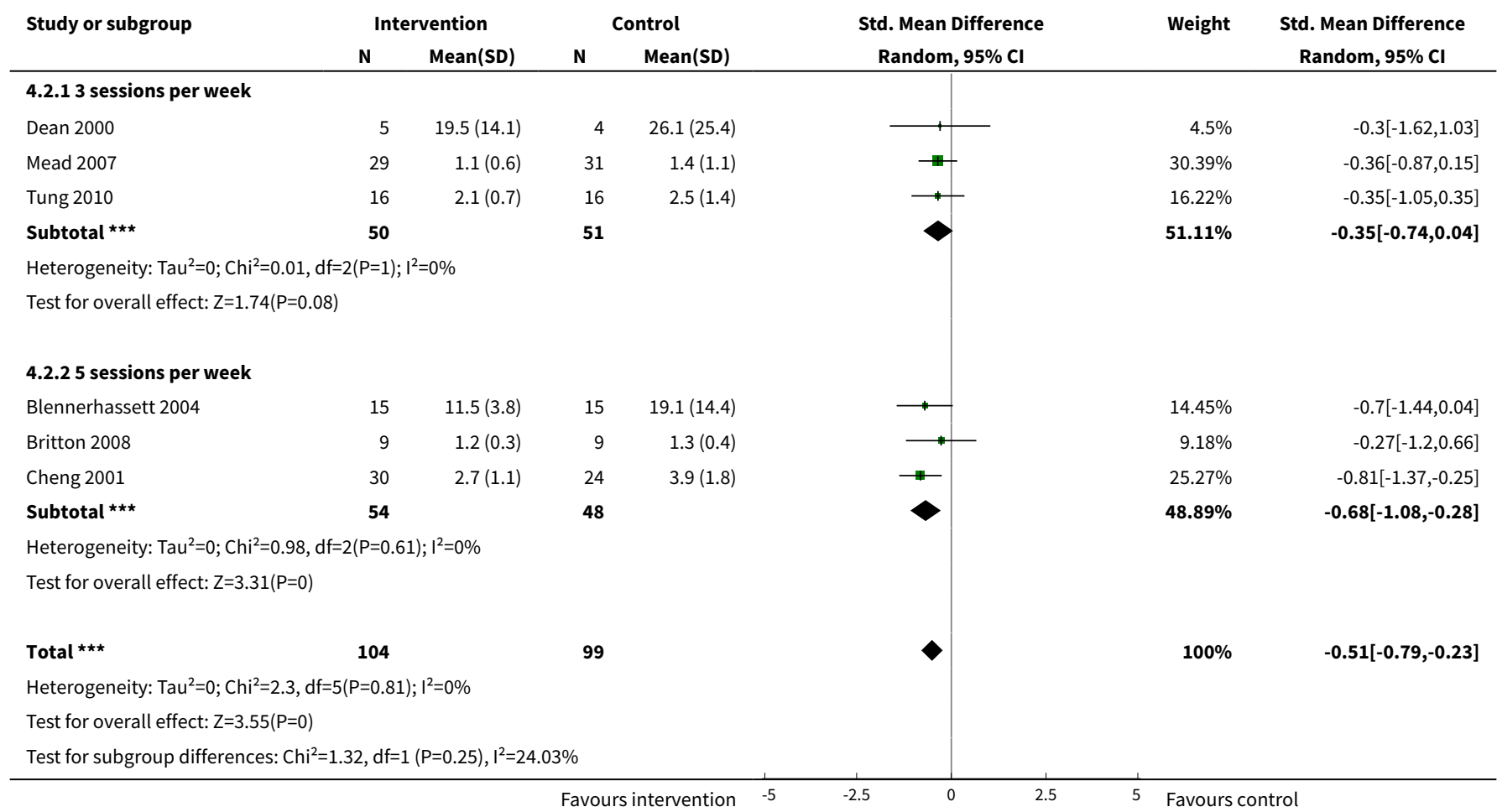

Analysis 4.3. Comparison 4 Subgroup analysis: duration and intensity of intervention, Outcome 3 Weeks of intervention: Lateral symmetry.

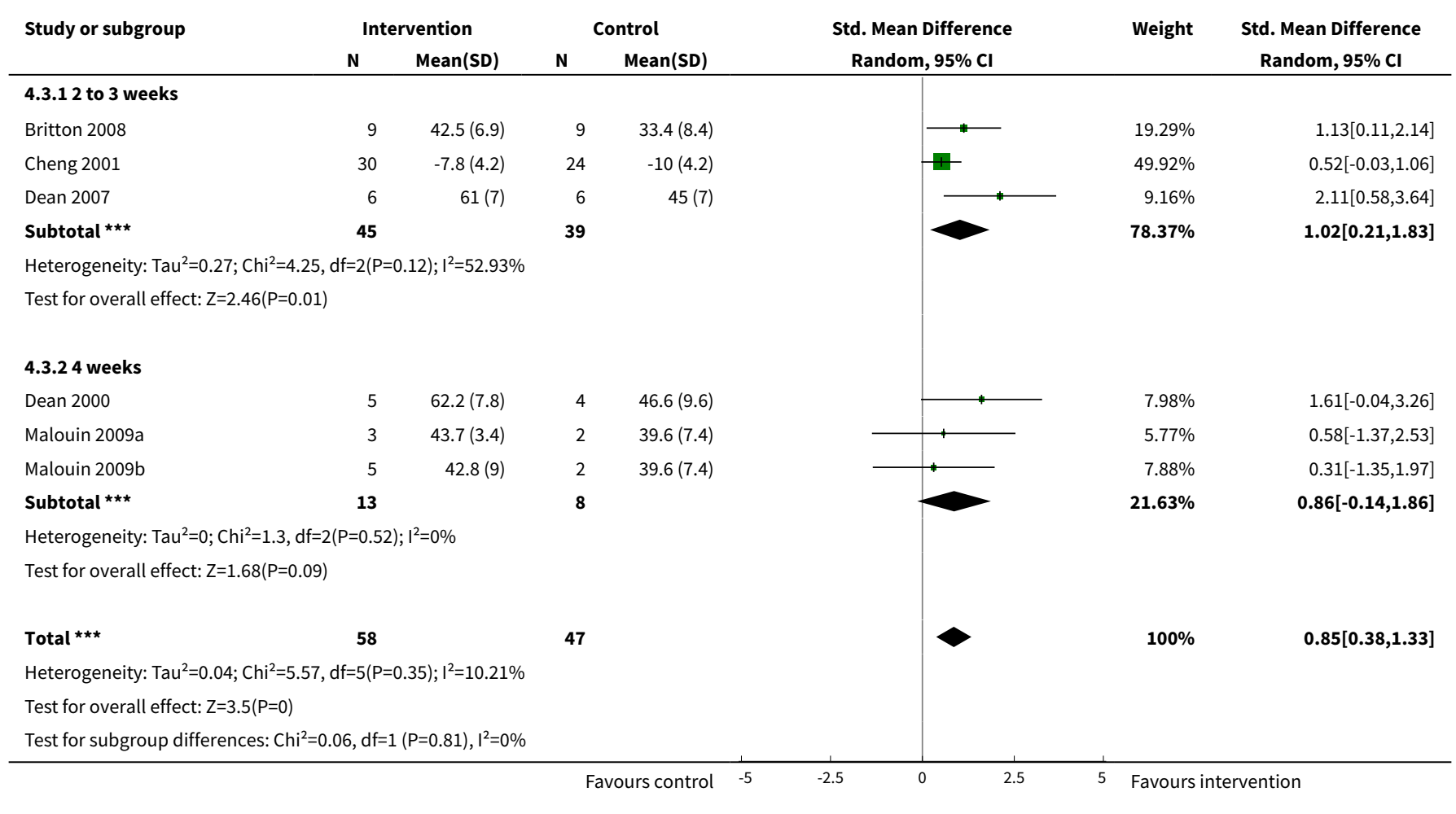




\section{Analysis 4.4. Comparison 4 Subgroup analysis: duration and intensity of intervention, Outcome 4 Sessions per week: Lateral symmetry.}

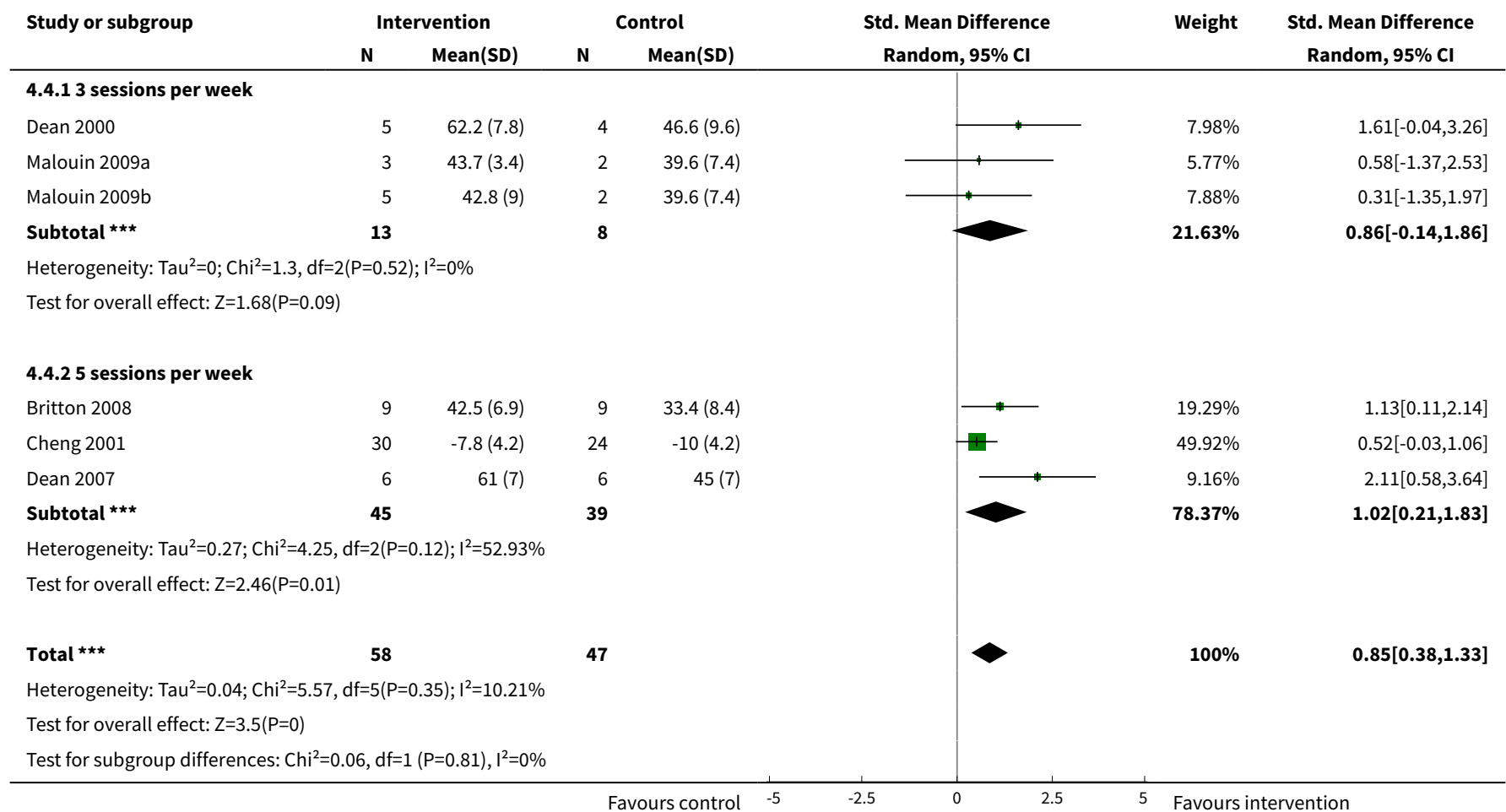

\section{Comparison 5. Subgroup analysis: time post-stroke}

\begin{tabular}{llllll}
\hline Outcome or subgroup title & $\begin{array}{l}\text { No. of } \\
\text { studies }\end{array}$ & $\begin{array}{l}\text { No. of } \\
\text { partici- } \\
\text { pants }\end{array}$ & Statistical method & Effect size \\
\hline 1 Time & 7 & 335 & $\begin{array}{l}\text { Std. Mean Difference (IV, Random, 95\% } \\
\text { Cl) }\end{array}$ & -0.34 [-0.62, -0.06] \\
\hline 1.130 to 51 days post-stroke & 2 & 48 & $\begin{array}{l}\text { Std. Mean Difference (IV, Random, 95\% } \\
\text { Cl) }\end{array}$ & -0.53 [-1.11, 0.05] \\
\hline 1.2 2.8 to 6 months post-stroke & 3 & 246 & $\begin{array}{l}\text { Std. Mean Difference (IV, Random, 95\% } \\
\text { Cl) }\end{array}$ & -0.33 [-0.84, 0.17] \\
\hline 1.3 More than 1 year post-stroke & 2 & 41 & $\begin{array}{l}\text { Std. Mean Difference (IV, Random, 95\% } \\
\text { Cl) }\end{array}$ & -0.34 [-0.96, 0.28] \\
\hline 2 Lateral symmetry & 6 & 105 & $\begin{array}{l}\text { Std. Mean Difference (IV, Random, 95\% } \\
\text { Cl) }\end{array}$ & $0.85[0.38,1.33]$ \\
\hline 2.130 to 51 days post-stroke & 2 & 30 & $\begin{array}{l}\text { Std. Mean Difference (IV, Random, 95\% } \\
\text { Cl) }\end{array}$ & 1.44 [0.54, 2.34]
\end{tabular}




\begin{tabular}{llllll}
\hline Outcome or subgroup title & $\begin{array}{l}\text { No. of } \\
\text { studies }\end{array}$ & $\begin{array}{l}\text { No. of } \\
\text { partici- } \\
\text { pants }\end{array}$ & Statistical method & Effect size \\
\hline 2.22 .8 to 6 months post-stroke & 1 & 54 & $\begin{array}{l}\text { Std. Mean Difference (IV, Random, 95\% } \\
\text { CI) }\end{array}$ & $0.52[-0.03,1.06]$ \\
\hline 2.3 More than 1 year post-stroke & 3 & 21 & $\begin{array}{l}\text { Std. Mean Difference (IV, Random, 95\% } \\
\text { CI) }\end{array}$ & $0.86[-0.14,1.86]$ \\
\hline
\end{tabular}

Analysis 5.1. Comparison 5 Subgroup analysis: time post-stroke, Outcome 1 Time.

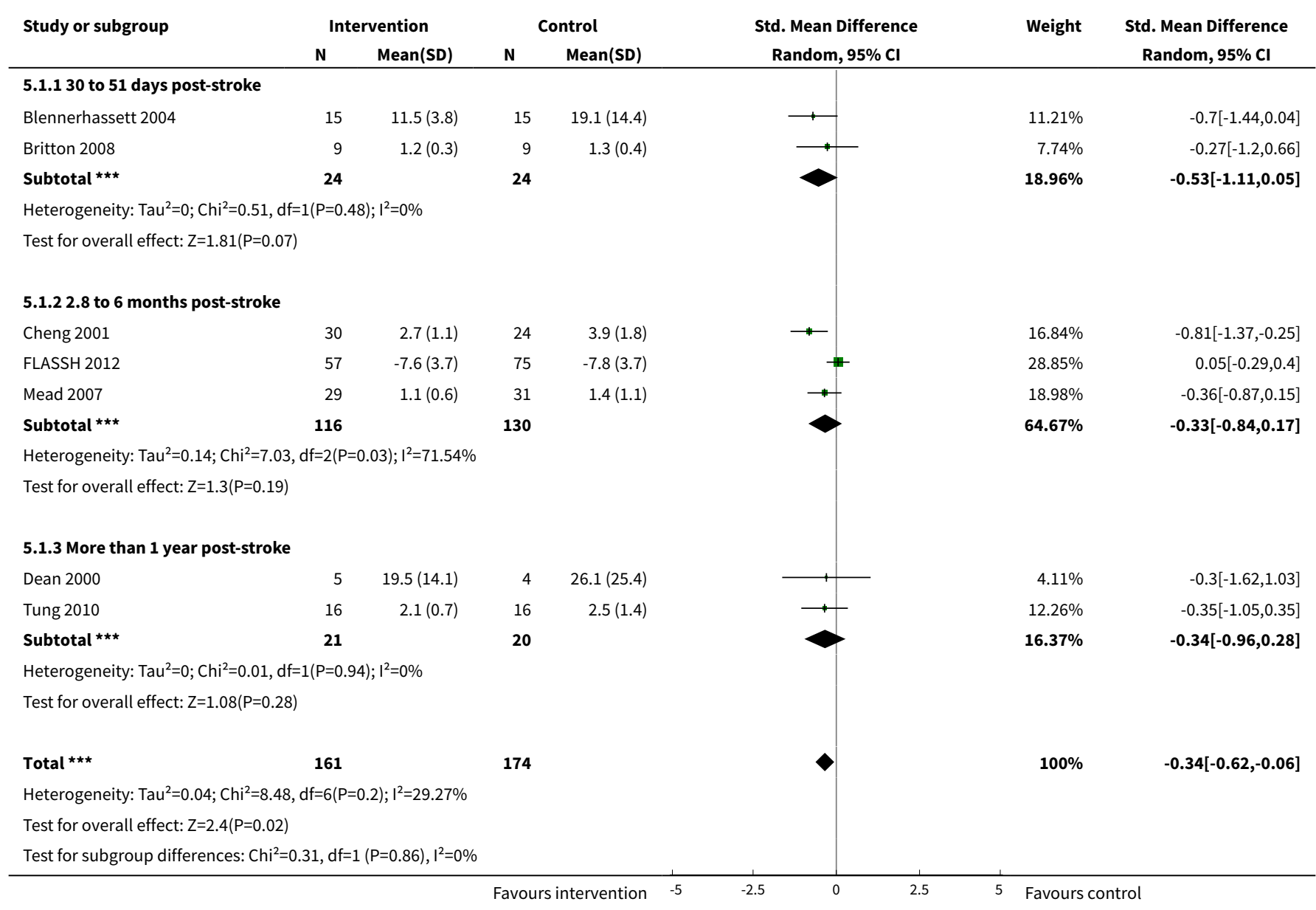

Analysis 5.2. Comparison 5 Subgroup analysis: time post-stroke, Outcome 2 Lateral symmetry.

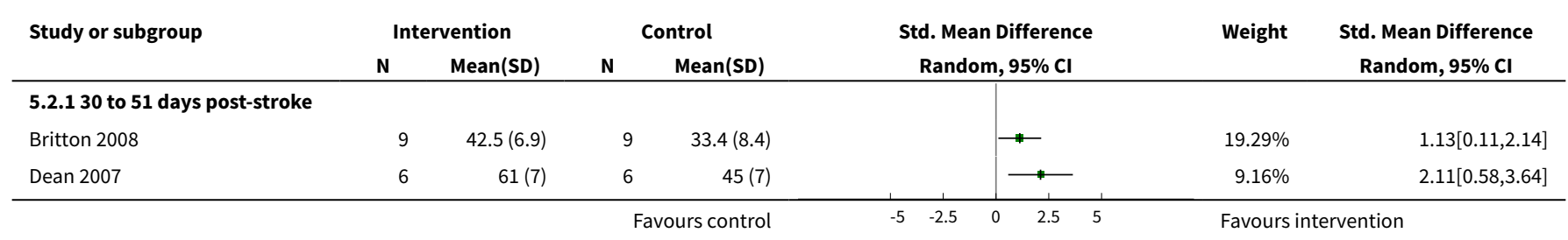




\begin{tabular}{|c|c|c|c|c|c|c|c|}
\hline \multirow{3}{*}{$\begin{array}{l}\text { Study or subgroup } \\
\text { Subtotal } \star \star \star\end{array}$} & \multicolumn{2}{|c|}{ Intervention } & \multicolumn{2}{|c|}{ Control } & \multirow{2}{*}{$\begin{array}{c}\text { Std. Mean Difference } \\
\text { Random, } 95 \% \mathrm{Cl}\end{array}$} & \multirow[t]{2}{*}{ Weight } & \multirow{2}{*}{$\begin{array}{c}\text { Std. Mean Difference } \\
\text { Random, } 95 \% \mathrm{Cl}\end{array}$} \\
\hline & $\mathbf{N}$ & Mean(SD) & $\mathbf{N}$ & $\operatorname{Mean}(S D)$ & & & \\
\hline & 15 & & 15 & & & $28.45 \%$ & $1.44[0.54,2.34]$ \\
\hline \multicolumn{8}{|c|}{ Heterogeneity: Tau $^{2}=0.04 ; \mathrm{Chi}^{2}=1.1, \mathrm{df}=1(\mathrm{P}=0.29) ; \mathrm{I}^{2}=9.14 \%$} \\
\hline \multicolumn{8}{|c|}{ Test for overall effect: $Z=3.15(P=0)$} \\
\hline \multicolumn{8}{|c|}{ 5.2.2 2.8 to 6 months post-stroke } \\
\hline Cheng 2001 & 30 & $-7.8(4.2)$ & 24 & $-10(4.2)$ & $\#$ & $49.92 \%$ & $0.52[-0.03,1.06]$ \\
\hline 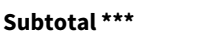 & 30 & & 24 & & & $49.92 \%$ & $0.52[-0.03,1.06]$ \\
\hline \multicolumn{8}{|c|}{ Heterogeneity: Not applicable } \\
\hline \multicolumn{8}{|c|}{ Test for overall effect: $Z=1.85(P=0.06)$} \\
\hline \multicolumn{8}{|c|}{ 5.2.3 More than 1 year post-stroke } \\
\hline Dean 2000 & 5 & $62.2(7.8)$ & 4 & $46.6(9.6)$ & —- & $7.98 \%$ & $1.61[-0.04,3.26]$ \\
\hline Malouin 2009a & 3 & $43.7(3.4)$ & 2 & $39.6(7.4)$ & $\longrightarrow$ & $5.77 \%$ & $0.58[-1.37,2.53]$ \\
\hline Malouin 2009b & 5 & $42.8(9)$ & 2 & $39.6(7.4)$ & $\longrightarrow$ & $7.88 \%$ & $0.31[-1.35,1.97]$ \\
\hline 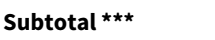 & 13 & & 8 & & & $21.63 \%$ & $0.86[-0.14,1.86]$ \\
\hline \multicolumn{8}{|c|}{ Heterogeneity: Tau $^{2}=0 ; \mathrm{Chi}^{2}=1.3, \mathrm{df}=2(\mathrm{P}=0.52) ; \mathrm{I}^{2}=0 \%$} \\
\hline \multicolumn{8}{|c|}{ Test for overall effect: $\mathrm{Z}=1.68(\mathrm{P}=0.09)$} \\
\hline Total $\star \star \star ~$ & 58 & & 47 & & $>$ & $100 \%$ & $0.85[0.38,1.33]$ \\
\hline \multicolumn{8}{|c|}{ Heterogeneity: $\mathrm{Tau}^{2}=0.04 ; \mathrm{Chi}^{2}=5.57, \mathrm{df}=5(\mathrm{P}=0.35) ; \mathrm{I}^{2}=10.21 \%$} \\
\hline \multicolumn{8}{|c|}{ Test for overall effect: $Z=3.5(P=0)$} \\
\hline Test for subgroup dif & $1, \mathrm{df}=$ & $P=0.22), I^{2}=3$ & & & & & \\
\hline
\end{tabular}

\section{Comparison 6. Feedback versus no feedback}

\begin{tabular}{lllll}
\hline $\begin{array}{l}\text { Outcome or subgroup } \\
\text { title }\end{array}$ & $\begin{array}{l}\text { No. of } \\
\text { studies }\end{array}$ & $\begin{array}{l}\text { No. of } \\
\text { partici- } \\
\text { pants }\end{array}$ & Statistical method & Effect size \\
\hline 1 Time & 1 & 30 & Std. Mean Difference (IV, Random, 95\% Cl) & $-0.11[-0.82,0.61]$ \\
\hline 2 Lateral symmetry & 1 & 30 & Std. Mean Difference (IV, Random, 95\% CI) & $0.53[-0.20,1.26]$ \\
\hline
\end{tabular}

Analysis 6.1. Comparison 6 Feedback versus no feedback, Outcome 1 Time.

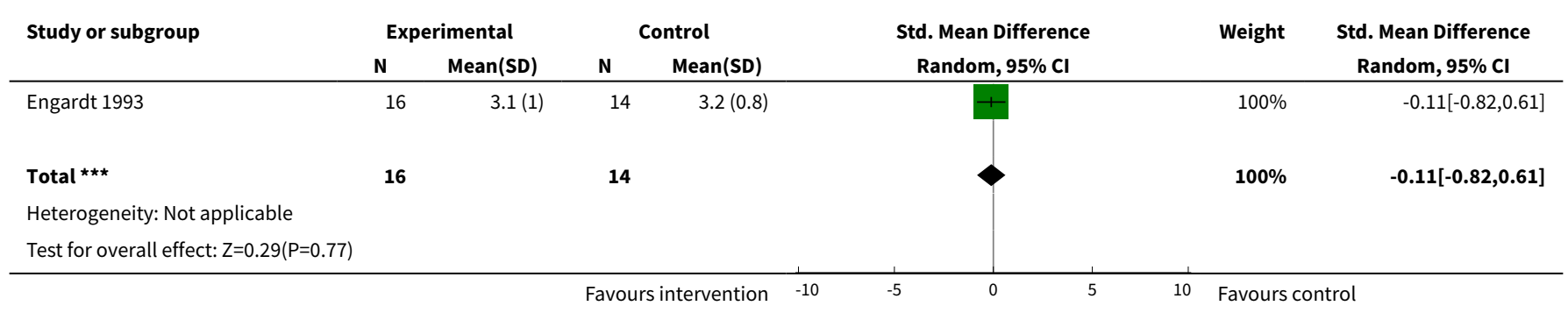


Analysis 6.2. Comparison 6 Feedback versus no feedback, Outcome 2 Lateral symmetry.

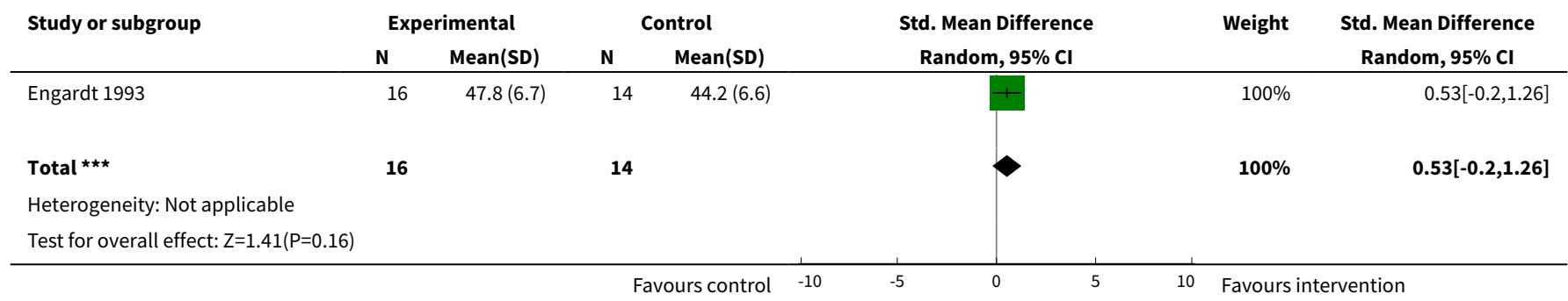

\section{APPENDICES}

\section{Appendix 1. Cochrane Central Register of Controlled Trials (CENTRAL) search strategy}

\#1 [mh ^"cerebrovascular disorders"] or [mh "basal ganglia cerebrovascular disease"] or [mh "brain ischemia"] or [mh "carotid artery diseases"] or [mh "intracranial arterial diseases"] or [mh "intracranial embolism and thrombosis"] or [mh "intracranial hemorrhages"] or [mh^stroke] or [mh "brain infarction"] or [mh ^"stroke, lacunar"] or [mh ^"vasospasm, intracranial"] or [mh^"vertebral artery dissection"] or [mh "brain injuries"] or [mh "brain injury, chronic"]

\#2 stroke or poststroke or "post-stroke" or cerebrovasc* or brain next vasc* or cerebral next vasc* or cva* or apoplex* or SAH

\#3 (brain* or cerebr ${ }^{\star}$ or cerebell ${ }^{\star}$ or intracran* or intracerebral) near/5 (isch*emi ${ }^{\star}$ or infarct* or thrombo* or emboli* or occlus ${ }^{\star}$ )

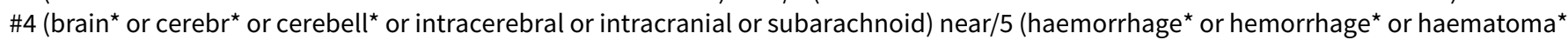
or hematoma* or bleed*)

\#5 [mh ^hemiplegia] or [mh paresis]

$\# 6$ hemipleg* or hemipar* or paresis or paretic or brain next injur ${ }^{\star}$

$\# 7 \# 1$ or \#2 or \#3 or \#4 or \#5 or \#6

\#8 "sit-to-stand"

\#9 (sit or sitting or rise or rising) near/5 (stand or standing)

\#10 stand $^{*}$ next up

\#11 (stand or standing or rise or rising or "getting up") near/10 (seat or seated or chair or sitting)

$\# 12$ \#8 or \#9 or \#10 or \#11

$\# 13 \# 7$ and \#12

\section{Appendix 2. MEDLINE (Ovid) search strategy}

1. cerebrovascular disorders/ or exp basal ganglia cerebrovascular disease/ or exp brain ischemia/ or exp carotid artery diseases/or exp intracranial arterial diseases/ or exp "intracranial embolism and thrombosis"/ or exp intracranial hemorrhages/ or stroke/ or exp brain infarction/ or vasospasm, intracranial/ or vertebral artery dissection/

2. (stroke or poststroke or post-stroke or cerebrovasc $\$$ or brain vasc $\$$ or cerebral vasc $\$$ or cva $\$$ or apoplex\$ or SAH).tw.

3. ((brain $\$$ or cerebr\$ or cerebell\$ or intracran\$ or intracerebral) adj5 (isch?emi\$ or infarct\$ or thrombo $\$$ or emboli\$ or occlus\$)).tw.

4. ((brain\$ or cerebr\$ or cerebell\$ or intracerebral or intracranial or subarachnoid) adj5 (haemorrhage\$ or hemorrhage\$ or haematoma

\$ or hematoma\$ or bleed\$)).tw.

5. hemiplegia/ or exp paresis/

6. (hemipleg\$ or hemipar\$ or paresis or paretic).tw.

7. 1 or 2 or 3 or 4 or 5 or 6

8. sit-to-stand.tw.

9. ((sit or sitting or rise or rising) adj5 (stand or standing)).tw.

10. ((stand or standing) adj up).tw.

11. ((stand or standing or rise or rising or getting up) adj10 (seat or seated or chair or sitting)).tw.

12. 8 or 9 or 10 or 11

13. 7 and 12

\section{Appendix 3. EMBASE (Ovid) search strategy}

1. cerebrovascular disease/ or basal ganglion hemorrhage/ or cerebral artery disease/ or cerebrovascular accident/or stroke/ or exp carotid artery disease/ or exp brain hematoma/ or exp brain hemorrhage/ or exp brain ischemia/ or exp intracranial aneurysm/ or exp occlusive cerebrovascular disease/

2. stroke patient/ or stroke unit/

3. (stroke or poststroke or post-stroke or cerebrovasc\$ or brain vasc\$ or cerebral vasc\$ or cva $\$$ or apoplex\$ or SAH).tw. 
4. ((brain\$ or cerebr\$ or cerebell\$ or intracran\$ or intracerebral) adj5 (isch?emi\$ or infarct\$ or thrombo\$ or emboli\$ or occlus\$)).tw.

5. ((brain\$ or cerebr\$ or cerebell\$ or intracerebral or intracranial or subarachnoid) adj5 (haemorrhage\$ or hemorrhage\$ or haematoma

\$ or hematoma\$ or bleed\$)).tw.

6. hemiparesis/ or hemiplegia/ or paresis/

7. (hemipleg\$ or hemipar\$ or paresis or paretic).tw.

8. 1 or 2 or 3 or 4 or 5 or 6 or 7

9. sitting/ or standing/ or * weight bearing/

10. sit-to-stand.tw.

11. ((sit or sitting or rise or rising) adj5 (stand or standing)).tw.

12. ((stand or standing) adj up).tw.

13. ((stand or standing or rise or rising or getting up) adj10 (seat or seated or chair or sitting)).tw.

14. 9 or 10 or 11 or 12 or 13

15. 8 and 14

\section{Appendix 4. CINAHL (EBSCO) search strategy}

$\mathrm{S} 21-\mathrm{S} 13$ and S20

$\mathrm{S} 20$ - S14 or S15 or S16 or S17 or S18 or S19

S19 - TI ((stand or standing or rise or rising or getting up) N10 (seat or seated or chair or sitting)) or AB ((stand or standing or rise or rising or getting up) $\mathrm{N} 10$ (seat or seated or chair or sitting))

S18 - TI ((stand or standing) N1 up) or AB ((stand or standing) N1 up)

S17 - TI ((sit or sitting or rise or rising) N5 (stand or standing)) or AB ((sit or sitting or rise or rising) N5 (stand or standing))

S16 - TI sit-to-stand or AB sit-to-stand

S15 - (MH "balance, postural”) or (MH “weight-bearing”) or (MH "seating")

S14 - (MH "rising") or (MH "sitting") or (MH "standing")

S13 - S1 OR S2 OR S3 OR S6 OR S9 OR S10 OR S11 OR S12

S12 -(MH "Gait Disorders, Neurologic+")

S11 - TI ( hemipleg* or hemipar* or paresis or paretic) or AB ( hemipleg* or hemipar ${ }^{\star}$ or paresis or paretic)

S10-(MH "Hemiplegia")

S9 -S7 and S8

S8 - TI ( haemorrhage* or hemorrhage* or haematoma* or hematoma* or bleed ${ }^{\star}$ ) or AB ( haemorrhage* or hemorrhage* or haematoma* or hematoma* or bleed*)

S7 - TI ( brain* or cerebr* or cerebell* or intracerebral or intracranial or subarachnoid ) or AB ( brain* or cerebr* or cerebell* or intracerebral or intracranial or subarachnoid)

S6 - S4 and S5

S5 - TI (ischemi ${ }^{\star}$ or ischaemi ${ }^{\star}$ or infarct ${ }^{\star}$ or thrombo* or emboli* or occlus ${ }^{\star}$ ) or AB (ischemi ${ }^{\star}$ or ischaemi ${ }^{\star}$ or infarct ${ }^{\star}$ or thrombo $^{\star}$ or emboli* or occlus* ${ }^{\star}$

S4 - $\mathrm{Tl}$ ( brain* or cerebr ${ }^{\star}$ or cerebell* or intracran ${ }^{\star}$ or intracerebral ) or AB ( brain* or cerebr ${ }^{\star}$ or cerebell ${ }^{\star}$ or intracran $^{\star}$ or intracerebral )

S3 - $\mathrm{TI}$ ( stroke or poststroke or post-stroke or cerebrovasc* or brain vasc* or cerebral vasc or cva or apoplex or SAH ) or AB ( stroke or poststroke or post-stroke or cerebrovasc* or brain vasc* or cerebral vasc or cva or apoplex or SAH )

S2 -(MH "Stroke Patients") OR (MH "Stroke Units")

S1 -(MH "Cerebrovascular Disorders") OR (MH "Basal Ganglia Cerebrovascular Disease+") OR (MH "Carotid Artery Diseases+") OR (MH "Cerebral Ischemia+") OR (MH "Cerebral Vasospasm") OR (MH "Intracranial Arterial Diseases+") OR (MH "Intracranial Embolism and Thrombosis") OR (MH "Intracranial Hemorrhage+") OR (MH "Stroke") OR (MH "Vertebral Artery Dissections")

\section{Appendix 5. AMED (Ovid) search strategy}

1. cerebrovascular disorders/ or cerebral hemorrhage/ or cerebral infarction/ or cerebral ischemia/ or cerebrovascular accident/

2. (stroke or poststroke or post-stroke or cerebrovasc $\$$ or brain vasc $\$$ or cerebral vasc $\$$ or cva $\$$ or apoplex\$ or SAH).tw.

3. ((brain $\$$ or cerebr $\$$ or cerebell\$ or intracran $\$$ or intracerebral) adj5 (isch?emi\$ or infarct\$ or thrombo $\$$ or emboli\$ or occlus\$)).tw.

4. ((brain $\$$ or cerebr\$ or cerebell\$ or intracerebral or intracranial or subarachnoid) adj5 (haemorrhage $\$$ or hemorrhage\$ or haematoma

\$or hematoma or bleed\$)).tw.

5. hemiplegia/

6. (hemipleg\$ or hemipar\$ or paresis or paretic).tw.

7.1 or 2 or 3 or 4 or 5 or 6

8. sitting/ or seating/ or weight bearing/

9. sit-to-stand.tw.

10. ((sit or sitting or rise or rising) adj5 (stand or standing)).tw.

11. ((stand or standing) adj up).tw.

12. ((stand or standing or rise or rising or getting up) adj10 (seat or seated or chair or sitting)).tw.

13. 8 or 9 or 10 or 11 or 12

14. 7 and 13 


\section{Appendix 6. British Nursing Index (Ovid) search strategy}

1. stroke/ or stroke rehabilitation/ or stroke services/

2. (stroke or poststroke or post-stroke or cerebrovasc\$ or brain vasc\$ or cerebral vasc\$ or cva $\$$ or apoplex\$or SAH).tw.

3. ((brain $\$$ or cerebr\$ or cerebell\$ or intracran\$ or intracerebral) adj5 (isch?emi\$ or infarct\$ or thrombo $\$$ or emboli\$ or occlus\$)).tw.

4. ((brain\$ or cerebr\$ or cerebell\$ or intracerebral or intracranial or subarachnoid) adj5 (haemorrhage\$ or hemorrhage\$ or haematoma

\$ or hematoma\$ or bleed\$)).tw.

5. (hemipleg\$ or hemipar\$ or paresis or paretic).tw.

6. 1 or 2 or 3 or 4 or 5

7. sit-to-stand.tw.

8. ((sit or sitting or rise or rising) adj5 (stand or standing)).tw.

9. ((stand or standing) adj up).tw.

10. ((stand or standing or rise or rising or getting up) adj10 (seat or seated or chair or sitting)).tw.

11. 7 or 8 or 9 or 10

12.6 and 11

\section{Appendix 7. REHABDATA search strategy}

We used the following search strategy for REHABDATA.

(Continued)

\begin{tabular}{|c|c|}
\hline 'Exact phrase' & 'At least one of the words' \\
\hline Sit to stand & Stroke \\
\hline Sit to stand & CVA \\
\hline Sit to stand & Hemiplegia \\
\hline Sit to stand & Hemiparesis \\
\hline Getting up & Stroke \\
\hline Getting up & CVA \\
\hline Getting up & Hemiplegia \\
\hline Getting up & Hemiparesis \\
\hline Standing & Stroke \\
\hline Standing & CVA \\
\hline Standing & Hemiplegia \\
\hline Standing & Hemiparesis \\
\hline Chair & Stroke \\
\hline Chair & CVA \\
\hline Chair & Hemiplegia \\
\hline Chair & Hemiparesis \\
\hline Rising & Stroke \\
\hline Rising & CVA \\
\hline
\end{tabular}


(Continued)

\begin{tabular}{lc} 
Rising & Hemiplegia \\
\hline Rising & Hemiparesis
\end{tabular}

\section{Appendix 8. OTseeker search strategy}

We used the following search strategy, with combinations of keywords, interventions (drop-down menu) and diagnosis (drop-down menu), for OTseeker.

\begin{tabular}{lll}
\hline 'Continued) & & \\
\hline N/A & 'Intervention' & 'Diagnosis' \\
\hline Getting-up & Basic ADL & Stroke \\
\hline Sit-to-stand & N/A & Stroke \\
\hline Rising & N/A & Stroke \\
\hline Standing & N/A & Stroke \\
\hline Rise & N/A & Stroke \\
\hline Rise-up & N/A & Stroke \\
\hline Stand or standing & N/A & Stroke \\
\hline Chair & N/A & Stroke \\
\hline
\end{tabular}

\section{Appendix 9. PEDro search strategy}

The PEDro database was searched using the 'Advanced Search Screen'. The following 'Abstract+title' options were combined with one option from the 'Subdiscipline' drop-down menu:

(Continued)

\begin{tabular}{ll}
\hline Abstract + title & Subdiscipline \\
\hline Sit-to-stand & Neurology \\
\hline Rising & Neurology \\
\hline Getting-up & Neurology \\
\hline Standing-up & Neurology \\
\hline Chair & Neurology \\
\hline
\end{tabular}

\section{H I S T ORY}

Protocol first published: Issue 3, 2008 


\begin{tabular}{lll}
\hline Date & Event & Description \\
\hline 22 March 2012 & New search has been performed & $\begin{array}{l}\text { This protocol has been updated since the previous version } \\
\text { was withdrawn from Issue 6, 2011 of the Cochrane Database of } \\
\text { Systematic Reviews. It now conforms to the latest format for } \\
\text { Cochrane reviews, and new authors have been added. }\end{array}$ \\
& \\
\hline
\end{tabular}

\section{CONTRIBUTIONS OF AUTHORS}

The views expressed here are those of the authors and not necessarily those of the Chief Scientist Office or the Scottish Government.

Alex Pollock led the review. She developed the protocol, and worked in conjunction with Charla Gray to run the searches, exclude obviously irrelevant references, apply inclusion criteria, extract methodological details, extract trial details and data, carry out data analysis, and write drafts of the review.

Charla Gray acted as the second review author. She worked in conjunction with Alex Pollock to run the searches, exclude obviously irrelevant references, apply inclusion criteria, extract methodological details, extract trial details and data, carry out data analysis, and write drafts of the review.

Brian Durward acted as an additional review author and provided content expertise relating to the intervention. He read and commented on drafts of the protocol, and, where required, acted as a third review author, and read and commented on drafts of the review.

Elsie Culham acted as an additional review author and provided content expertise relating to the intervention. She was consulted to discuss inclusion, methodological details and comparisons if an additional opinion was required. She read and commented on drafts of the review.

Peter Langhorne provided additional methodological expertise, acted as an additional review author as required, and read and commented on drafts of the review.

\section{DECLARATIONS OF INTEREST}

None known.

\section{SOURCES OF SUPPORT}

\section{Internal sources}

- No sources of support supplied

\section{External sources}

- Chief Scientist Office, Scottish Government, UK.

* Alex Pollock is employed by the Nursing, Midwifery and Allied Health Professions Research Unit, which is funded by the Chief Scientist Office in Scotland.

\section{DIFFERENCES BETWEEN PROTOCOL AND REVIEW}

In the protocol, the listed secondary outcomes included:

- death and dependency;

- maximum anterior-posterior (A-P) movement of centre of pressure during sit-to-stand.

Within the review these have been removed as secondary outcomes. We removed death and dependency following agreement amongst review authors that the interventions being studied should not be associated with death or dependency. We removed maximum A-P movement of centre of pressure following discussion and agreement among the review authors that there is no indication of impairment related to this measure, and no evidence as to which direction of change in A-P movement would be a beneficial outcome.

Only one study included in this review assessed anterior-posterior centre of pressure displacement during sit-to-stand (Cheng 2001, 54 participants). This found no statistically significant effect of the intervention when compared with control (SMD $-0.02,95 \% \mathrm{Cl}-0.55$ to 0.52 ). 


\section{N DEX TERMS}

\section{Medical Subject Headings (MeSH)}

${ }^{\star}$ Stroke Rehabilitation; Movement [ ${ }^{\star}$ physiology]; Postural Balance [physiology]; Posture [*physiology]; Randomized Controlled Trials as Topic; Time Factors

\section{MeSH check words}

Adult; Humans 